\title{
TIMING OF INTRAVENOUS THERAPY, VENEPUNCTURE AND CANNULATION EDUCATION FOR NURSES.
}

by

Bronwynne Lesley Anderson

A thesis submitted to the Victoria University of Wellington

in partial fulfilment of the

requirements for the degree of

Master of Arts (Applied)

in Nursing

Victoria University of Wellington

2010 


\begin{abstract}
Internationally it is becoming more acceptable for nurses to carry out intravenous (IV) therapy, venepuncture and cannulation. There does not appear to be consensus about when nurses should undergo this education either nationally or internationally.

The aim of this research project was to try and identify when IV therapy, venepuncture and cannulation education should take place and also to identify what different District Health Boards (DHBs) and nursing schools in New Zealand consider should be included in undergraduate nursing curricula related to IV therapy, venepuncture and cannulation. An email survey method was employed, which returned 36 responses. Descriptive statistics were used to analyse these responses.
\end{abstract}

This research project has utilised an exploratory descriptive approach to examine perceptions of registered nurses, who are employed in hospitals and schools of nursing, about whether nurses in New Zealand should be prepared to administer intravenous therapy, undertake venepuncture and cannulation prior to, or following, registration. Participants were asked to share their personal beliefs, thoughts and understanding about the topic. Benner's framework of Novice to Expert was used as a theoretical framework for this study.

The major findings that emerged from this study were that IV therapy should be a core component of undergraduate study and that there should be a national education and training programme. There was however, no agreement about the timing of venepuncture and cannulation education and training.

The findings of this study indicated that education and competency are an issue which needs to be addressed by the different health providers and associated educators. This would lead to the development of a nationally agreed framework, with agreed standards.

Key Words: Intravenous Therapy, Infusion Therapy, Venepuncture, Cannulation, Education Programmes, Undergraduate, New Graduate Nurses, Registered Nurses. 


\section{ACKNOWLEDGEMENTS}

My hobbies include sewing, patchwork and quilting. In one of my first presentations on my master's journey, I used the analogy of a patchwork quilt and how all the little pieces of material are collected and pieced together to finally produce a beautiful item that will be useful to the receiver. I see my master's journey as being like a patchwork quilt, as it has allowed me to sort through a variety of literature as if they were different coloured materials. I have been able to eventually piece these all together and allow me to complete my thesis and my journey. In completing my thesis I hope that I have produced a piece of work that might be useful to other people.

To the number of people who have supported me along the pathway I offer my acknowledgments. Firstly, to my boys Sean and Simon, I know at times I have not always kept the bikkie jars full, had all the washing done on time or made you your favourite meals when I have been busy with my writing. However, I hope that I have set a good example to you, which will encourage you through any obstacles that life may throw at you and that you will both achieve all the goals that you set for yourselves.

In memory of both my parents that I have lost during my Masters journey. You were so proud when I qualified first as a nurse and then as a midwife. I know that you have been watching over me through this journey and will be watching me as I celebrate my success.

To all my local friends that have supported me through my journey, I thank you for understanding and supporting me and showing an interest in what I have been doing. You all know who you are. Now you will all get to see much more of me. To Paddy \& Bronwyn and Joanne who opened their doors, welcomed me into their homes and offered a bed during my many visits to Wellington - my heartfelt thanks. To all my overseas family and friends for their support and encouragement via email, I wish you could be here to celebrate with me. 
To my work colleagues that have helped me find elusive articles and helped with grammar when I have been ready to throw it all away. Your encouragement and belief in me has been wonderful, especially in my dark days when I didn't believe in myself. To my collator and helper - a big thanks!!! To Brigit my clinical supervisor, I thank you for all your support.

To UCOL thank you for the study leave and financial support without which I could not have completed the journey.

To NZNO for the Florence Nightingale scholarship award towards my study.

To Margaret Adamson who encouraged me to start on this pathway. She knew my passion for IV therapy and suggested that one day my thesis could be related to this topic! To all the other lecturers I had through my different papers, you were all great role models.

I thank Rose McEldowney who guided me in the beginning stages of my thesis as my supervisor. But mostly to Karen McBride-Henry who had to take me on, two thirds of the way through, as my supervisor. I offer her my biggest thanks for picking up the pieces. Your patience, guidance, challenging, supervision and encouragement has been wonderful and kept me on track to completing and not giving up.

"Ngiyabonga ka khulu"! I could not have done it without you. 


\section{TABLE OF CONTENTS}

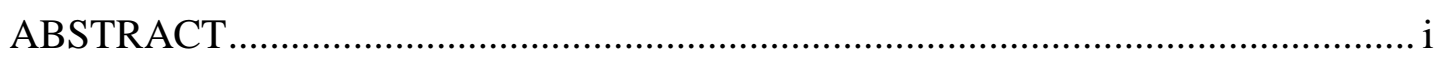

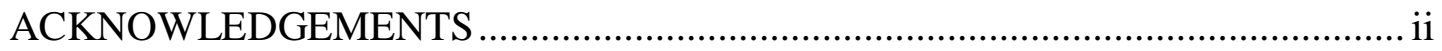

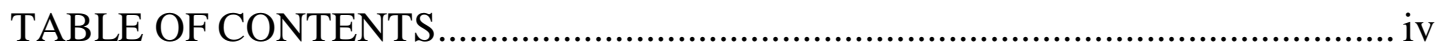

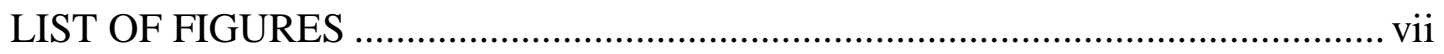

LIST OF TABLES .................................................................................... vii

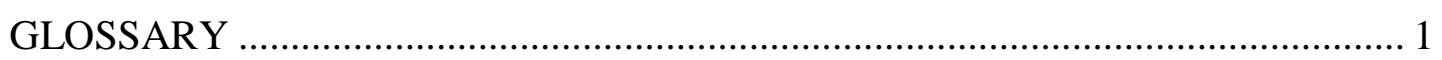

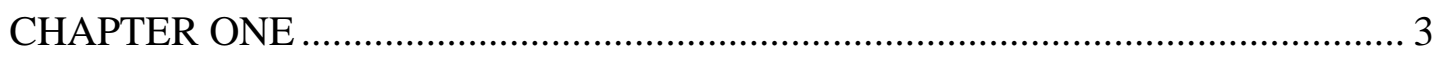

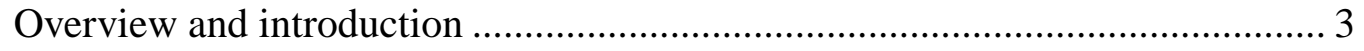

Personal reflection (Researcher's story) …..................................................... 4

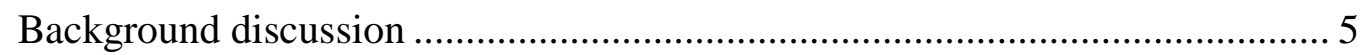

Research aims, question and objectives ..................................................... 7

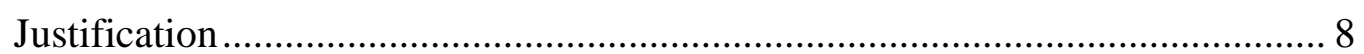

Intravenous therapy education for undergraduates ....................................... 9

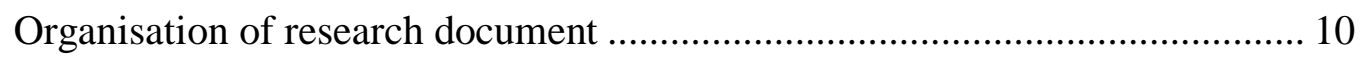

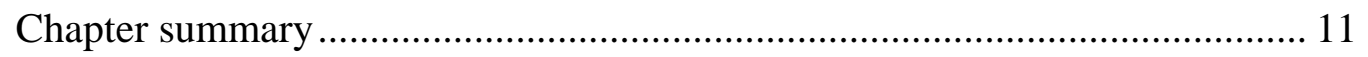

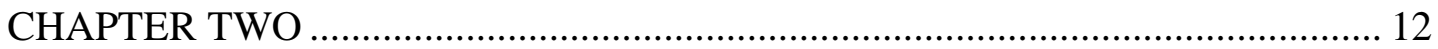

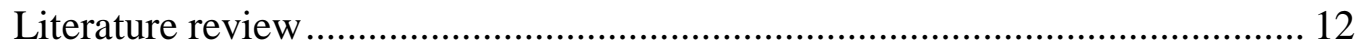

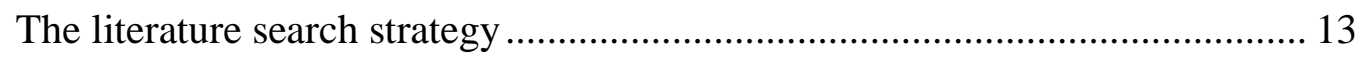

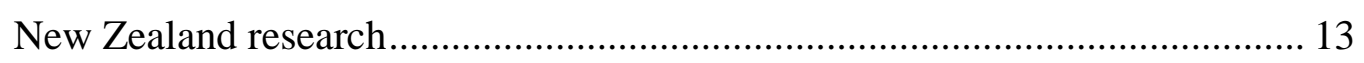

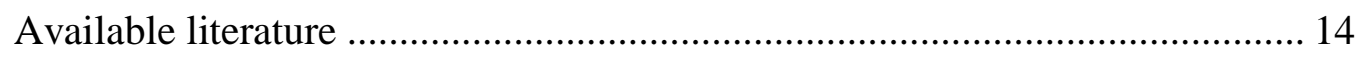

Extended or expanded role ........................................................................ 14

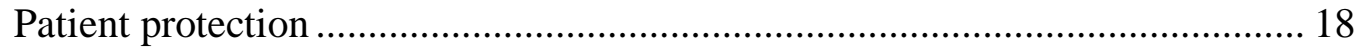

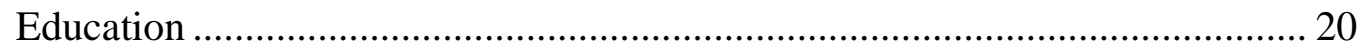

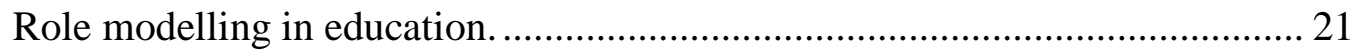

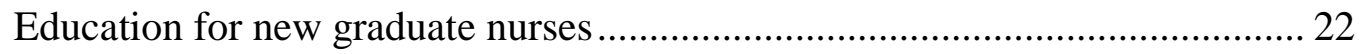

Intravenous therapy education for undergraduates .......................................... 24

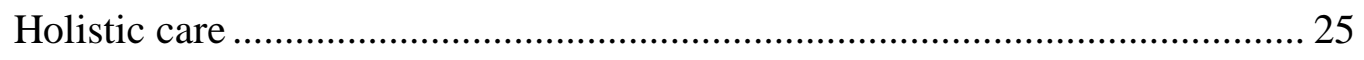

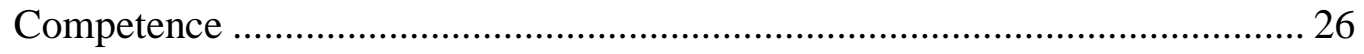

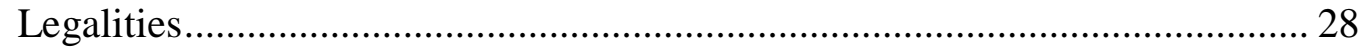

Implications of the literature review for this research .................................... 31

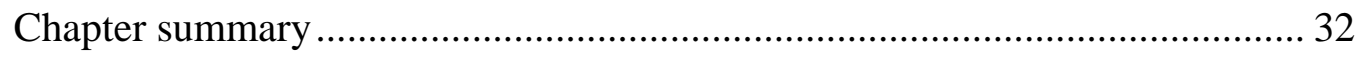

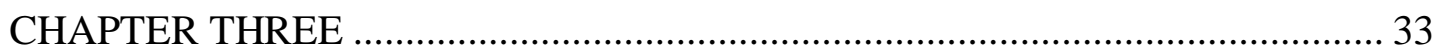




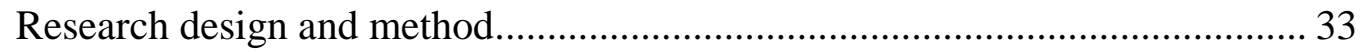

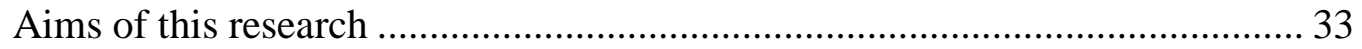

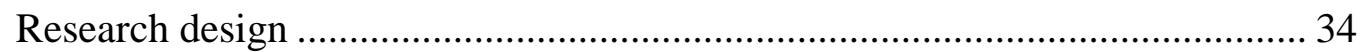

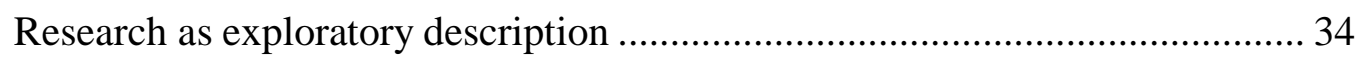

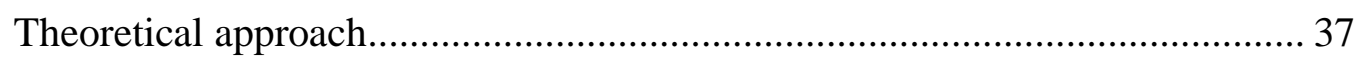

Choosing the questionnaire approach ....................................................... 42

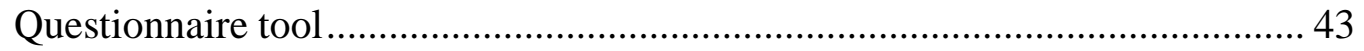

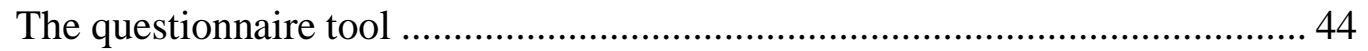

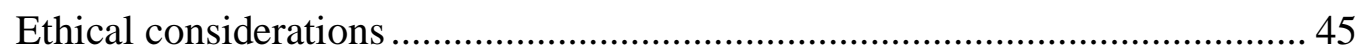

Research procedure and participants ......................................................... 46

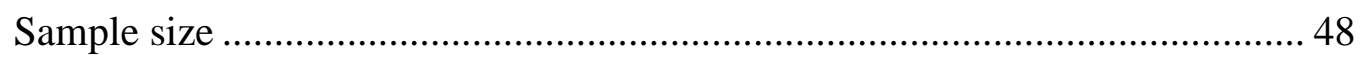

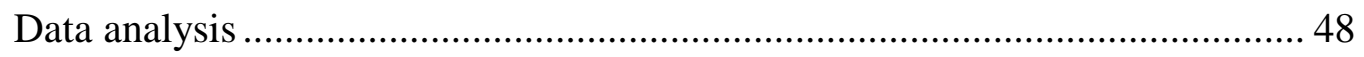

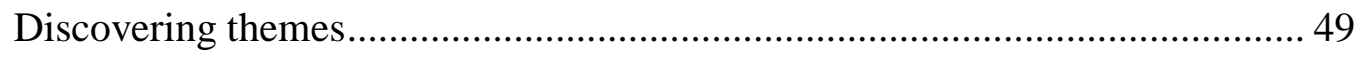

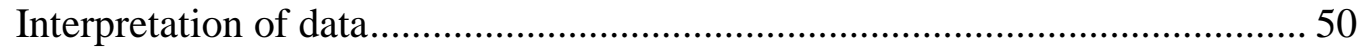

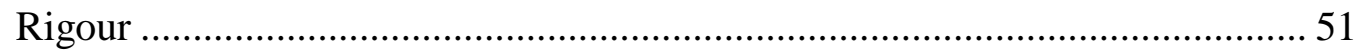

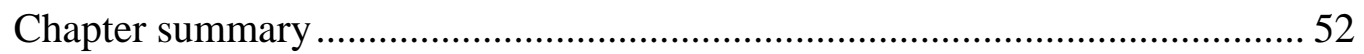

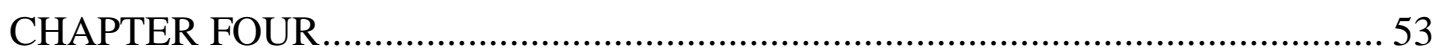

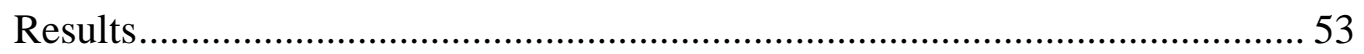

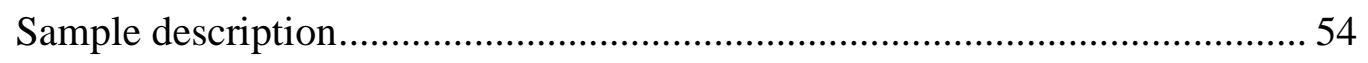

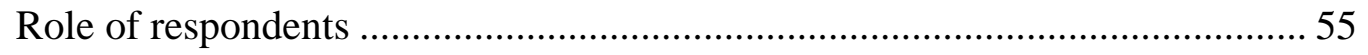

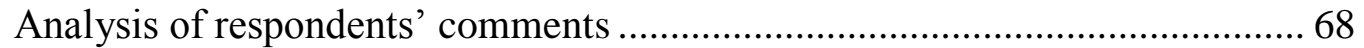

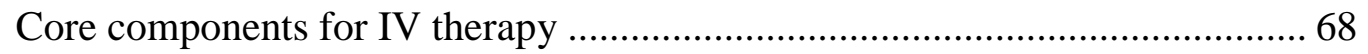

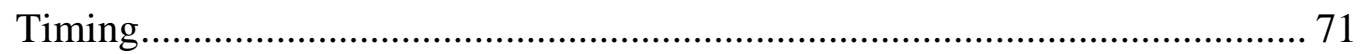

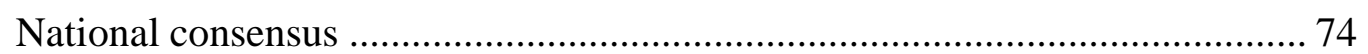

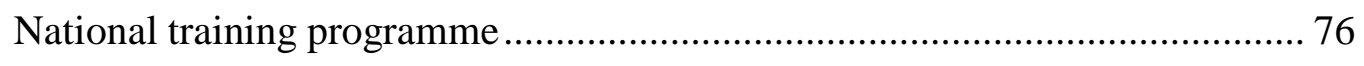

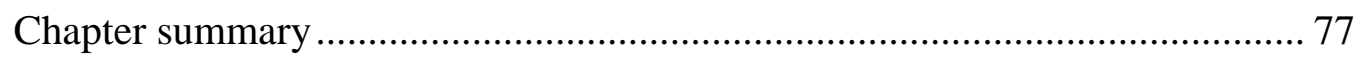

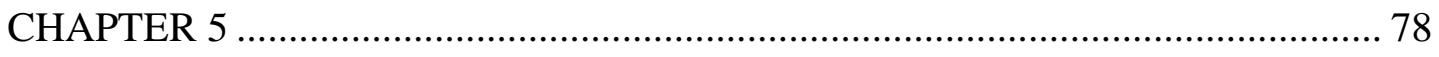

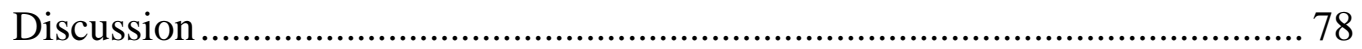

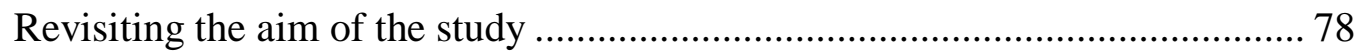

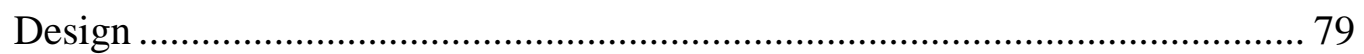

Responses from different work settings and roles....................................... 79

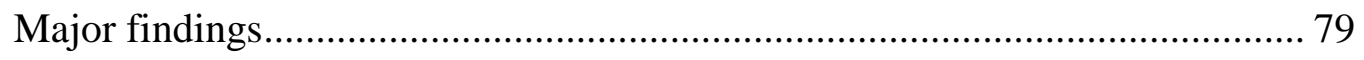

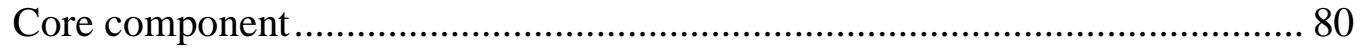

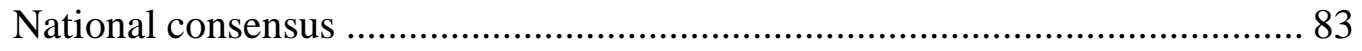

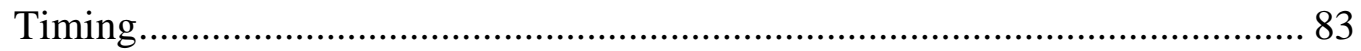




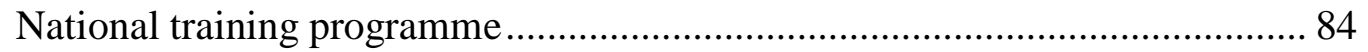

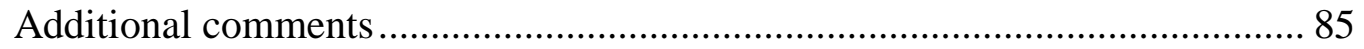

Implications for practice in New Zealand ...................................................... 87

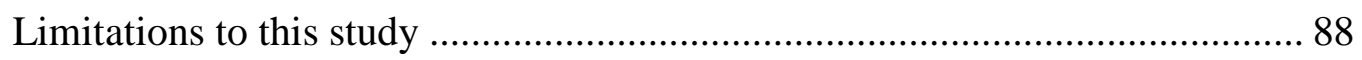

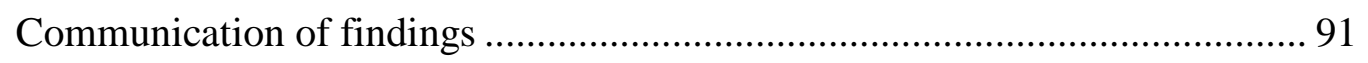

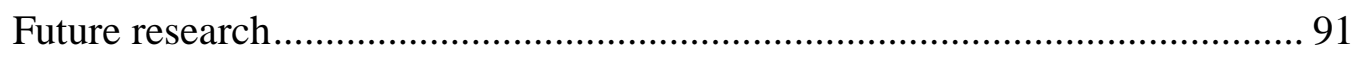

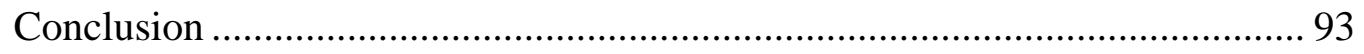

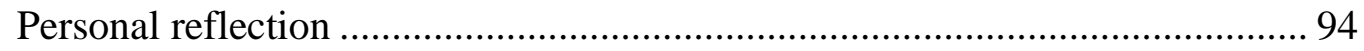

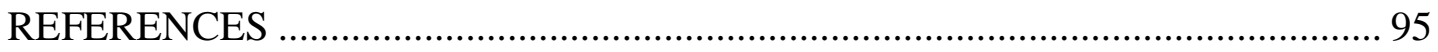

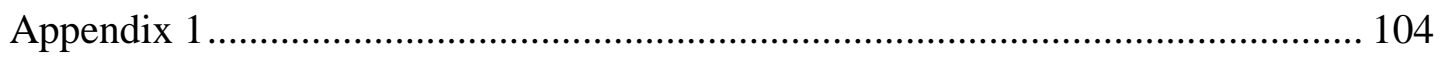

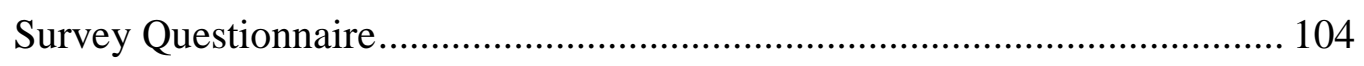

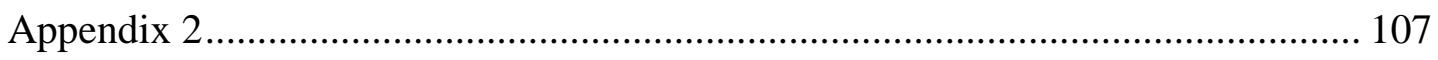

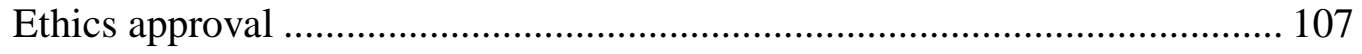

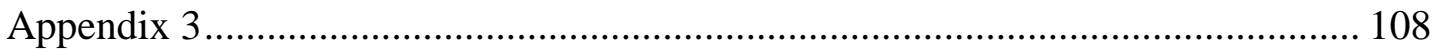

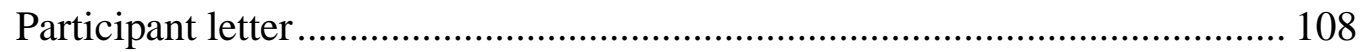

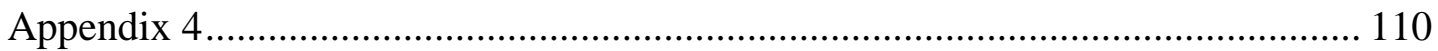

Research assistant confidentiality form …............................................... 110

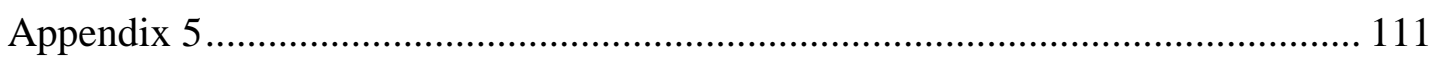

Director of nursing letter...................................................................... 111

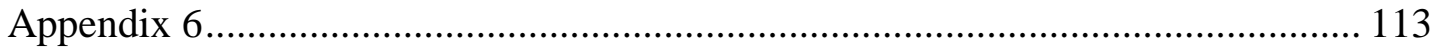

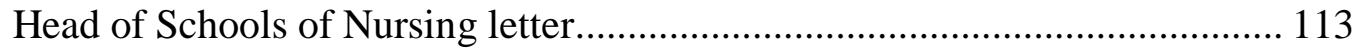




\section{LIST OF FIGURES}

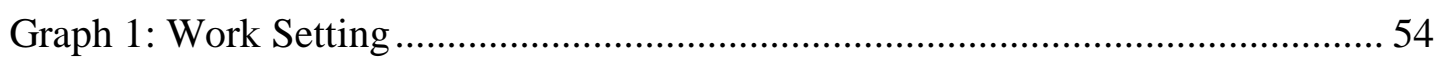

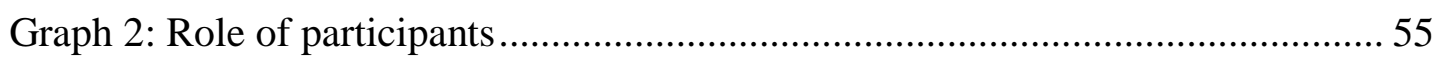

Graph 3: Intravenous therapy during degree study ............................................. 56

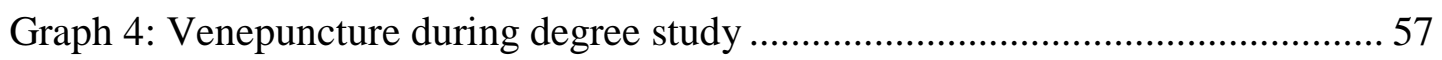

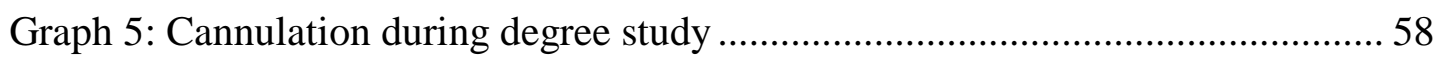

Graph 6: Gain confidence and competence IV therapy during new graduate year ... 59

Graph 7: Gain confidence and competence in venepuncture during new graduate year

Graph 8: Gain confidence and competence in cannulation taught during new

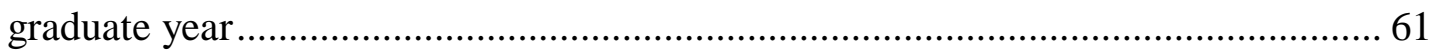

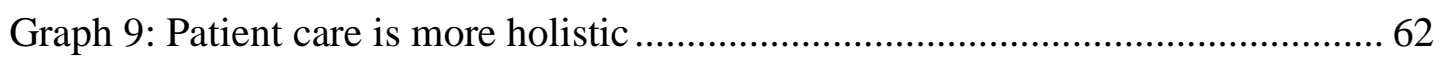

Graph 10: All registered nurses should perform venepuncture ............................... 63

Graph 11: All registered nurses should perform cannulation .................................. 64

Graph 12: Registered nurses should decide for themselves when to undergo training 65

Graph 13: National consensus as to when this education should take place ............. 66

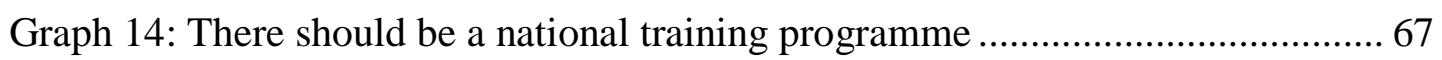




\section{LIST OF TABLES}

Table 1: Benner's Levels related to infusion therapy ............................................. 39

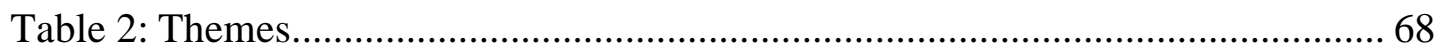

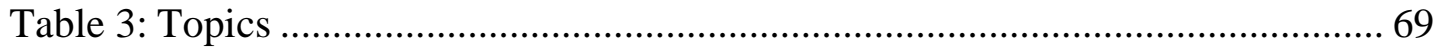




\section{GLOSSARY}

Undergraduate nurse - A person who is enrolled in a College of Nursing and who, at the culmination of the curriculum is eligible to take the Nursing Council of New Zealand final examination for registered nurse status (NCNZ, 2007).

New graduate nurse - A registered nurse in first year of clinical practice post registration (MOH, 1998).

Infusion Therapy - The introduction of liquids into the body in a process that circumvents the gastro-intestinal tract. Usually the liquid is introduced into a vein (intravenously), less often an artery (arterially), the subcutaneous adipose tissue (subcutaneously), the bone (intraosseously) or into the epidural space (epidurally) (Hankins, Waldman Lonsway, Hedrick \& Perdue, 2001).

Intravenous Therapy - is the infusion of fluids, medication, blood products and nutritional support via a venous access device (VAD) into a peripheral or central vein (Wells, 2008).

Venepuncture - is the introduction of a needle into a vein to obtain a blood sample for haematological, biochemical or bacteriological analysis (Lavery \& Ingram, 2005)

Cannulation - is the term given to the procedure where a small, flexible plastic tube, or cannula, is inserted into a peripheral vein to give intravenous medication, analgesia or fluids and to take blood samples (Fitzsimons, 2001).

Peripheral - pertaining to the outside, surface or surrounding area of an organ, other structure or field of vision (Anderson, Elliot, Keith \& Novak, 2002).

Tissuing - (also called infiltration) - occurs when there is leakage of intravenous infusion into the surrounding tissues (Dougherty \& Lamb, 2008). 
Phlebotomy - incision of a vein for the letting of blood, as in collecting blood from a donor (Mosby, 2002).

Peripherally Inserted Central Catheters (PICC) - a percutaneous IV line inserted into the antecubital vein and advanced till it reaches the superior vena cava and can stay insitu for one year or longer (Dougherty \& Lamb, 2008).

Midlines - a catheter inserted into an antecubital vein which is then fed through the vein until it reaches the upper arm vein but does not extend past the axilla (Dougherty \& Lamb, 2008). 


\section{CHAPTER ONE}

\section{Overview and introduction}

One of the most common procedures experienced by any patient entering a hospital in New Zealand, and indeed in any hospital internationally, is having venepuncture, cannulation and possibly receiving some form of intravenous (IV) therapy (Davies, 1997; Josephson, 1999; Walker, Farraj, Papavassiliou, and Arvanitis, 2006; Wilkinson, 1996). The statistics quoted by these above mentioned authors range between seventy to ninety per cent of patients receiving some type of venous access or treatment when admitted to a hospital. Historically it has always been the role of a doctor to perform these procedures; however, nurses in extended or expanded roles now carry out these interventions more frequently. Research into intravenous therapy, venepuncture and cannulation is mostly limited to overseas studies, for example, Brouwer (1995), Gray (1997), Gruber, Gomersall, Joynt, Shields, Chu, and Derrick (2007), Hankins, Waldman Lonsway, Hedrick, and Perdue (2001), Spader (2006) and Weinstein (2001). These studies mainly look at issues around competency, legalities, holistic care and advanced practice. Some recent New Zealand research has emerged from authors such as Breton and Ferguson (2009) and Cassie (2009) who also look at certification and IV competencies in New Zealand. No specific studies were located that indicated when specific IV education and training is provided for nurses from any country.

Issues relating to IV therapy are often debated in literature. These are briefly explored in this chapter in order to provide a background and justification for the research. The researcher's story is explored and this will give an indication of why the researcher has an interest in the research topic. An overview of the research is presented along with research aims, objectives and the research question. Following that, a brief discussion of some of the major findings in the literature is undertaken. 


\section{Personal reflection (Researcher's story)}

My interest in intravenous therapy began during my student nurse days. I completed my nursing training at a very large hospital in South Africa in 1985. During our training we learnt about intravenous therapy, venepuncture and cannulation, working alongside the doctors and anaesthetists. Studdy, Nicol and Fox-Hiley (1994), discuss that students learned quickly and became more confident from observing role models and practicing in clinical areas rather than in a classroom. As students we would watch the doctors and then they would teach us how to carry out the procedures. We were fully aware of our limitations and the fact that we had to practice under the 'standing orders' of the doctors. These skills enabled us to care holistically for our patients when we were short of doctors in our training hospital.

After completing my general nursing and midwifery study, I worked for the provincial Blood Bank as a phlebotomist, where as a group of registered nurses, we could collect up to 600 units of blood a day. This greatly enhanced my venepuncture skills and clinical practice. I have always been interested in intravenous therapy, venepuncture and cannulation and have tried through my years of nursing in different areas to pass on the passion to my fellow nurses.

When I immigrated to New Zealand in 1994 I was employed at a District Health Board as a midwife. In my first month, I arrived on duty to find a situation where a client was becoming dehydrated as her cannula had 'tissued'. The staff had been waiting a few hours for a Registered Medical Officer to come and re-site the cannula to recommence her fluids. I immediately resited her cannula and started the infusion again. A few days after this incident, I was informed that midwives and nurses did not cannulate patients at this hospital. This really surprised me, as I could not see how you could care holistically for your patient without being able to cannulate them or even be able to take routine bloods as requested by doctors.

I later became involved in setting up the intravenous therapy education and training for interested nurses at the hospital. I felt I had expert clinical knowledge and was happy to share this in order to improve patient care. In due course, I became the 
Infusion Therapy Co-coordinator for the hospital and also became the inserter of Peripherally Inserted Central Catheters (PICC) and Midlines. During this time, I also delivered tutorial sessions to the new Registered Medical Officers who were employed and it fascinated me how many of them had never learnt to cannulate patients during their years of education and training.

My current role is as an educator of undergraduate nursing students. I deliver theory sessions to these students and I also attend clinical placements to visit them while they are in practical placements. When students are doing their placements (particularly the third year of nursing education), the question often arises, both from the students and also the placement providers, as to whether or not they are allowed to become more involved in the role of intravenous therapy, venepuncture or cannulation. As I am aware of what I did during my nursing training, I have to ensure that I do not cross the boundaries of what is 'allowed' with current students by the hosting clinical placement.

\section{Background discussion}

As previously stated, according to Davies (1997), Josephson (1999), Walker et al., (2006) and Wilkinson (1996) between seventy and ninety per cent of all patients admitted to hospital will receive some form of intravenous therapy during their hospital stay. This means that these patients will be cared for by nurses, who will need to have the IV related education in order to care for them.

Globally there appears to be no consensus about the 'right time' for nurses to undergo intravenous therapy, venepuncture or cannulation education. Anecdotal evidence from discussions held with registered nurses from Australia, Philippines, South Africa and the United Kingdom, indicates that these undergraduate nurses are taught intravenous therapy, venepuncture and cannulation routinely during their three years of study and they all believe it is important to have this background from an early stage in their careers. Discussions with New Zealand nurses produces a raft of varying opinions, from those that agree, to those that are vehemently opposed, to 
teaching undergraduate nursing students these topics. It was after many of these conversations, that the researcher realised the importance of doing this research, in anticipation of finding an answer to the question "Should nurses be prepared to administer IV therapy, undertake venepuncture and cannulation prior to or following registration?"

There are research articles that discuss medical officer education and training for intravenous therapy, venepuncture and cannulation, and some of these articles discuss nurses taking on this role (Bakewell, 1994; Edwards, 1995; Feddock, 2007; Gray, 1997; Gruber et al., 2007; Walker et al., 2006). Consensus seems to be that if nurses have the knowledge and the skill, can carry out the action and answer for the results of their practice, then they should be able to take on roles that might previously have been carried out by medical officers and be seen to be practicing autonomously (Collins and Henderson, 2001; Coulon, Mok, Krause and Anderson, 1996; Shields and Watson, 2007).

Due to the litigious society that exists in the United States of America (USA) and Canada, Weinstein (2001) discusses that nurses should meet minimum eligibility criteria before being allowed to deliver any form of intravenous (IV) therapy. Hankins et al., (2001) also discusses the importance of consumer protection and therefore, the need for registered nurses to be licensed before being allowed to practice any form of IV therapy. Corrigan, Pelletier, and Alexander (2000), Hankins et al. (2001), Josephson (1999) and Weinstein (2001), also from USA, are all agreeable that nurses must adhere to Intravenous Nurses Society Standards of Practice. Vesely, Stranz, Masoorli, and Hadaway (2002) support the need for reliable scientific evidence to support clinical practice, as they suggest that although there is philosophical consensus on this need, that many guidelines that are issued, all vary in their recommendations. Hanchett (2005) suggests that there is a lack of evidence to support evidenced-based practice and continues to suggest that there is a need for rigorous research to build a systematic and comprehensive scientific foundation to support all aspects of IV therapy. There appears to be a large gap existing between theory and practice (Coutts-Jarman, 1993; Farwell and Bramadat, 1990; Funk, Champagne, Wiese and Tornquist, 1991; Hunt, 1981). Jackson (1997) suggests that organisations need to be committed to major changes in health care 
delivery and that they can then mould packages to directly respond to the needs of patients.

Therefore, before deciding whether or not IV therapy, venepuncture and cannulation should become a requirement of undergraduate study, a baseline of usefulness for the nurse and perceived benefit for patients should be established. The baseline information gained from this examination will be beneficial to plan education programmes for nursing curricula so students receive the maximum benefit of these skills in the lab and clinical setting. It could also be useful for hospitals to decide what education and training they will need to provide to newly employed staff nurses, based on knowing what education they have already undergone during their undergraduate study.

Considering the literature discussed and the fact that there is no consensus about many aspects of IV education, it is important that research is carried out to determine what registered nurses in New Zealand believe the correct time is for nurses to be educated about IV therapy, venepuncture and cannulation.

\section{Research aims, question and objectives}

There are large gaps in the literature, both nationally and internationally, about the specific timing of education for IV therapy, venepuncture and cannulation. There is a plethora of general literature relating to IV therapy, venepuncture and cannulation, but none of this literature deals specifically with the issue of when this education and training should take place. Therefore, this exploratory descriptive study will examine clinical nursing educators' and registered nurses' perspectives about the optimal timing of education of undergraduates or new graduates in the role of IV therapy, venepuncture and cannulation.

The guiding question for this research is: "Should nurses in New Zealand be prepared (educated and trained) to administer IV therapy, undertake venepuncture and cannulation prior to, or following registration?" 
The research objectives in this study are:

* To identify when IV therapy, venepuncture and cannulation education and training of undergraduate and new graduate nurses should take place.

* To identify what aspects of IV therapy, venepuncture and cannulation should be included in undergraduate nursing curricula according to the different District Health Boards (DHBs) and nursing schools in New Zealand.

This study will use an exploratory descriptive method to attempt to answer the research question. A questionnaire using both open and closed questions examining what respondents understand and believe about IV therapy, venepuncture and cannulation, is employed to assist in answering the research question.

It was anticipated that respondents to the survey would share their understanding, beliefs and awareness of the possibilities that education and training of IV therapy, venepuncture and cannulation would bring to undergraduate nursing and provide a comprehensive portrayal of the group's collective perceptions (Polit and Hungler, 1997). By establishing this information, it is hoped that future nurses would have the necessary training and education tailored to allow them to advance their practice from an early point in their career. This in turn would create opportunities for the nurses to provide more holistic care for their patients. Therefore the results of this study will be used to inform the theory and practice development at pre and post registration level.

\section{Justification}

A review of the literature about pre and post graduate training preparation in venepuncture and cannulation reveals little evidence about what training should be provided for nurses and at what stage of their careers this training should take place. These issues are confirmed by Morris (2006); Pine (2007); Scott (2003) and Workman (2000), who are all from the United Kingdom (UK) and who have examined these issues in their country. Throughout this study, the researcher has indicated which countries the authors of the researched literature have originated 
from. This has been to try and show trends of what different countries have researched, but these have not been analysed due to the specific nature of the current study. It has certainly highlighted future areas that the researcher would like to pursue. The researcher believes that as there is a lack of specific evidence about what training should be provided, that it would be beneficial to carry out further studies.

During the course of this study, the researcher has had many opportunities to have discussions with a number of clinical experts in the field of intravenous therapy. It is of interest to note that many of them discussed how, in some countries (South Africa, UK, USA, Australia), student nurses are taught while they are working with the anaesthetists, but there are no 'formal' training or education sessions. There are different standards accepted in different parts of the world and nationally between different DHBs in New Zealand. Farrand, McMullan, Jowett and Humphreys (2006), from the UK, discuss how traditionally nurse education followed an 'apprentice style' and that students learnt many of the core components of their future role by observation and then clinical practice. Morris (2006) also discusses the major problem of there not being any universal policy regarding preparation and administration. She continues to say that each hospital and educational institute all have their own rules and regulations. This can have a major impact on staff and students transferring from one hospital to another. When considering what Morris (2006) reports, national and international rules and regulations relating to intravenous therapy education and training should be mandated. This study will inform and contribute to such debates.

\section{Intravenous therapy education for undergraduates}

In the researcher's role as a nurse educator, she had discussions with students over a range of topics. These discussions explored what students believed they needed to be taught prior to going to placement. These discussions have also been held with registered nursing staff in the clinical placements. It is interesting to see the division in their beliefs about what the educational requirements are for undergraduate nurses. 
Some registered nurses suggested in the discussions, that they have high expectations of the new graduate nurse and what clinical skills they believe they should be able to carry out once registered. There were however, other nurses who believed that these skills should be undertaken as extra study courses after registration on an as needed basis. Some felt they are learning skills that they will not be able to carry out competently if they do not practice them regularly.

These differences are often created when the students have had their clinical placements and realize what skills would have been beneficial for that particular placement. The students acknowledge that they cannot be taught everything, and one of the possibilities they have given is that there be some extra courses available for them to undertake as optional papers, if they so wish. Currently, they are given an option to undertake a level four resuscitation course instead of a basic first aid course. They have now suggested that they might like to have other options available, such as venepuncture, cannulation, wound care, ear syringing, and vaccination courses. This is confirmed by Spader (2006), who suggests that each educational institution should be responsible to focus on individual students and their ability to seek information and develop their own skills.

\section{Organisation of research document}

In Chapter One the outline for why this particular topic was chosen to be researched and some of the background to the researcher's interest in the topic has been discussed. It has introduced the aim, the guiding question and the approach taken for the research.

An exploration of the literature surrounding infusion and intravenous therapy, venepuncture and cannulation education and training will be presented in Chapter Two. It will identify the apparent absence of research specifically related to the topic under study. 
The choice of research study design and method, sampling plan and procedures will be discussed in Chapter Three. Inclusion criteria and recruitment methods will also be presented. Additionally, the protection of human subjects and ethical considerations will be reviewed as appropriate to this study.

Data analysis of the respondent's replies and comments will be reviewed in Chapter Four. Following this, a descriptive analysis of the responses to the questions from the questionnaire is offered.

A discussion of the findings will be offered in Chapter Five. The implications for education and practice will also be discussed using supportive current literature. Limitations of this study and suggestions for further research will also be explored.

\section{Chapter summary}

This chapter has introduced the topic of this study and the background motivation for undertaking it. The relevance of this research and the reasoning has been discussed. A brief overview of the research that examines the topic of IV therapy, venepuncture and cannulation has also been presented. To give the reader an idea of how the thesis will unfold a delineation of each of the thesis chapters followed. The following chapter will look at the gaps that remain in the literature relating to this topic. 


\section{CHAPTER TWO}

\section{Literature review}

This chapter presents a review and critique of literature related to intravenous therapy, venepuncture and cannulation, in relation to undergraduate and new graduate nurses. Throughout the search for relevant information, recurrent themes emerged from the literature on the topic of IV cannulation. These themes are: extended or expanded roles, education, holistic care, competence and legal issues. This chapter will discuss the search strategy used, each of the themes that were identified and introduce the literature to support them.

Research into infusion and intravenous therapy, venepuncture and cannulation is mostly limited to overseas studies, such as those carried out by Davies (1997), Evans, Boxer and Sanber (2007), Inwood (1996), Koh (1996) and Logan, Forbes and Carachi (1996). Inwood (1996), Koh (1996) and Evans et al. (2007) research looks at designing education programmes and what should be included, while Davies (1997) looks at the role of nurses in IV cannulation. Logan et al. (1996) research discusses how it is important for medical students to be exposed early to clinical skills and also that they are correctly supervised. A large amount of the literature did not concentrate on one specific area and appeared to be cross dimensional which covered IV therapy, venepuncture and cannulation. It has not been possible to separate the literature under the separate headings of IV therapy, venepuncture and cannulation, as the majority of the information collected combines at least two and sometimes all aspects of the chosen areas for this study. In reviewing the literature that the researcher found and used for this study, it was apparent that no clinician or researchers have specifically commented on the topic of this study, which shows a gap in the literature surrounding the timing of IV therapy, venepuncture and cannulation education and training for nurses. Further exploration is offered after describing the literature search strategy. 


\section{The literature search strategy}

The literature review was completed subsequent to a search of the following electronic databases: MEDLINE, CINHAHL, Ebsco Host, CODA and Google Scholar. Key words used in the search included; intravenous therapy, infusion therapy, education/training, venepuncture, cannulation, undergraduate and new graduate nurses. Literature was also obtained through cross-referencing articles and studies that appeared relevant while reading some of the articles. The search was restricted to English language, and no limitations were placed on types or dates of studies. This decision was made due to the limited number of relevant research undertaken within the last ten years. Library databases and journals were accessed through the University of Victoria, the local District Health Board and the local tertiary libraries. Two hundred and seventy six journal articles were reviewed and ninety three were used for this study. Twelve books relating to infusion therapy were reviewed. The Nursing Council of New Zealand and New Zealand Nurses Organisation websites were utilised for any relevant documents. Infusion therapy manuals from three hospitals were reviewed, but no specific information from them was used for this study.

Available relevant New Zealand specific literature will now be presented.

\section{New Zealand research}

It is encouraging to note that some New Zealand research has recently emerged such as that from Breton and Ferguson (2009) and Cassie (2009). The New Zealand research by Breton and Ferguson (2009) looks mainly at the issue of IV certification and whether it is really necessary and surveys nurses on the issue. Cassie's (2009) research revolves around extended, advanced and expanded practice and who should decide who can undertake these roles. Neither of these studies sheds any light on the issue being researched for this project. This highlights the importance of further research being undertaken. The question guiding this research is: should nurses in New Zealand be prepared to administer intravenous therapy, undertake venepuncture and cannulation prior to or following registration? 


\section{Available literature}

There was a lack of literature around the topic of specific training, timing of this education and where this education should take place. In relation to the research question, the following literature review is broad, but it includes studies comprising any information relating to the research question of whether nurses in New Zealand should be prepared to administer intravenous therapy, undertake venepuncture and cannulation prior to or following registration. It is important to acknowledge that, because there appeared to be limited published research within New Zealand, this did not mean that there is no current research taking place. The literature that was examined for this research study appears to have been undertaken by a wide variety of people in different roles, for example; clinical nurse specialists, lecturers, nurse advisors, doctors and registered nurses and this gives a variety of perspectives.

The review begins by exploring the extending role of nursing, as this appears to be the most common topic that appears in the literature from the search carried out by the researcher.

\section{Extended or expanded role}

Workman (2002) states that there is minimal documented evidence available about the impact on nurses in extending their roles to include venepuncture and cannulation. This topic is open to debate and there are many different opinions about the benefits of nurses learning to do venepuncture and cannulation at an early stage of their careers (Last, Self, Kassab and Rajan, 1992; Marshall and Luffingham, 1998; Ung, Cook, Edwards. Hocking, Osmond and Buttergieg, 2002).

Research reveals that most of the practical training literature for nursing staff has originated in the USA (Corrigan et al., 2000; Hankins et al., 2001; Josephson, 1999; Weinstein, 2001). Much of the UK literature appears to concentrate on the care and maintenance of peripheral cannula and not on the education or training of nurses. This concept is supported by David and Pritchard (1988) and Inwood (1996), who suggest that there were no programmes specifically designed for nurses and it was 
difficult for them to find much information about the topic. Coutts-Jarman (1993); Farwell and Bramadat (1990); Funk et al., (1991); Hanchett (2001) and Hunt (1981), confirm that intravenous nursing still requires a theoretical base and a specific nursing theory to be developed, which might be accepted by all practicing clinicians. Spader (2006) discusses a belief by experts that a culture of misconceptions and myths about practice has perpetuated due to the lack of standardized education and training in intravenous therapy.

Generally, clinical practices that become commonplace, have a tendency for individuals' attitudes toward these to become relaxed. Scott (2003), states that individual wards, units and tutors need to ensure that individual practitioners keep abreast with current research to avoid this. "Evidence-based nursing practice is the conscientious, explicit and judicious use of theory-derived research-based information in making decisions about care delivery to individuals or groups of patients and in consideration of individual's needs and preferences" (Ingersoll, 2000, p.152). Ingersoll's (2000) description of evidence-based nursing focuses on bridging the gap between science and clinical practice, and on how nursing research can ultimately benefit patient care. Evidence-based practice considers not only best researched evidence, but also clinical expertise and patient values (DiCenso, Guyatt and Ciliska, 2005).

Cassie (2009) discusses the implications for New Zealand nurses extending their practice in her research that looks at nurses' credentials. According to Cassie (2009), nurse leaders have been meeting to try and set up a framework with nationally agreed standards. This is general research and not specific to intravenous therapy. The necessity of IV certification for New Zealand is also discussed by Breton and Ferguson (2009). They concluded that ongoing IV education and training results in improved patient outcomes and clinical practice. However, there was uncertainty whether IV certification gave the same results and further research was urgently needed. Although Cassie's (2009) research is not directly related to Ferguson's research project, it does have some implications for future IV practice in New Zealand. It is evident at a national level, that there is a clear need for further research to be undertaken around a number of IV related issues in New Zealand. 
All the research used in this study about extended roles originated from the United Kingdom (UK). Workman (2000), describes an extended role as being a duty that is allocated to a nurse that appears to be outside of the current scope of nursing practice and that an expanded role as being where a nurse practices at a higher level of nursing practice within the boundaries of nursing. This is echoed by Rowden (1987), who suggests that an extended role is one that is not covered in basic training. There are still clinicians and academics who believe that cannulation is a doctor's job and that nurses will be taken away from their traditional role and compromise patient care if they become the doctor's substitutes (Davies, 1997; Fitzsimons, 2001; Last et al., 1992). However, there are some researchers who believe that patient care is enhanced by nurses expanding their roles (Fitzsimons, 2001). Shields and Watson (2007), state that poor education and mistakes lead to death, so it is therefore, imperative for nurses to have education of the highest standard, to ensure that they are aware of how to access the best evidence and use critical thinking in order to provide high standards of care for patients. They continue by saying that as long as nurses are specialising with postgraduate study and Master Degrees, doctors should not feel threatened if nurses are extending their roles to encompass duties previously seen to 'belong' to doctors. Ultimately, this will be beneficial to the patients.

Edwards (1995) from the UK, is supportive of nurses extending their roles, but suggests that certification of the roles actually limits and dampens responsiveness to changing needs and that this in turn neglects the importance of holistic care. Currently in New Zealand, nurses are being encouraged to further their education. For example, the nurses who had 'trained' under the 'old' system and held hospital diplomas are now undertaking their undergraduate degrees and nurses with degrees are continuing their study to achieve Master Degrees. This should be seen in a positive light by medical doctors. Freeth and Nicol $(1998$, p.455) say that "there is a need for greater co-operation and collaboration between healthcare professionals, as this will lead to quality patient care that would better serve the needs of the patients". This does not necessarily mean that nurses are taking on the role of medical doctors, but that they are extending their roles in the best interest of the patients, which will provide more holistic care. Castledine (1992, p.671) explains the need for education in nursing very well: “...nursing is not the execution of uncomplicated tasks carried out at the discretion of others, nor is it a vocation of which short-term technical 
training will suffice. It is a job that requires highly educated, knowledgeable and competent individuals."

Dodds (1991) points out, that nurses are 'trained' to become compliant and this may cause them to accept tasks outside their professional scope of practice. However, Bowler and Mallik (1998) suggest that nurses need to agree with medical staff about who is ultimately responsible for specific activities that may have been requested by doctors. This is not the case in New Zealand, as each practitioner is responsible for their own practice. Edwards (1995) discusses that it is important for nurses to undertake the extended roles voluntarily and not to be coerced into extending their roles for the benefit of the healthcare facility. Pearson (1987), states that taking on extended roles is not a new phenomenon and that if nurses might not agree with their new responsibilities and accept them, then technicians will. Interestingly, there is already mention in some literature of health care assistants beginning to undertake these 'tasks' (Carlisle et al., 1999; Collins, Phillips, Dougherty, de Verteuil and Morris, 2006).

It is important that taking on extra tasks is not just seen as a mechanical task that anyone could be trained to do (Bowler and Mallik, 1998). There are advantages and disadvantages to nurses expanding their roles. For example, they might feel that they gain intellectual stimulation and professional satisfaction and this is sometimes worth more than monetary value. However, Hyde in (Dougherty and Lamb, 2008) states that this increased responsibility brings an increased capacity for liability, which means that nurses require a working knowledge of the professional and legal responsibilities as they apply to their practice. This in turn contributes to enhancing the therapeutic nurse-patient relationship.

Bowler and Mallik (1998) suggest that if a nurse's role is expanded, it can lead to dynamic and sensitive practice. If a nurse is able to provide excellent venepuncture, cannulation and intravenous therapy skills, then they are providing care that is far more holistic than if they had to wait for medical personnel to provide it. Coulon and colleagues (1996) suggest that the client needs to remain the central focus of excellent care at all times. Their discussions with patients will often point to the fact that patients perceive nurses to be more compassionate and caring than doctors when inserting cannula. If nurses are going to extend 
their roles then they should have adequate knowledge. It is important to achieve consensus about the training and knowledge required. Carlisle and colleagues (1999, p.1262) support this belief when they state the "need for the profession as a whole to move towards a consensus and for educators to work with managers to identify what should be accepted as the minimum acquisition of certain skills."

\section{Patient protection}

In order to ensure competent care is provided to all patients, all practitioners are now bound by the Health Practitioners Competence Assurance Act 2003 (HPCAA). This includes nurses administering IV therapy or performing venepuncture and cannulation. This act was passed in September 2003, by the New Zealand Parliament. The Ministry of Health (2003, p.7) states the HPCAA is about public safety and specifically: "The principal purpose of this act is to protect the health and safety of members of the public by providing for mechanisms to ensure that health practitioners are competent and fit to practice their professions". Under the HPCAA, the Nursing Council of New Zealand (NZNC) is required to audit and approve educational institutions and their programmes for the education of nurses (Nursing Council of New Zealand, 2005). The HPCAA has also cemented the relationship between competence and practice, and as a result, each registered nurse in New Zealand must provide evidence of clinical practice hours. The minimum requirement is 750 hours within the previous five years or 450 hours within the last three years (NZNC, 2007). These are important mechanisms to ensure patients are provided with care from competent nurses.

It is important that nurses practice autonomously within their scope of practice, but it is crucial that they are sensitive to changing health care needs. It is interesting to note that there are often different beliefs between management and ward staff about what 'skills' a nurse needs to make for better patient care. This is discussed by Carlisle, Luker, Davies, Stillwell and Wilson (1999), with the importance being placed on the fact that each individual environment needs to be explored to decide which core skills are required. 
Inwood (1996) discusses how venepuncture and cannulation have been part of nursing skills in the U.S.A, Canada and Australia for a considerable time, but there has still not been any specific training programme developed specifically for nurses. However, Spader (2006) highlights that due to the rapidly changing health care system, IV education and training are not keeping up with the required pace. GreenThompson (2006) and Gruber et al., (2007) both discuss the importance of cannulation and venepuncture training for medical undergraduates and this is included in their basic training. A course was developed for final year students and is available free of charge to any medical school from Gruber and colleagues (2007). There were a few articles relating to doctors undergoing venepuncture and cannulation training, but these did not include nurses being trained with the same programmes. Again, it was not always a 'definite skill' that doctors had to be competent at prior to going to work in a hospital setting. Logan, Forbes and Carachi, (2005) discuss that medical students are often taught in a random and unpredictable manner in the wards and this is not acceptable practice. They continue to say that the earlier students are "exposed" to learning venepuncture and cannulation skills, the less daunting it is for them. Surely this rationale could inform nursing undergraduate education.

Scott (2003), states the concern that in this age of clinical governance, there are still some healthcare professionals that are unable to practice intravenous therapy safely. Due to their recommendations, they have now launched national IV standards in the UK. In the USA, nurses must adhere to Intravenous Nurses Society Standards of Practice. Currently it appears that most New Zealand hospitals, or nursing schools, all develop and produce their own training programmes and there is no national consensus about what is required to be taught. Intravenous Nurses New Zealand (IVNNZ) is encouraging hospitals to have their training courses assessed by them for accreditation. This would then allow nurses, transferring from one IVNNZ accredited hospital to another, to transfer their certification without having to undergo training at the new place of employment. However, if a hospital does not apply for accreditation and the nurse moves places of employment then those skills are not transferable. This is a significant waste of time and money, as it will mean that someone who is totally proficient at venepuncture and cannulation has to undergo training and up skilling at every place of employment. 
It is also important for all registered nurses to accept responsibility for maintaining their own skills and knowledge, ensuring that they keep themselves up to date with latest research. In the researcher's discussions with different nurses, many of them admit to having been 'taught through necessity' while working in practice. However they have later attended and undergone 'official' venepuncture or cannulation training through their place of employment. This further confirms the lack of consistency with training for nurses in New Zealand. Further anecdotal discussion with overseas qualified nurses, who have venepuncture and cannulation experience from other countries, indicate that they find it frustrating as to why there is no 'portability' of their capabilities.

Anecdotal evidence and a review of the literature identify the need to explore the feasibility of offering education and training to the undergraduate nurses prior to them entering the workforce. It is anticipated that undertaking this exploratory discriptive study will illuminate understanding and awareness of possibilities of pre or post graduation education and training in intravenous therapy, venepuncture and cannulation.

This discussion will now highlight IV therapy education internationally and whether it is consistent with national IV therapy education. An exploration of other researchers' opinions on what should be offered through education will also be presented.

\section{Education}

The literature review revealed a lack of research internationally and in New Zealand specifically relating to the timing of the training. There are numerous pieces of literature available that look at aspects of IV therapy such as Scott, (2003), Spader, (2006) and Ung et al.,(2002) to name a few. It is acknowledged that there is a lack of specific research relating to education in intravenous therapy, according to Workman (2000) who is from the UK. Much of the research that comes from Australia (AUS) discusses the need for undergraduates to learn about practical 
nursing skills, but they are not specific about which skills are needed (Evans, 2007; Farrand et al., 2005; Freeth and Nicol, 1998). As discussed in chapter one, literature searches show that most of the practical training literature for nursing staff originates from the USA (Weinstein, 2001). The majority of literature from the UK appears to concentrate on the care and maintenance of peripheral cannula (Lamb, 1993). Inwood (1996) from UK discusses that it appears that there is still no specific training programme developed only for nurses, even though venepuncture and cannulation have been part of nursing skills in the United States of America (USA), Canada and AUS for a considerable time. Spader (2006) from the USA says that the lack of standardised education and training in intravenous therapy has resulted in the perpetuation of a culture of misconception and myths about practice. During the search for literature, it was interesting to note that many of the articles (Brouwer, 1995; Fitzsimons, 2001; Spader, 2006; Ung et al., 2002) from countries such as AUS, South Africa (SA) and the UK, talk about 'students' learning about intravenous therapy and other modalities, but they often don't specify whether they are undergraduate, new graduate or nurses with more clinical experience wanting to expand their roles. Feddock (2007) from the USA states it is imperative that clinical skills need to be patient centred and taught by someone who can be a close mentor so that they should be able to assess and provide feedback to the student. This discussion is about medical doctors' education and training, but the researcher can see it applying to nurses as well. Feddock (2007) continues to say that although educational facilities play a large part in providing clinical skills, it is important that the hospitals need to work in partnership and be supportive to ensure the practical components of the theory can be put into place.

\section{Role modelling in education.}

Studdy and colleagues (1994) from the UK discuss that students learn quickly and become more confident from observing role models and practising in clinical areas rather than in a classroom. However, discussions held by the researcher with nurses, when in her infusion therapy coordinator role, confirmed that the nurses appreciated the hours that were spent in the class setting. The researcher was able to discuss and 
demonstrate the process. As the nurses observed the researcher demonstrating on the mannequin, they were also able to pick up the hints and tips that the researcher gave them. The nurses then also had the opportunity to practice on the mannequin and not have to practice on a patient for their initial attempts. The researcher believes that this amalgamates the two options that Studdy and colleagues (1994) discussed and allows the students to feel more confident in their skills prior to working in the clinical setting. Crowley (2008) from the UK discussed that simulation allows students to have the chance to practice. They can see where they are making mistakes and gives them a second chance and no-one gets hurt. It remains imperative that the lecturer should always be available to help guide them in the correct technique.

Hammer and Souers (2004) from the USA argue that classroom instruction and demonstration alone are not the most effective way to prepare students to meet skill demands. They suggest that to keep up with changing technical advances, it might be appropriate to use computer-assisted IV catheter simulation models. This allows students to learn and practice critical thinking skills in a controlled environment without placing patients at risk. In the literature from the UK, it has shown a clear need for teaching skills either in a simulated setting or in a clinical setting (Alavi, Loh and Reilly, 1991; Gomez and Gomez, 1984; Koh, 1996; McAdams, Rankin, Love and Patton, 1989; Neary, 1994; Neighbours, Eldred and Sullivan, 1991; Reilly and Oermann, 1985). Each of these different authors suggested that there were advantages and disadvantages to both ways of teaching. As can be noted from these dates of publication, there are not many recent studies to show what essential skills are needed for new graduate nurses.

\section{Education for new graduate nurses}

Boxer and Kluge (2000) undertook a study in Australia, to determine what general skills were considered to be essential in nurse's first year of practice after registration. It is interesting to note in this study that although the skills of intravenous therapy, venepuncture and cannulation are all mentioned, it was only 
intravenous therapy which was regarded as an essential skill. However, they did not discuss who should be performing the venepuncture or cannulation, if new graduates were not participating in this part of patient care. Collins and colleagues (2006) state that cannulation is a skill learnt by many but not always used in practice and this is often because there is a lack of supervision available by an experienced practitioner. This was echoed in anecdotal discussion with nurses who mentioned that not all nurses want to learn to perform venepuncture or cannulation. This is because they don't believe the area that they are working in allows them to perform these tasks regularly enough and therefore, they would not be proficient in performing them. In conflict with this, there were other nurses who said that it was like riding a bicycle and you never forget how to do it once you have had correct and proper training. However, no research has been completed in New Zealand to explore these issues, beyond anecdotal evidence to suggest any problems with this aspect of education for nurses.

Ung and colleagues (2002) from Australia discuss that when nurses are undergoing education and training at undergraduate level, that they have a more positive outcome in continuing what they have learnt. Edwards (1995) suggests in her study, that the nurses most recently educated, experienced fewer difficulties in role expansion and were more likely to take on the new roles. Ung and colleagues (2002) continue to say that throughout AUS and UK that peripheral intravenous cannulation is becoming a nursing responsibility and this has a major impact on patient care. They discuss that having years of experience in general nursing alone does not improve the ability to provide this care for patients. Wilkinson (1996) from the UK conducted a survey around nurses' concerns about IV therapy and devices. The results indicated that safer IV outcomes result from appropriate training of personnel and it is imperative that they have a good understanding of techniques and the risks involved. It also became apparent that planning and expert management of this therapy is necessary to minimise risks to patients and nurses alike.

The question of whether it is important for undergraduate nurses to be educated in intravenous therapy will now be discussed. 


\section{Intravenous therapy education for undergraduates}

Norton (1993) from the UK discusses how some undergraduate students are resented in their clinical placements, because of the different knowledge they are receiving from different educational institutions, in comparison to what the registered nurses believe they should be learning. They also presume them to be less interested in practical aspects of nursing care. Ashworth and Morrison from the UK state: "there is a very deep rooted belief felt by a majority of nurses that the more an individual accumulates qualifications, the less common sense they show" (Ashworth and Morrison 1989, p.1012). However, they continue by saying that there is little evidence to confirm that non-degree nurses have more success with delivering practical nursing care.

Ung and colleagues (2002) describe the graduate diploma course in Australia as preparing nurses for clinical practice by ensuring the courses are tailored towards skills development for clinical practice. This ensures they will be able to carry out all the care for their specific patients and not be dependent on others to perform these skills for them. Evans and colleagues (2007) discuss the importance of undergraduate programmes ensuring that skills taught will be practical and relevant for a new graduate to use as they transition into the role of a registered nurse. In addition they say that sometimes there is a perception that undergraduates are not being well prepared by the educational institutes. However, discussions with students often indicate that they don't have good role models when they are placed into clinical placements, as the registered nurses find it difficult to facilitate education when they are pressed for time in a busy work environment.

Spader (2006) discusses that more nursing regulating boards are beginning to have positions about the mandatory inclusion of specialized skills, for example - IV therapy in nursing programmes. However, this is not a pre-requisite of New Zealand Nursing Council, and each nursing school determines independently what they include as mandatory training. The New Zealand Nursing Organization (2008) has guidelines about nurses being allowed to practice intravenous therapy in conjunction with local policy. Cassie (2009) discusses the implications for New Zealand nurses extending their practice in her research that looks at nurses' credentials. She 
discussed that nurse leaders have been meeting to try and set up a framework with nationally agreed standards.

Timing and the different types of education have been looked at in relation to national and international standards, and this research will now look at whether these skills will provide holistic care.

\section{Holistic care}

It is important that nurses adopt a holistic approach to care "in which the physical, mental and social factors in the patient's condition are taken into account, rather than just the diagnosed disease" (Wainwright, 1987, p.213). Nurses also need to reflect on their practice, as this will guide them to provide better holistic care for their patients, but they still need to apply this to evidence based practice. Schön (1987) discusses "reflection-in-action", which happens 'right now' and "reflection-onaction" that happens as a "cognitive post-mortem", which the nurse can use as a problem solving framework to develop and adapt ideas to extend and validate their practice. Studdy et al., (1994) suggests that students should be given the opportunity to practice in clinical areas, but that clinical lecturers should provide time to supervise reflection. At the same time it is important that patients are not subjected to the novice practicing on them. Technical care is a huge part of nursing. It is integral for a nurse to be able to carry out technical skills to provide holistic care. Simpson (1989) showed that patients often associate quality of nursing care to the technical skills that they carry out. Ryan (1992) suggests that the quality improvement process is a beneficial way to improve the situation and that nurses can provide more holistic care for their patients if they can prove that it is more beneficial for them to insert cannulae themselves, rather than waiting on doctors to come and do it.

There is common agreement by a number of authors that there has been an increasing trend for registered nurses to perform 'tasks' that were previously only performed by doctors to suit the needs of the patients (Gray, 1997; Workman, 2000; Woodrow, 1997). However, when doing a literature search there is a wide range of views as to 
who should be 'allowed' to perform these 'tasks' and very little about when the best time would be to learn how to perform them. Bergman (1981), Collins and Henderson (2001), Gray (1997), McBrien (2006), Pyne (1992) and Wilkinson (1996), from UK, USA and Tel Aviv, all discuss that it is essential that nurses should clearly identify why they are taking on the new roles, which should be to ensure patients are receiving optimal, quality and holistic care. If nurses are performing these roles mainly because there is a shortage of junior doctors, then they really need to relook at their roles. Whatever nurses are doing should be in the best interest of the patient and not what is for the benefit of the hospitals. The nursing model has long been subservient to the medical profession (Rolfe, 1996 and Turnbull, 1994).

When nurses provide holistic care for their patients, it is also important that they are competent to provide this care. The discussion will now examine the literature on this issue.

\section{Competence}

Regardless of when nurses learn to cannulate, maintaining competency means that nurses should keep up to date with knowledge and current practice, for example, updating their knowledge on skin cleansing prior to cannulation. They need to reflect on their own practice and be fully accountable for their actions (Dougherty, 2008).

In an age of clinical governance, it is imperative that nurses practice safely, but it is difficult if there are no national or international guidelines to follow (Scott, 2003). Nurses need to remain committed to updating their knowledge and ensuring their skills and competencies are maintained. If this training is provided within an organized framework, it will inevitably be safer for patients. Castledine (1992) states that when the nursing profession takes on certain aspects of medical care, the practitioners must remember their actions are likely to be judged against what a 'reasonable' physician would do in similar circumstances. It is therefore, imperative that nurses are aware of their scope of practice and that they are accountable for their actions and have considered all the implications. In New Zealand, registered nurses have domains of practice that guide their scope of practice (NCNZ, 2007). 
Therefore, nurses should undertake these new roles with all the knowledge that is required to provide the highest standard of care for their patients.

Nurses have become more independent within their practice, which means they must have evidence to support the methods they use. Making time to research, and utilize educational training, enables a registered nurse to undertake skills with confidence (Joseph, 2008). There is also an expectation from the NCNZ that nurses should continue to learn and to maintain their competence (NCNZ, n.d.).

Many nurses have learnt how to perform these procedures through necessity, before being able to attend 'official training courses' (Brouwer, 1995; Spader, 2006; Shields and Watson, 2007). These researchers from SA and the UK, report that this is due to the demands in the departments they work in, for example, Intensive Care and Emergency Departments. Masoorli (2002) from the USA argues however, that on the job training does not hold up legally and that nurses need to ensure they have documented training to protect themselves. This would equate to certificated training in New Zealand.

Albarran and Whittle (1997) discuss nurses working at different levels of competency, which allows them to perform different procedures as they advance through different stages of their careers. They also discuss that when nurses expand their knowledge and correlate it with their clinical experience, their contribution to patient care will be greatly enhanced. This would fit with Benner's (2001) theory of advancing from novice to expert. Benner states that clinical knowledge continues and is gained over time and that it is interesting to note that the clinicians themselves are often unaware of the gains that they have made. Benner also states that it imperative that clinicians don't just try to learn the latest technology or procedures, but that they should gain in-depth skill in clinical judgment.

Competency is an issue that must be addressed by the different health providers. Morris (2006) discusses the concern that some students are learning from observing bad practice. The main concern is that it is unclear as to who is responsible for the assessment of qualified nurses who gained competence. Secondly, it is questioned whether newly qualified nurses fully appreciate the implications of administering IV 
drugs? The necessity of IV certification for New Zealand is discussed by Breton and Ferguson (2009). The conclusion they arrived at, was that ongoing IV education and training resulted in improved patient outcomes and clinical practice, but they suggested that uncertainty remains as to whether IV certification gave the same results. They go on to say that it is imperative that further research is urgently needed. Rieu (1994) explains that nurses need to be prepared for and assessed as being competent in their extended roles, or in the event of any error they will not receive much support from their managers. However, this is an interesting issue and has also been discussed by Last et al. (1992), who question why a nurse needs a piece of paper to say they are competent to carry out ' $x$ or $y$ ' when they undergo normal growth in their roles without needing proof of certification for each new task they undertake. Last et al. also question that if there is no requirement to prove competency, then how can management be sure staff are safe? They query "how managers can allow those who are able to fly to do so, but still provide a safety net to prevent those who never could fly, or even worse, those who think they can but cannot, from falling down?" (Last et al., 1992, p.675). Applying evidence-based principles into practice provides a powerful new direction, away from the tradition of ritualistic nursing practice, towards a more scientific basis, propelling nursing into a higher level of professionalism (Winch, Creedy and Chaboyer, 2002).

Legislation is different in each country regarding the practice or scope of a nurse, so it is important not to presume that one country will follow the practice of another. While looking at all the common themes that have emerged in the literature, it is imperative that the legalities of all of these are noted and discussed.

\section{Legalities}

Most hospitals in New Zealand have their own systems to control whether nurses are maintaining their competency in relation to intravenous therapy, venepuncture and cannulation. However, currently there are no national New Zealand competencies; therefore it is essential that each procedure undertaken by a nurse should be correctly documented. This should include evidence of the procedure and any issues that arose 
during it (Hobson, 2008). Lavery and Ingram (2005) remind us that it is imperative that nurses ensure they have identified the patient, obtained informed consent and that they have a good knowledge of what procedure they are performing. Morris (2006) discusses the issue of nurses being reminded that they are accountable for their actions and omissions, regardless of who has given them an instruction to follow, and to this end they also need to be reminded that if they supervise and oversee an undergraduate nurse undertaking these duties, then they are accountable for that student's actions as well.

As discussed in chapter one, patient safety is protected by the introduction of HPCAA in 2003 and also by auditing of random practitioners by the Nursing Council of New Zealand (NCNZ). This means that the responsibility for safe practice has been placed back into the hands of the practitioner. The practitioner has to ensure they maintain competence and are accountable for their own practice. The 1994 New Zealand Health and Disability Consumers Act (Health and Disability Commissioner, 1994), and the Code of Health and Disability Services Consumers' Rights (Health and Disability Commissioner, n.d) ensures that the rights of all people accessing health or disability services are protected.

If nurses in New Zealand implemented current best evidence-based practice, then they would ensure their patients were receiving safe care, with minimal risks involved. This is also reinforced by principle Four in NZNC Code of Conduct for Nurses, which states "The nurse justifies public trust and confidence" (NZNC, 2008, p.6). Within this principle, criteria 4.3 states: "uses professional knowledge and skills to promote patient/client safety and wellbeing" (NZNC, 2008, p.6). Therefore, all patients should feel confident in the care they receive.

When the researcher made enquiries about whether the NCNZ stipulated what education or training hospitals or schools of nursing should provide in relation to IV or infusion therapy, she was informed that the decision is made by each individual hospital or education provider. Therefore the researcher has looked at which NCNZ competencies could or should include the education that nurses need regarding IV therapy, venepuncture and cannulation and when it is needed. 
The competency and indicators from NZNC (2007) that could be related to IV and infusion therapy are as follows:

Competency 1.4 states that the Registered nurse promotes an environment that enables client safety, independence, quality of life, and health.

- Accesses, maintains and uses emergency equipment and supplies.

- Maintains infection control principles.

- Recognises and manages risks to provide care that best meets the needs and interests of clients and the public.

Competency 1.5 states that the Registered nurse should practice in a manner that the client determines as being culturally safe.

- Applies the principles of cultural safety in own nursing practice.

- Reflects on their own practice and values that impact on nursing care in relation to the client's age, ethnicity, culture, beliefs, gender, sexual orientation and/or disability.

- Avoids imposing prejudice on others and provides advocacy when prejudice is apparent.

Competency 2.8 states that the Registered nurse will reflect upon, and evaluate with peers and experienced nurses, the effectiveness of nursing care.

- Identifies their own level of competence and seeks assistance and knowledge as necessary.

- Accesses advice, assistance, debriefing and direction as necessary.

Competency 2.9 states that the Registered nurse shall maintain professional development.

- Contributes to the support, direction and teaching of colleagues to enhance professional development.

- Updates knowledge related to administration of interventions, treatments, medications and best practice guidelines within area of practice.

- Takes responsibility for one's own professional development and for sharing knowledge with others. 
Collaboration and participation with colleagues and members of the health care team to facilitate and coordinate care by the Registered nurse is stated in Competency 4.1

- Promotes a nursing perspective and contribution within the interprofessional activities of the health care team.

- Provides guidance and support to those entering as students, beginning practitioners and those who are transferring into a new clinical area.

- Collaborates with the client and other health team members to develop a plan of care.

- Maintains and documents information necessary for continuity of care and recovery.

\section{Implications of the literature review for this research}

As yet there are no national competencies for New Zealand's nurses in relation to intravenous therapy, venepuncture and cannulation. The international literature suggests that approaches to nurse preparation for intravenous therapy, venepuncture and cannulation vary. The literature explored, expressed that a degree of preparation is necessary, but failed to identify the value of one method of education and training over another. Very little of the literature presented was qualitative and descriptive in nature. In addition, no research has made causal links between the educational preparation of undergraduate and new graduate nurses or patient outcomes. The five major themes that emerged from the international literature were: extended or expanded roles, education, holistic care, competence and legal issues. There is a vast amount of literature available that relates to IV therapy, venepuncture and cannulation, but from the research reviewed at for this study, it can be seen that there is still a large gap in the knowledge base about IV therapy, venepuncture and cannulation education and associated timing in the available international literature. No one in New Zealand has conducted this specific research, therefore this study seeks to provide some much needed research around the question "should nurses in New Zealand be prepared (educated and trained) to administer intravenous therapy, undertake venepuncture and cannulation prior to or following registration?" 


\section{Chapter summary}

This chapter has outlined some of the literature available that has been written by a number of researchers, registered nurse clinicians and clinical educators internationally on the topic of IV therapy, venepuncture and cannulation. This has shown the focus on extending and expanding registered nurses practice, rather than development of the nursing profession prior to becoming registered. It has also identified the gap in literature that fuels the need for this study. This examination has helped to inform the study design chosen which will be discussed in the following chapter. 


\section{CHAPTER THREE}

\section{Research design and method}

The previous chapters have identified from the literature, what registered nurses and clinical educators' perceptions are, in relation to when the optimal timing would be for nurses to be educated in intravenous therapy, venepuncture and cannulation. In this chapter the researcher will outline the research study design and method. There will be discussion on the questionnaire tool that was used and the participants who completed the questionnaire. Additionally, the protection of human participants and ethical considerations are discussed. The chapter will conclude with a section on how the researcher intends to communicate the findings from the research.

\section{Aims of this research}

Using an exploratory descriptive design for the study, the aim of this research was to facilitate an understanding of clinical educators and registered nurse clinicians' perspectives about the optimal timing of education of undergraduate or new graduates in the role of intravenous therapy, venepuncture and cannulation. The question looked at in this study was: "Should nurses in New Zealand be prepared to administer intravenous therapy, undertake venepuncture and cannulation prior to or following registration?"

One of the fundamental goals for undertaking this research, was to be able to share the findings with the different schools of nursing and the District Health Boards, which may inform different possibilities in relation to planning education and training for their students or staff. 


\section{Research design}

To answer the research question, a non-experimental, cross-sectional, descriptive design was employed to gain an understanding from registered New Zealand nurses about their beliefs and understanding of when nurses or students in New Zealand should be prepared to administer intravenous therapy, undertake venepuncture and cannulation education and training. There has been minimal research done in New Zealand regarding IV therapy. The convenience sample of registered nurses' perceptions was evaluated through the use of a questionnaire, at a single point in time, thus yielding cross-sectional data (Burns and Grove, 1999; Greenfield, 1996; Nieswiadomy, 2008). The following sections explore these issues in greater depth.

\section{Research as exploratory description}

Data gathered from quantitative research designs focus on measuring quantity and the relationship between variables. Such research is considered suitable where there is pre-existing knowledge about a particular subject that allows the use of a standardised instrument such as the questionnaire to be used (Bowling, 2005). However, as there is not a great deal of pre-existing published research about this chosen topic, an exploratory descriptive method was used for this project. Cormack (2000) discusses that this type of method is appropriate for areas where there is little factual or theoretical knowledge. It allows the researcher to find out what is happening out there, and allows meanings to be associated with the discoveries. The researcher needs to have insight and intuition and needs to be flexible so that the study can be moved into new areas as their knowledge from the study increases. This type of study allows for a variety of data-collecting methods such as unstructured interviews and observation. The possibilities of unknown outcomes and other discoveries about the subject are greatly enhanced. The researcher has no control over the variables because of the exploratory nature of the study. This approach is also supported by nurse researchers such as Macnee (2004) and Polit and Hungler (1997). Nieswiadomy (2008) also supports the exploratory approach as the method to use when there is limited knowledge on a topic. 
Descriptive research using a quantitative methodology often refers to the gathering of information to describe populations (Brink and Wood, 1983). The data gathered can be used to describe, compare or explain attitudes and attributes of a population. Descriptive statistics allow a researcher to make statements about a population group or groups, though this does not allow the researcher to make inferences beyond the subject group (Hicks, 1996).

Schneider, Whitehead and Elliott (2007), from Australia and New Zealand, indicate that there is a need to promote research studies by nurses and midwives. They suggest that these can be undertaken by different clinical departments from different institutions and this will indicate common aspects of patient care in various clinical settings. Group research will develop valid tools to accurately measure clinical phenomena and nurses and midwives will gain increased methodological expertise due to the increasingly sophisticated computer technology becoming available. They continue to say that research helps to expand the body of scientific knowledge that provides the foundation of midwifery and nursing theory and evidence-based practice.

Schneider and colleagues (2007) explain that qualitative research is becoming increasingly popular for nursing and midwifery studies as it allows them to get an understanding of the individual's beliefs and how they relate to the care environment. The usefulness of this method is that through the enquiry of chosen participants, it raises the awareness of the need for change. Schmidt and Brown (2009) suggest that descriptive studies can offer advantages over other methods, in that they allow flexibility in methods for data collection, which can often lead to rapid data collection and cost savings for the researcher.

In describing the method of how the researcher carried out the study, it is important that enough information is given to the reader, to ensure that any other researcher could replicate the study. It might mean that the replication of the study is not feasible if the study only chooses one specific event (Polgar and Thomas, 2008). The researcher has in this study chosen more than one specific area, which will allow for future replication. 
During the course of doing their research, the researcher examined some previous studies that had used an exploratory descriptive method. The researcher also investigated prior research studies that had been done through the university where she was undertaking her study. There were no studies matching the research that she was undertaking, but the researcher found a few studies that had used exploratory descriptive methods such as Skally (2007) and Turner (2007). Reading through these research documents proved to be really valuable to the researcher, as there were not many published research books that discussed combining exploratory and descriptive methods, which was to be expected. Some of the theses used qualitative descriptive design, but they were also useful in helping the researcher to find other references. The researcher was able to use these to advance her understanding of the methodological approach.

A number of nurses within New Zealand have used an exploratory descriptive approach for their research studies and it has proved successful in describing clinical topics about which little is known. There have been a range of topics explored, from studies about elderly rest home residents, looking at dignity in the work lives of nurses through to exploration of nurse educator roles and preceptorship.

Skally (2007) undertook a research project on the preparation of New Zealand nurse educators teaching in clinically focused postgraduate programmes. Her study was carried out to inform the New Zealand nursing profession on the preparedness of its educators teaching clinical nursing postgraduate programmes. Skally specifically addressed the issue of whether new nurse educators entering into teaching are prepared and supported in their roles as postgraduate teachers. The results of this research reveal a culture where nurse educator preparation lacks uniformity and consistency. Individually, New Zealand nurse educators were found to be highly clinically prepared for their positions and motivated and enthusiastic about their roles, but $40 \%$ of respondents did not hold any teaching qualification.

Turner's (2007) thesis was titled: Preceptorship in nursing: preceptors' and preceptees' experiences of working in partnership. It looked at preceptorship in nursing and how there is considerable emphasis placed on health care organisations to support newly appointed graduate nurses. The primary focus of his exploratory 
descriptive qualitative study, explored the perspectives of preceptors and preceptees. They had worked in partnership and discussed how they established and sustained their respective roles. He interviewed three sets of registered nurses who had recently completed a preceptorship experience and the end result after a thematic analysis of his descriptive data, revealed four main themes which were: 1) The preceptorship relationship grows out of respect for each other and develops as a result of honest and open communication. 2) Preceptees who have an initial positive experience into their new work area settle quickly and efficiently into their new role. 3) Preceptees appreciate preceptors who are welcoming, supportive and willing to undertake the role, while preceptors are happy to undertake the role if the graduate displays an interest in learning and are willing to be guided. 4) The preceptee learns what it means to be a registered nurse in the particular working context, while the preceptor learns how to support learning processes and evidence-based practices. Turner was able to conclude that further exploration and investigation of those themes and of the relationships that evolve during preceptorship partnerships is needed and in so doing, organisations can prepare both the preceptor and preceptee as they begin to undertake their role to ensure future partnerships will be successful.

Having consulted some examples of exploratory descriptive studies as indicated above, has confirmed the researcher's belief that this method is appropriate in New Zealand context when exploring nursing and education issues. The researcher will now discuss the theoretical approach used in further detail.

\section{Theoretical approach}

The framework chosen to inform this research was Benner's (2001) novice to expert framework, which was originally written in 1984. Benner (2001) developed a nursing framework, based on work by Dreyfus and Dreyfus (1980). The Dreyfus Model of Skill Acquisition claims that when individuals acquire a skill through external instruction, they normally pass through five stages.

Patricia Benner's (2001) work “Novice to Expert: Excellence and Power in Clinical Nursing Practice" has been instrumental in defining and highlighting clinical growth 
in nursing. Benner's articulation of the different stages of clinical development in nursing practice has assisted many preceptors and seasoned nurses in setting realistic expectations for new graduate nurses. The exemplars in her work are inspiring and motivating.

Benner (1994) explains how all nurses grow in practice through the following levels:

- Novice,

- advanced beginner,

- competent,

- proficient,

- expert.

Benner discusses the Dreyfus model. Which is based on situational, experience based premises, which distinguishes between levels achieved through theory and principles learned in the classroom and the context dependent skills which are only acquired in real situations. She then developed a model that could be used to develop nursing students and all nurses in intravenous and infusion therapy. Benner explains how practices grow through experiential learning and eventually students are able to transmit that learning into practical settings. This framework represents the different stages of the professional nurses' development throughout their careers (Benner, 1994). In the course of this study, from the replies from respondents, it has emerged that there are a number of nurses who believe that undergraduate nurses need to complete their education with a good educational baseline in basic intravenous therapy, which the researcher believes would put them at the competent level.

Undergraduate nurses should be developed in all aspects of nursing care. It is the clinical placements during the degree programme that will determine the learning experiences they will encounter and which will assist in the development of their ability to apply theory to practice. That will allow them to become knowledgeable and skilled professional nurses. The learning opportunities they might encounter, and might enhance their practice cannot be predetermined. Such opportunities will influence the levels of competency they might reach. The question however is: when should they stop improving their skills and knowledge base and who determines that? As nurse educators, we are constantly encouraging reflective 
practice by the undergraduate students. If we teach the basics, they will be able to reflect on each situation and decide if they want to advance. The researcher is convinced that there will be some students that emerge at the end of their education and training and be able to claim that they are at least an advanced beginner or maybe even competent in venepuncture and cannulation within the policies of the local DHB.

Using information found in Benner (1994) and Collins et al. (2006), the researcher compiled Table 1 to explain how Benner's model can be used to explain the levels of competency related to cannulation and venepuncture.

Table 1: Benner's (1994) Levels related to infusion therapy

\begin{tabular}{|c|c|c|}
\hline Level & Description of Benner's (1994) levels & $\begin{array}{l}\text { Related to IV, venepuncture } \\
\text { and cannulation }\end{array}$ \\
\hline Novice & $\begin{array}{l}\text { - No experience of situations in } \\
\text { which they are expected to } \\
\text { perform. } \\
\text { - Features of task world recognised, } \\
\text { but no situational experience. } \\
\text { - Rule governed behaviour. }\end{array}$ & $\begin{array}{l}\text { - Need education in } \\
\text { relation to skills and } \\
\text { procedures } \\
\text { - Have understanding } \\
\text { of IV therapy, but } \\
\text { never participated. }\end{array}$ \\
\hline $\begin{array}{l}\text { Advanced } \\
\text { beginner }\end{array}$ & $\begin{array}{l}\text { Can demonstrate marginally } \\
\text { acceptable performance. } \\
\text { - Cope with real situations }\end{array}$ & $\begin{array}{l}\text { Beginning to } \\
\text { perform } \\
\text { venepuncture and } \\
\text { cannulation } \\
\text { - Caring for patients } \\
\text { with IV therapy } \\
\end{array}$ \\
\hline Competent & $\begin{array}{l}\text { - Sees actions in terms of plans of } \\
\text { which he/she is aware. } \\
\text { - Lacks speed and flexibility of } \\
\text { proficient nurse. } \\
\text { - Has ability to master and cope } \\
\text { with clinical skills needed. }\end{array}$ & $\begin{array}{l}\text { - Understands basic } \\
\text { skills and } \\
\text { techniques and able } \\
\text { to carry them out } \\
\text { unsupervised. } \\
\text { - } \quad \text { Still building up } \\
\text { speed }\end{array}$ \\
\hline Proficient & $\begin{array}{l}\text { - Uses perception. } \\
\text { - Understand situation and perceive } \\
\text { meaning in terms of long term } \\
\text { goals. }\end{array}$ & $\begin{array}{l}\text { - Able to interpret } \\
\text { best plan for patient } \\
\text { and discuss with } \\
\text { Drs. }\end{array}$ \\
\hline Expert & $\begin{array}{l}\text { Has enormous background of } \\
\text { experience. } \\
\text { - Intuitively grasps each situation } \\
\text { - Performance becomes fluid and } \\
\text { flexible }\end{array}$ & $\begin{array}{l}\text { Very able in } \\
\text { carrying out all } \\
\text { aspects of IV } \\
\text { therapy, } \\
\text { venepuncture and } \\
\text { cannulation. }\end{array}$ \\
\hline
\end{tabular}


The researcher will now briefly indicate each of Benner's (1994) levels of practice. It will then be shown how the researcher has used Benner's (1994) stages and how they could be applied to the education of undergraduate or registered nurses in relation to their abilities with IV therapy, venepuncture and cannulation. Adaptations of how it could fit in with IV therapy, venepuncture and cannulation, have been thought through, after reading the responses from questionnaires received for this study and also from articles read for this study.

Benner's (1994) novice level shows that these nurses have no experience of the situations in which they are expected to perform. For them to be admitted to this level, they need to be taught about the features in order for them to be able to recognise what is being undertaken, without actually participating in the procedure. They are also taught rules to guide their actions. In relation to IV therapy, venepuncture and cannulation at a novice level, nurses need to be able to demonstrate knowledge and understanding of the following:

- Professional and legal issues.

- Normal and abnormal anatomy of arm, veins, arteries and nerves.

- Rationale for infection control.

- Selection of equipment, patient preparation.

- Causes and preventions of complications in relation to IV therapy, venepuncture and cannulation.

- Safe and effective use of equipment on a simulation arm.

Benner's (1994) advanced beginner level states that the nurse can demonstrate marginally acceptable performance. These nurses have coped with enough real situations, in order to be able to either note themselves or have it pointed out to them that there are recurring aspects. In relation to IV therapy, venepuncture and cannulation, these advanced beginners are:

- Beginning to perform venepuncture and cannulation under supervision.

- Caring for patients with IV therapy.

- Able to offer appropriate rationale for all actions. 
The third stage that Benner (1994) discusses is the competent stage. This occurs when the nurse sees their actions in terms of long term plans of which he/she is aware. This nurse still lacks the speed and flexibility of the proficient nurse level, however they do have the ability to master and cope with clinical skills needed. They are able to apply knowledge and understanding of professional and legal issues. In relation to IV therapy, venepuncture and cannulation at this level, the nurse is:

- Able to apply knowledge and understanding of significance of abnormal venous anatomy in relation to site selection.

- Able to apply knowledge and understanding of infection control precautions prior to, during and after.

- Able to select appropriate equipment in different situations.

- Able to appropriately prepare patient psychologically and physically with consideration of the family/carer.

- Able to recognise causes and preventions of complications in relation to IV therapy, venepuncture and cannulation. Seeks assistance or advice when appropriate.

- Able to apply knowledge to procedures under supervision.

- Able to take appropriate care of blood samples and seek assistance or advice when appropriate.

Benner's (1994) proficient stage states that perception is the 'key' word and the nurse perceives the situation as a whole and not in terms of the aspects. The nurse fully understands the situation and perceives the meaning in terms of long term goals. In relation to IV therapy, venepuncture and cannulation at this level, the nurse is able to interpret the best plan for the patient and discuss outcomes with Doctors.

Benner's final level is that of expert. This nurse has an enormous background of experience. This nurse intuitively grasps each situation and their performance becomes fluid and flexible. In relation to IV therapy, venepuncture and cannulation at this level, the expert nurse would:

- Perform an adequate number of procedures in order to maintain skills.

- Constantly evaluate technique, recognise difficulties, causes and future preventative measures. 
- Be able to teach, support and supervise others as a role model in all circumstances related to IV therapy, venepuncture and cannulation.

Having discussed the possibilities of using Benner's levels and how they could be applied to education of IV therapy, venepuncture and cannulation, the following section begins by describing the studies method and leads to the development of the questionnaire.

\section{Choosing the questionnaire approach}

The chosen approach to gain data for this study was a questionnaire. This was chosen because the researcher believed as an educator that participants might feel constrained by time if the researcher were to try and do a telephone or a face-to-face interview. Nurses are often heard to complain about how busy their lives are and for this reason, the researcher decided that sending out an emailed questionnaire would allow the participants to complete the questions in their own time. The researcher also believed that it would give her a larger group of participants from a wider area across New Zealand. In addition, more people are using email for communication and the researcher believed that although not a very scientific reason, it would be interesting to see what the response rate would be like using this method instead of postal questionnaires. Achieving large numbers in response rates to postal questionnaires is often difficult (Babbie, 2007; Barribal, Christian, While and Bergen, 1996; de Vaus, 2002; Parahoo, 2006).

One of the additional advantages that the researcher found by distributing the questionnaires by email was that there was no cost towards travel, for either the researcher or the participants and this allowed a larger group to be targeted for the questionnaire. A further advantage was that conducting an email questionnaire was that it did not involve costs of toll or cell phone calls. 


\section{Questionnaire tool}

When the decision was made to undertake this research, the researcher attempted to find any previous questionnaire tools that might have been used. As has already been discussed, due to the lack of previous studies both nationally and internationally, the researcher had to try and develop a tool that would answer questions that they were interested in. If the researcher had been able to find any previous international studies, it would have been interesting to be able to compare the study findings. An internet search was done using the terms (infusion therapy) AND (venepuncture) AND (cannulation) AND (education) AND (questionnaire OR survey OR tool). None of these combinations highlighted any previous studies. The literature review was completed subsequent to a search of electronic databases (see Chapter 2).

The final questionnaire tool (Appendix 1) was developed, after discussion with the seven pilot participants, who were other academic educators and clinical practitioners who had an interest in intravenous therapy. The questionnaire was designed around issues that related to clinical practice. The researcher also included questions drawing on their own personal clinical expertise relating to the education of nurses in regard to the topic of intravenous therapy, venepuncture and cannulation. The proposed questionnaire was subsequently revised by independent academics and that input was also included in the questionnaire.

A group of seven academic lecturers at the researcher's place of employment were asked to participate in a trial of the questionnaire. The participant letter and the questionnaire were emailed to them by the researcher in exactly the same form that was to be sent out for the study. These participants were asked to complete the questionnaire as soon as possible to enable the researcher to make any required changes. It was important to ensure that the questionnaire was easy to read and would not take a long time for them to fill out. Some of the pilot study participants discussed previous occasions that they had to fill in questionnaires that were so complicated that they had decided against participating. All of the pilot participants stated that it took them less than fifteen minutes to complete the questionnaire. The responses from these pilot study participants are not included in the results chapter, 
as they did not complete the final questionnaire, because it was altered post trial. The pilot study participants tested the proposed final questionnaire tool to measure perceived ease of use and user acceptance of the tool.

Bowling (2002) emphasized that it was important to group similar questions together to make it less complicated for respondents. Burns and Grove (1999) state that if questionnaires are too long, then respondents fail to mark all of the questions which can threaten the validity of the tool. The finalised questionnaire was also approved as part of the ethics application. The layout of the questionnaire tool (Appendix 1) will now be discussed.

\section{The questionnaire tool}

The first section of the questionnaire aimed to gain background information regarding what position the respondent held at their place of employment and also where their place of employment was. It was anticipated that comparable opinions about the topic being researched may emerge.

The questionnaire tool had twelve closed questions, which required participants to choose whether they agreed or disagreed with the statements. Closed questions have predetermined answers selected by the researcher (Polgar and Thomas, 2008). The benefit of closed questions is that they take less time to collect and analyse, but the unfortunate aspect is that they allow for less depth for answers, which might frustrate respondents (Polgar and Thomas, 2008). The questionnaire used a five-point Likert scale for evaluation. Likert scale response formats to closed questions can measure the opinion or attitude of a respondent (Burns and Grove, 1999). The questionnaire also included a grid that asked the participants to rank when they believed the education or training should, or could, take place. Following this, there were two open questions relating to that ranking. Parahoo (2006) suggests that open ended questions are useful when researchers are looking for answers and they want to obtain respondent's views. However; there is always the possibility that respondents do not interpret the question differently to what the researcher intended. 
Finally, all participants had the opportunity to describe their views on the possibilities of inclusion of IV therapy, venepuncture and or cannulation skills into core training, which is important in emphasising their individual meaning and understanding of the research topic (Bell, 1993). The questionnaire data was analysed for choice and frequency of responses to closed questions. Participants were able to share their own professional experiences and could focus on their understanding of the topic.

The participants were offered the opportunity of receiving a brief report once the study has been completed. It is envisaged that a report would also be sent to the schools of nursing and all the DHBs in New Zealand.

\section{Ethical considerations}

Prior to collection of any data, ethics approval was sought and approved via Victoria University of Wellington (see Appendix 2).

A letter of explanation (see Appendix 3) was provided for all participants that explained their rights to remain anonymous and gave assurance of confidentiality. Completion and return of the questionnaire implied consent.

Questionnaires were collated by an independent person who signed a "non disclosure of information" agreement (see Appendix 4). All the electronic data had all identifiable email addresses removed prior to being forwarded to the researcher. This information was kept in a data password access file held by the researcher until the thesis was completed. All printed information is being contained securely in a locked file. All the data will be destroyed by shredding after two years (August 2011) in accordance with the conditions of ethical approval. Access to the data was only available to the primary researcher, the supervisor and the collator of the questionnaires. During the course of the research, the researcher made all possible attempts to safeguard organizational and individual's rights. Throughout the 
research, privacy and confidentiality were addressed and individual's identities were protected. The researcher is aware that due to the size of the New Zealand nursing community, that some fellow colleagues may identify different individuals or institutions that have participated in the research. To overcome this, the researcher used codes for the respondents and has not named any tertiary education providers or hospitals in the research document. All personal communication will be shown in bold italics to identify other people's thoughts about the subject to distinguish them from the researcher's own writing.

\section{Research procedure and participants}

The decision was made that the study should include all the Schools of Nursing and all the DHBs in New Zealand. To only send questionnaires to either of these groups, would give a bias of results and also the study might not be a suitable size. All Directors of Nursing (DoN) at the DHBs (21) and all the Heads of Nursing Schools (HoS) (19) in New Zealand were approached by email. It was requested that they pass on a letter of explanation and the questionnaire to prospective study participants. It was intended that they would choose senior registered nurses with an interest in intravenous therapy or someone that was working in this area as an educator. The time limit set for the distribution and return of the questionnaires was a four week timeframe in the early part of 2009.

A convenience sample was acquired via a snowball approach (Schneider et al., 2007). This approach is described as useful when there is a lot of general interest in the chosen topic. In this case, some extra questionnaires were distributed and these people could then reply in the same manner as all other participants, so that the researcher could not identify them. When individuals meet the criteria for a study and network with colleagues who also meet the criteria, they sometimes invite these people to also participate in the study. This is known as snowball sampling which is a form of convenience sampling 
A description of the participants is provided in the results section. Twenty were returned from DHBs and 11 from Schools of Nursing and five who indicated that they were from 'other areas'. There is further discussion about the research findings in Chapter Four.

The letters explaining the purpose of the research and the questionnaires were emailed by the collator of the questionnaires to all the Directors of Nursing (DoN) (see Appendix 5) at the DHBs and all the Heads of School (HoS) (see Appendix 6) at the Schools of Nursing. They were asked to pass on a letter of explanation (Appendix 3) and the questionnaire (Appendix 1) to prospective study participants. The collator requested that the DoNs and HoSs inform her as to how many staff they distribute questionnaires to, for statistical purposes. She kept a spreadsheet of how many questionnaires were distributed and how many replies were received.

Two weeks after the initial email was sent out, a follow up email was sent by the collator about the questionnaire, to the people who had not responded. The cut off date for replies was one month after the original request was emailed. The majority of the replies were returned by email to the collator. Some people asked the collator to post out a copy of the questionnaire as they could not access it on their computers as they did not have the same software that the researcher had used. These were returned by mail to the collator. Once the collator removed any identification, for example, email addresses from the returned questionnaires, then the information was passed on to the researcher to analyse and interpret the data.

The collator chosen for this study had previously assisted other researchers. It was anticipated that she would have a reasonable understanding of what would be required to assist with the research. A meeting was held with the collator to discuss what the researcher needed reasonably early in the process of the research study. It was seen that the collator's role would be to despatch and retrieve questionnaires and replies and ensure that the replies would remain anonymous to the researcher. There will be some comments made in Chapter 5 about the outcome of this decision. Discussion will now continue about how the data was collected, collated and analysed. 


\section{Sample size}

Steinberg (2004) indicated that thirty cases should be the minimum when undertaking descriptive research, which was the goal set for this study. Thirty six replies were returned for this study. This study is an exploratory descriptive study and it also includes both quantitative and qualitative aspects. Kumar, (2005) and Parahoo, (2006) both suggest that quantitative studies are usually smaller than quantitative studies. Nieswiadomy (2008) discusses that exploratory, descriptive studies allow a flexible approach to be taken when there is little previously written on the chosen topic of research; however, they do not suggest whether the research should be undertaken on a large or small scale. It was expected that the minimum number of people asked to complete a questionnaire would be forty, as this is the combined number of DHBs and Nursing Schools.

\section{Data analysis}

As the collator received each questionnaire, she cut and pasted all the replies into a new word document. Each of the respondents was allocated a code depending on what they identified their role being and then they were allocated a number depending on the order in which their replies were received. If they were involved as an IV educator, they were coded as 'I'. Educators were allocated 'E'. Lecturers were allocated an ' $L$ '. Directors of nursing were allocated a ' $D$ '. People who identified as other were allocated ' $\mathrm{O}$ '. This code was applied to all comments that they had made. This approach to handling data collation is discussed by (Bowling, 2005; Burns and Grove, 1999; de Vaus, 2002; Walliman, 2001). 
The collator ensured that before she forwarded any replies to the researcher, that she had removed all identifying email addresses and names. Once all the identifiers were removed, the collator emailed a copy of the word document with all the comments from the respondents for the researcher to be able to 'cut and paste' comments and use them as required for analysis. It was also important that when the researcher received the MS Word documents from the collator, that they double checked that the code and numbers the collator had allocated responded to the actual role of the respondent. This ensured that there were no mistakes made with response rate figures when inserting them into the graphs. No computer programme was utilised to analyse the responses. As there was not a suitable programme, this meant that the number of responses for each question was manually added into an Ms Excel sheet and the graph then made using the Ms Excel graph tool. These graphs were developed from the responses to the questions which utilised a Likert scale response. The interesting point to note was that most of the comments came from people in IV, educator and lecturer roles.

Simple descriptive statistics were employed to analyse quantitative responses from the questionnaire.

\section{Discovering themes}

The collator printed off a copy of each of the returned questionnaires. The researcher was able to 'colour code' the replies to question five which resulted in theme identification. Roberts and Taylor (1999) discuss a thematic analysis of the transcriptions using what they refer to as 'colour coding'. Each returned questionnaire was analyzed, initially using different coloured marker pens and focusing on the project aims to guide the analysis. The researcher divided the themes, words, ideas and sections that appeared to be most commonly used, according to the project aims. Some of the themes had overlapping issues that are discussed under the most appropriate section. Once identified into a theme, the researcher placed all the same colour coded replies in separate folders. 
The researcher read over this information a number of times and began to make their interpretations of the data. It was important for the researcher to have breaks from the data in-between each reading and during this time 'reflecting' on what the respondents were saying or believed. The researcher had to try to keep their own thoughts and beliefs aside. This assisted the researcher to address the issue of bias within the project. Finally, the researcher merged similar ideas into main themes that were: extension and expansion of roles, timing of student education, undergraduate, newly registered nurses, doctor roles and legalities, competencies and accountability.

\section{Interpretation of data}

Polit and Beck (2004) discuss that results from a study need to be systematically interpreted before they can be communicated effectively. They describe interpretation as a process of making sense of results and examining their implications. Interpretation of the data took place after the researcher had read and reflected on the data obtained. Interpretation differs from that of data analysis and involves working with the data to construct knowledge (Polit, Beck and Hungler, 2001). In other words, the researcher describes what has occurred in their area of study and that it may focus on usefulness of the findings for clinical practice. There will be further discussion in Chapter Five with regard to implications for practice in New Zealand.

During interpretation of the data, the researcher looked for common responses from the survey respondents. This was to ensure that the choice of Benner's (1994) model was able to show how nurses are at different levels of infusion therapy throughout their careers as shown on pages $39-41$.

Throughout this period, the researcher drew on their experiences in nursing practice, nursing management and clinical education, as well as the literature review, programme documents from their own place of employment and also from one other hospital and questionnaire data, to draw conclusions and then to finally determine their findings. The researcher also had discussions with their supervisor and fellow 
nursing colleagues to validate data. The aims of the project were used to focus the research and to highlight the key themes that emerged from the data. The study focused on exploration and description, and emphasis was placed on the purpose and aims of the study.

\section{Rigour}

Reliability and validity are aspects of rigour that need to be applied in quantitative research (Stommel \& Wills, 2004). Reliability refers to the consistency of measurement for each question. Validity is established when the questions measure the attributes or characteristics intended (Stommel \& Wills, 2004). It is suggested by Kumar (2005) that each question should be able to be justified and they should meet

the objectives of the study. Therefore, the content validity was established by experts reviewing the potential tool and in the original pilot of the tool by getting a group of health professionals who were interested in venepuncture and cannulation to participate (Stommel \& Wills, 2004). Pallant (2007, p.7) defines validity of a study as "the degree to which it measures what it is supposed to measure". Different groups of experts were used to pilot the questionnaire and adjustments were made by also adding suggestions from independent academics.

Kumar (2005) suggests that if interview conditions are consistent, then reliability is ensured. This is not easy to monitor when questionnaires are distributed electronically, as the researcher has no control over when or where the questionnaires will be completed. Auditability, credibility and confirmability, must be demonstrated in order that it can be determined if a research project has addressed the issue of rigour (Roberts and Taylor, 1999). Interpretation of qualitative results was initially done by the researcher. Discussions were then held with the researcher's initial supervisor and 2 members of the pilot team. This was to ensure that the responses received from the study were seen to be representative of the actual beliefs of the majority of practicing Registered nurses. 
To create an audit trail, the researcher has outlined all the methods and processes followed throughout the project. The issue of credibility is addressed by the fact that this research project is a part of a formal qualification and therefore it has required supervision. The researcher's supervisor and also that of a 'second reader' have been used to critique their work. Robson (1997) suggests that "exposing one's analysis and conclusions to a colleague or other peer on a continuous basis can assist in the development of both the design and the analysis" (p. 404). Confirmability will be demonstrated by ensuring that auditability and credibility are demonstrated throughout the project. This has been achieved by describing the research process used and also in the documentation of the results (see Chapter Four).

\section{Chapter summary}

This chapter has discussed the research design, questionnaire tool, participant selection and the procedure that was used to gain the necessary information. Ethical issues that were relevant were identified and discussed. The use of an exploratory descriptive design is appropriate for this thesis. Pre-existing questionnaires have the advantage of saving time; however there were no pre-existing questionnaires. Rigour of the research was discussed. In addition the procedure for data collection, ethical issues, participant selection, and analysis were addressed. The following chapter will concentrate on the results that emerged from the perspectives of clinical educators and other registered nurse clinicians who completed the questionnaire. 


\section{CHAPTER FOUR}

\section{Results}

This chapter will present the results of the study. This has been an exploration of clinical educators and registered nurse clinicians' perspectives about the optimal timing of education of undergraduate or new graduates in the role of intravenous therapy, venepuncture and cannulation. Data is analysed using descriptive statistics to further understand the respondent's perspectives.

The results presented are to reflect the order of the questions that were in the questionnaire distributed to Schools of Nursing and DHBs. Results are presented in two sections and the first section describes the demographic information relating to the participants. The second section provides a description and analysis for each question from the questionnaire. Each graph or table is presented together on a separate page with the discussion, to make for easier reading. Qualitative data from the open-ended questions is reported by means of participant's comments and appears later in this chapter. 


\section{Sample description}

A total of 40 emails were distributed to DHBs, Schools of Nursing and other interested participants. In total there were 36 responses to the questionnaire over a period of four weeks. To identify any trends between the thoughts and work places of the participants, they were asked to indicate their work setting. Of the 36 respondents to the questionnaire, 55.5\% $(\mathrm{N}=20)$ indicated they were employed by a hospital (10 from a tertiary teaching hospital and 10 from a smaller regional hospital), 30.5\% ( $\mathrm{N}=11)$ indicated they were employed by Nursing Schools, 3\% $(\mathrm{N}=1)$ indicated they were employed in a non-governmental agency and $11 \%(\mathrm{~N}=4)$ who identified as being employed by some other means (see Graph 1). Not all respondents completed every question; therefore, sample sizes may vary for each question.

\section{Graph 1: Work Setting}

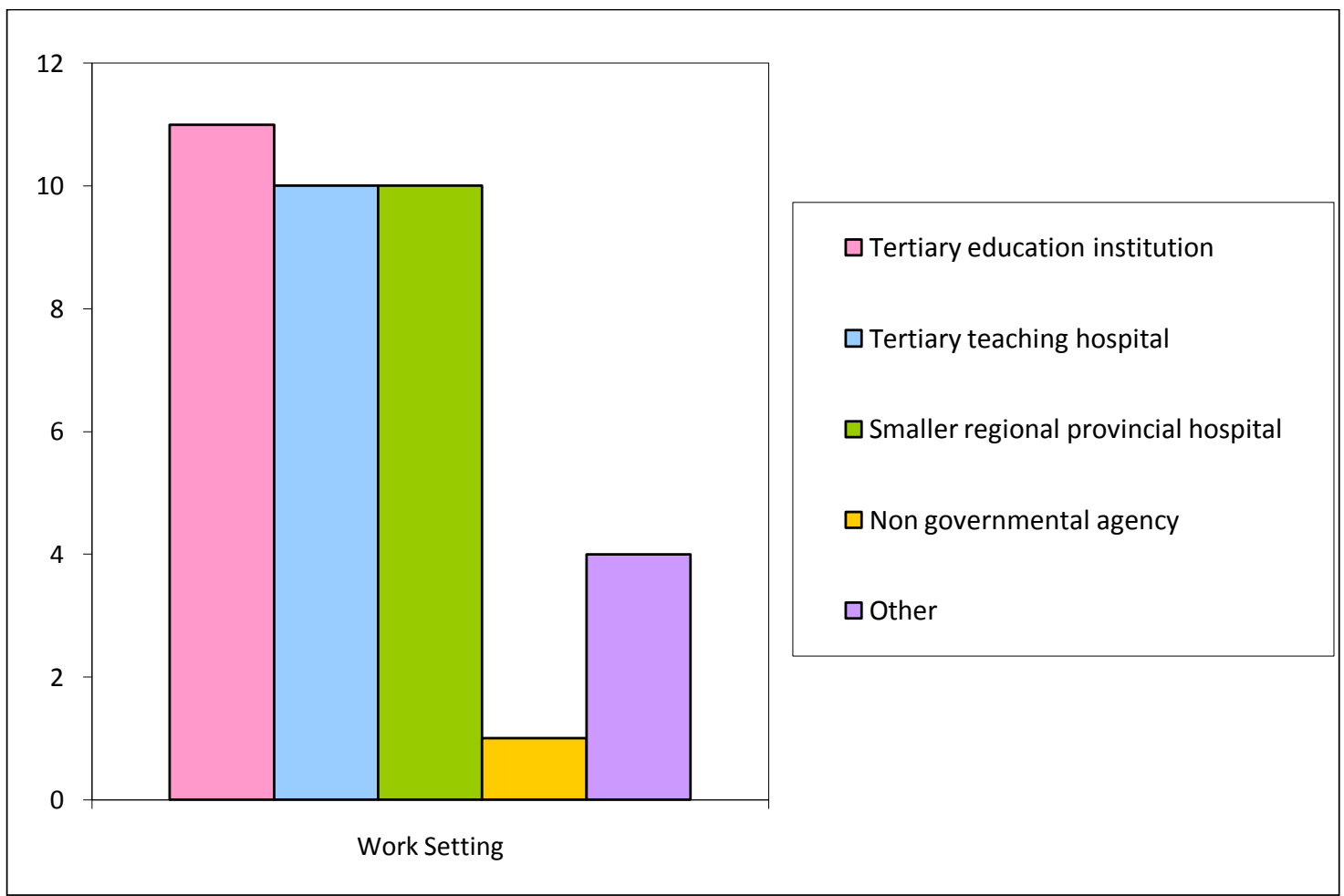




\section{Role of respondents}

The respondents were then asked to describe their role within their institution to give an indication of who was responding to the questionnaire. It was intended that there would be a cross section of clinicians and educators responding to the research request. It was also anticipated that trends might emerge depending on the areas that respondents worked in.

Responses to question one indicated that, within their place of employment, the majority of the respondents were in an education role of some description. There were $41.7 \%(\mathrm{~N}=15)$ of the IV nurse educators and clinical nurse educators who indicated they were from DHBs, and $30.5 \%(\mathrm{~N}=11)$ of the nurse educators indicated that they were from Schools of Nursing. Eighteen out of 20 of the positive comments about the need to advance undergraduate skills came from the IV nurse educators at DHBs and nurse educators at educational institutes. The roles of the respondents can be seen in Graph Two.

\section{Graph 2: Role of participants}

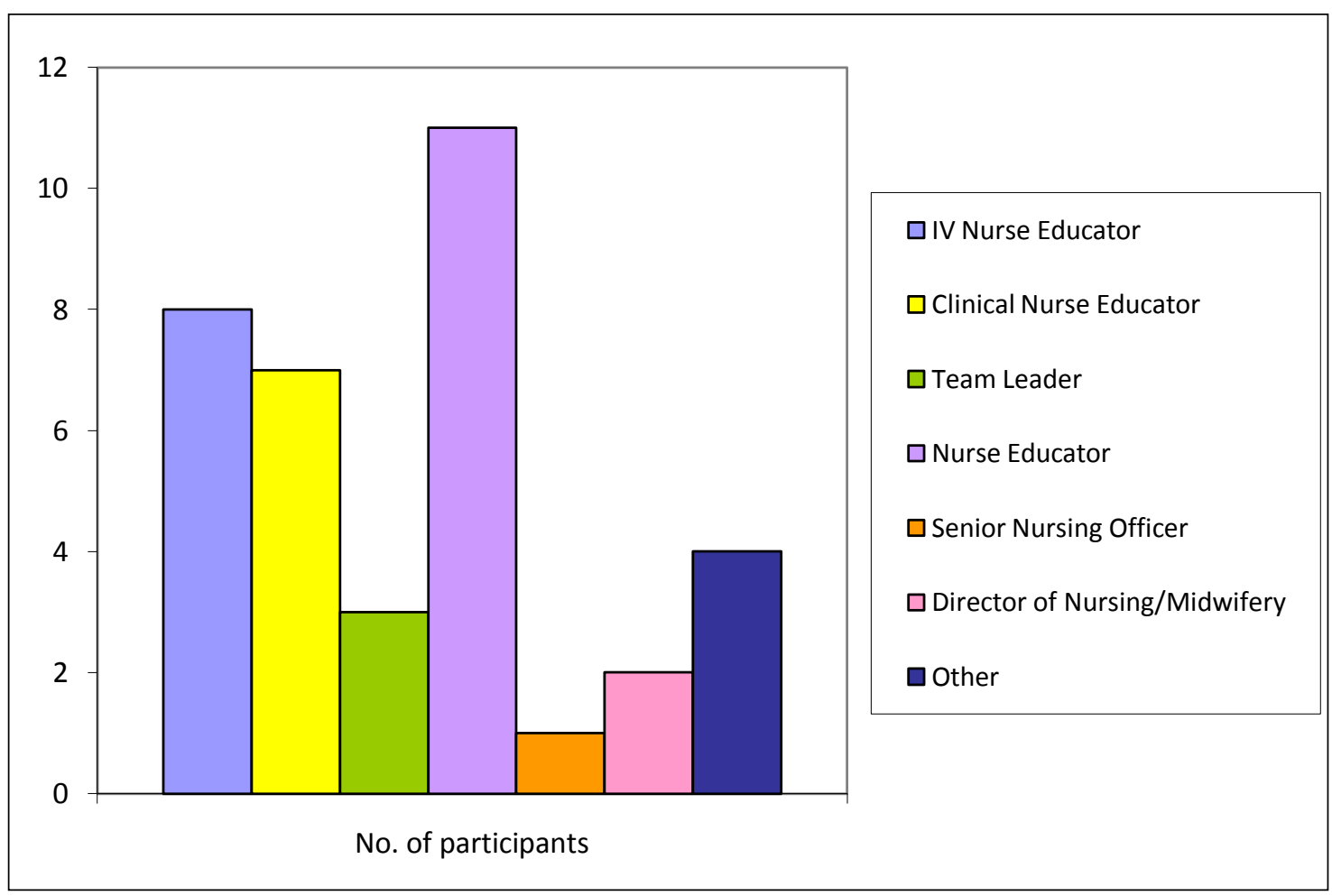


The next section of the questionnaire employed Likert scale questions to gauge responses. The responses ranged from one to five. With one indicating strongly agree, two indicating agree, three indicating disagree and four indicating strongly disagree. Five indicated the response that they were not sure. There were 12 questions in this section (see Appendix 1). Along with the total replies, Graphs 3 to 14 will present the percentage agreement and percentage disagreement for each question. In discussion of the results, responses of strongly agree or agree and strongly disagree or disagree will be grouped together to make it easier to read results. The results will be shown separately in the graphs.

Responses to see what was felt by respondents about whether undergraduate students should be taught basic intravenous therapy during their degree study is indicated in Graph two. One hundred per cent $(\mathrm{N}=36)$ supported education of intravenous therapy at undergraduate level. There were no respondents to this question who felt that intravenous therapy knowledge should not be delivered at undergraduate level.

Graph 3: Intravenous therapy during degree study

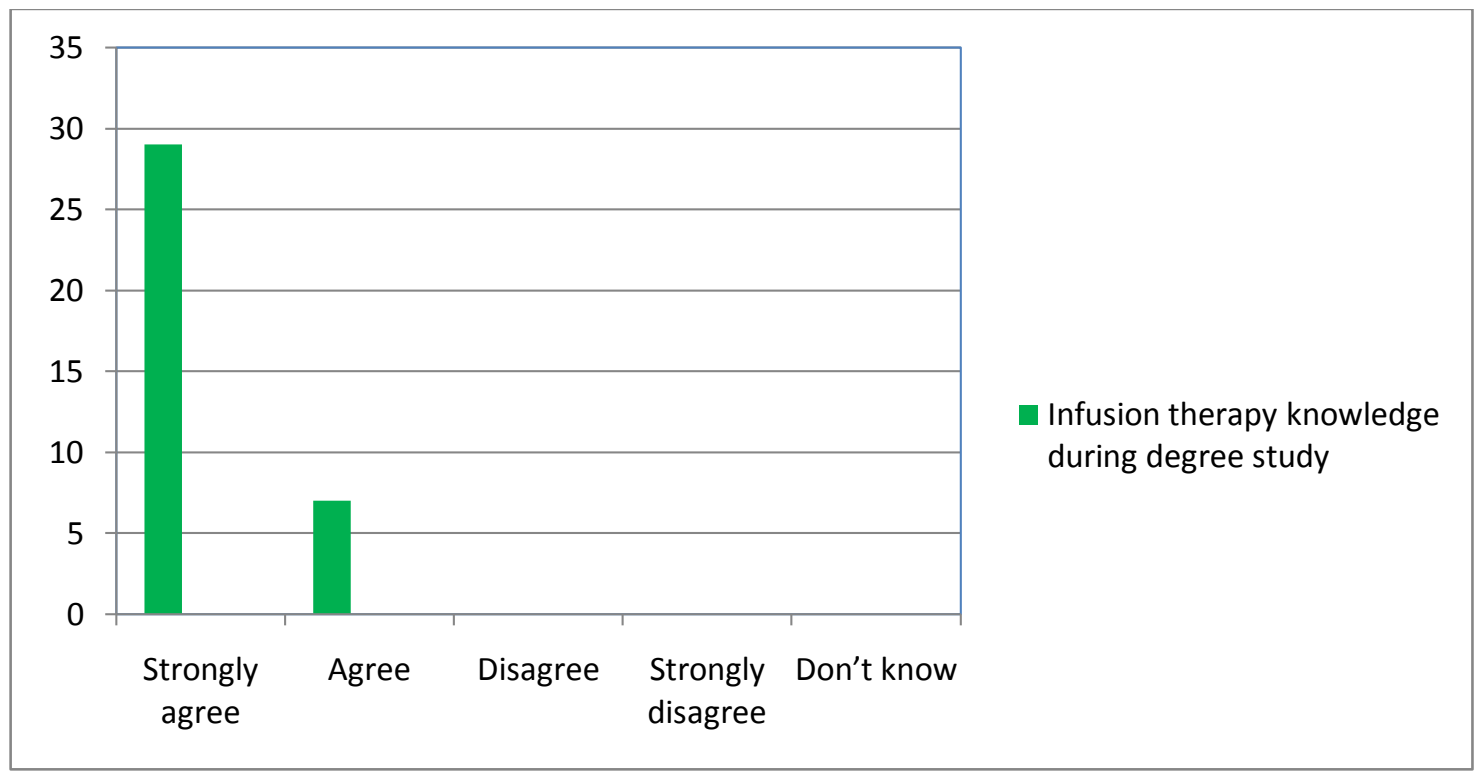


Of the 36 respondents that responded to the question asking if venepuncture should be part of the student education at undergraduate level, 50\% $(\mathrm{N}=18)$ agreed. These respondents were mainly educators (nine), lecturers (two), one DoN and three from other areas. There were $47.2 \%(\mathrm{~N}=17)$ who disagreed with this statement. There were $2.7 \%(\mathrm{~N}=1)$ who did not clarify their position. There was a $100 \%(\mathrm{~N}=36)$ response to this question. All these responses are illustrated in Graph Four.

Graph 4: Venepuncture during degree study

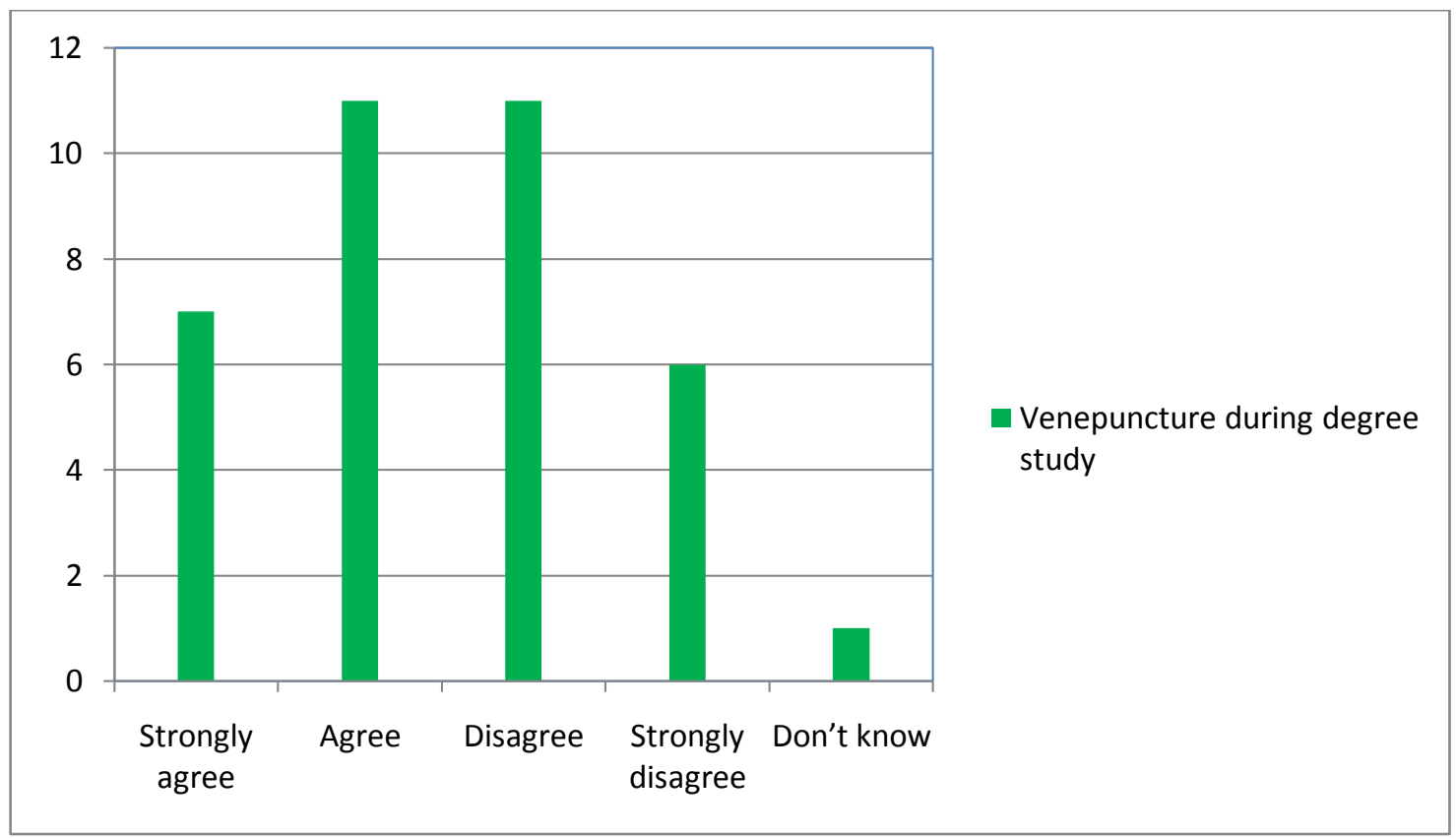


Respondent's views to the question about whether undergraduate students should be taught cannulation during their degree study provided the following results. Thirty six point one per cent $(\mathrm{N}=13)$ agreed with cannulation education taking place during undergraduate study. The statement is not supported as can be seen by the negative responses, which showed $55.5 \%(\mathrm{~N}=20)$ who disagreed. There were 5.6\% $(\mathrm{N}=2)$ respondents who did not show a strong preference for either choice. There were $2.7 \%(\mathrm{~N}=1)$ respondents that did not respond to this question. These results are depicted in Graph Five.

\section{Graph 5: Cannulation during degree study}

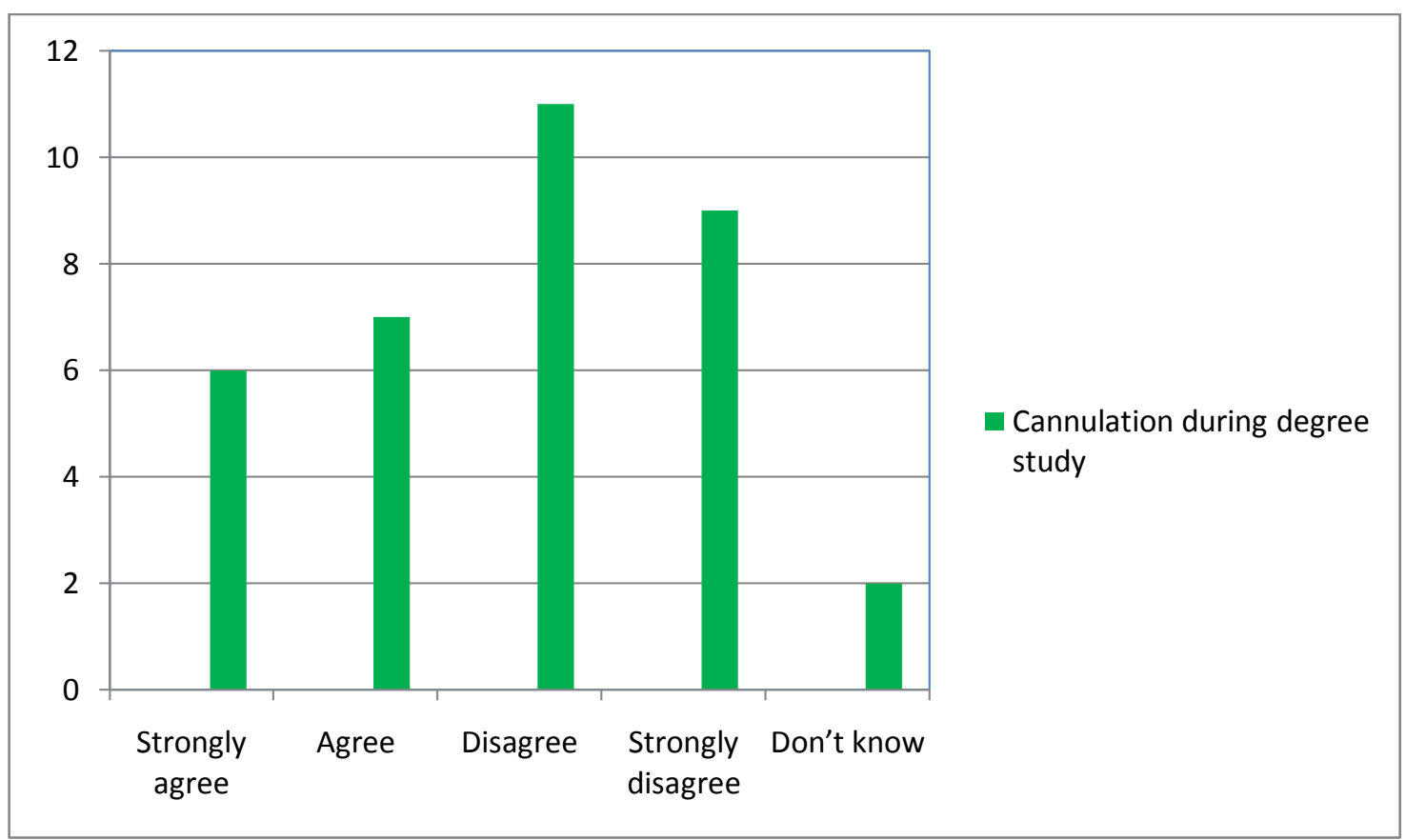


Following on from the undergraduate nursing questions, the newly graduated nurses were looked at to see whether the respondents felt that this group needed to gain confidence and competence in intravenous therapy during their new graduate year. These responses showed that, $86.1 \%(\mathrm{~N}=31)$ respondents agreed with this idea. There were $8.3 \%(\mathrm{~N}=3)$ that disagreed that new graduates would be gaining confidence and competence in intravenous therapy. There was a response rate of $5.6 \%(\mathrm{~N}=2)$ who stated that they did not know if the new graduate year would allow confidence and competence to grow (see Graph 6).

Graph 6: Gain confidence and competence IV therapy during new graduate year

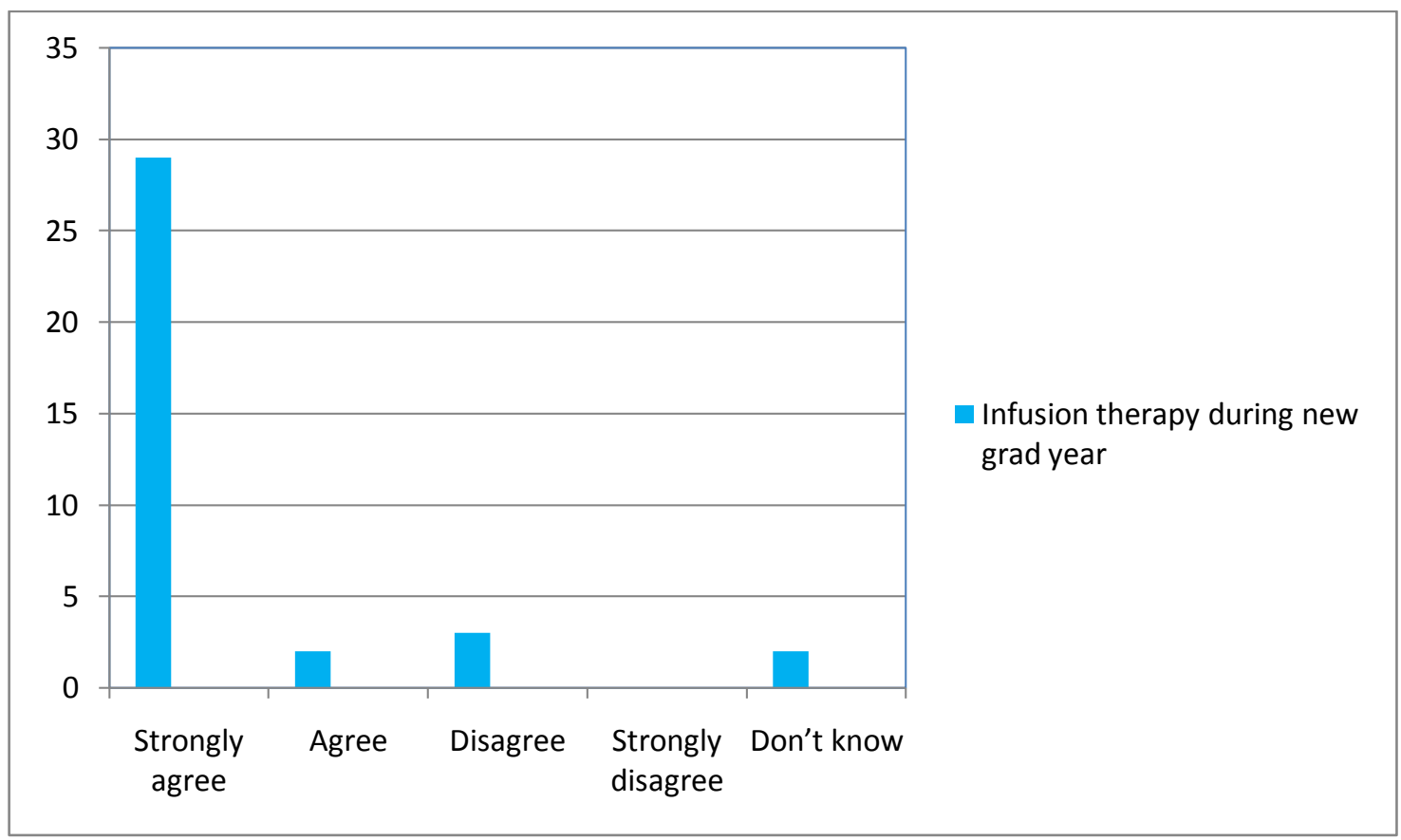


There were $61 \%(\mathrm{~N}=22)$ of respondents who agreed with the need for newly graduated nurses to gain confidence and competence in venepuncture. There were $30.5 \%(\mathrm{~N}=11)$ respondents who disagreed with this statement. There were $2.7 \%$ $(\mathrm{N}=1)$ who did not know if this education should take place at this time. There were $5.6 \%(\mathrm{~N}=2)$ of respondents who did not respond to this question. Responses as to whether or not newly graduated nurses need to gain confidence and competence in venepuncture during their new graduate year are highlighted in Graph 7.

Graph 7: Gain confidence and competence in venepuncture during new graduate year

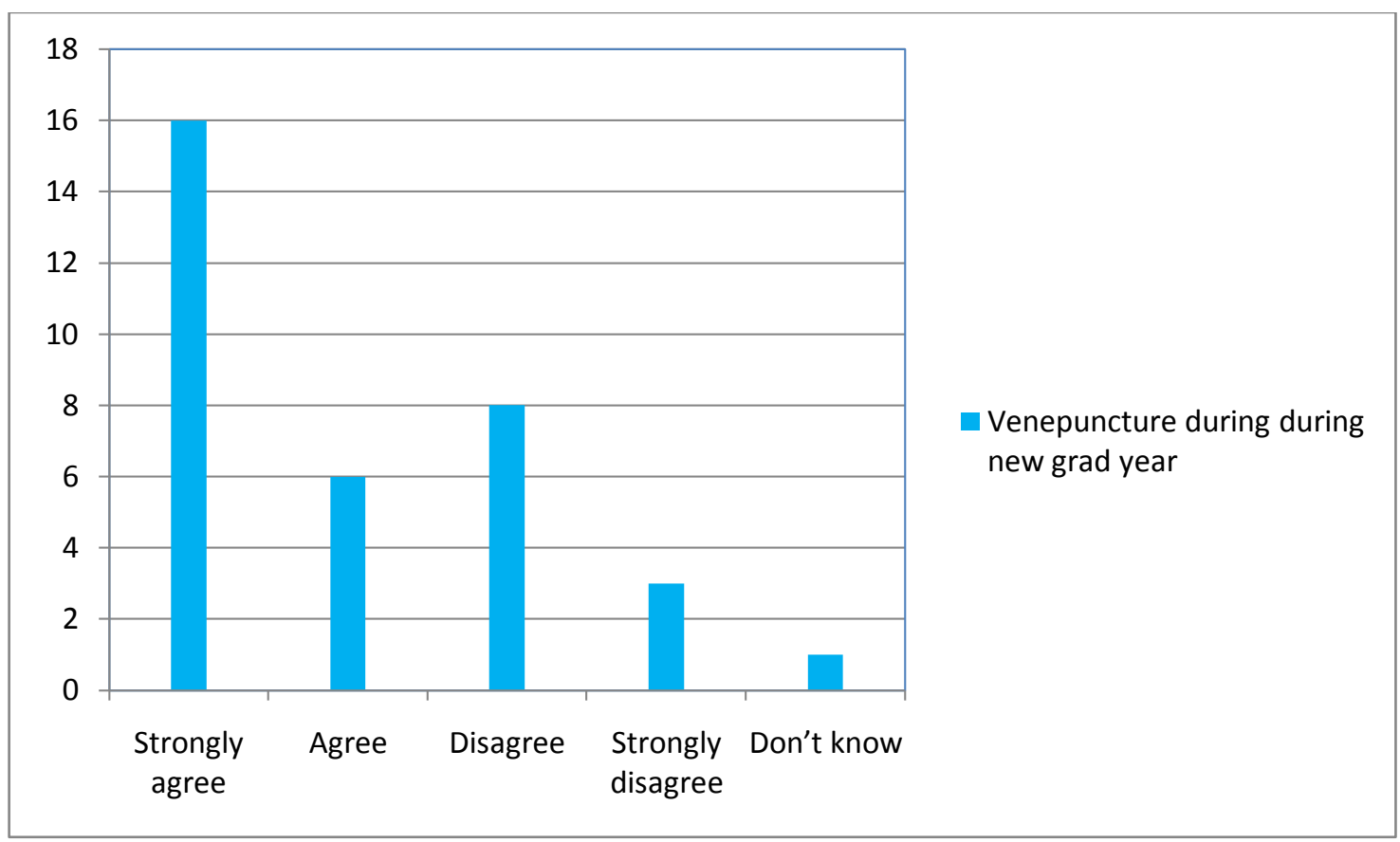


The final question relating to new graduate nurses asked the question of whether newly graduated nurses need to gain confidence and competence in cannulation during their new graduate year (see Graph 8$)$. There were $55.5 \%(\mathrm{~N}=20)$ respondents who agreed with this statement. There were $36 \%(\mathrm{~N}=13)$ respondents who disagreed with the statement. There were $2.8 \%(\mathrm{~N}=1)$ respondents who did not know and $5.6 \%$ $(\mathrm{N}=2)$ of respondents who did not respond to this question.

Graph 8: Gain confidence and competence in cannulation taught during new graduate year

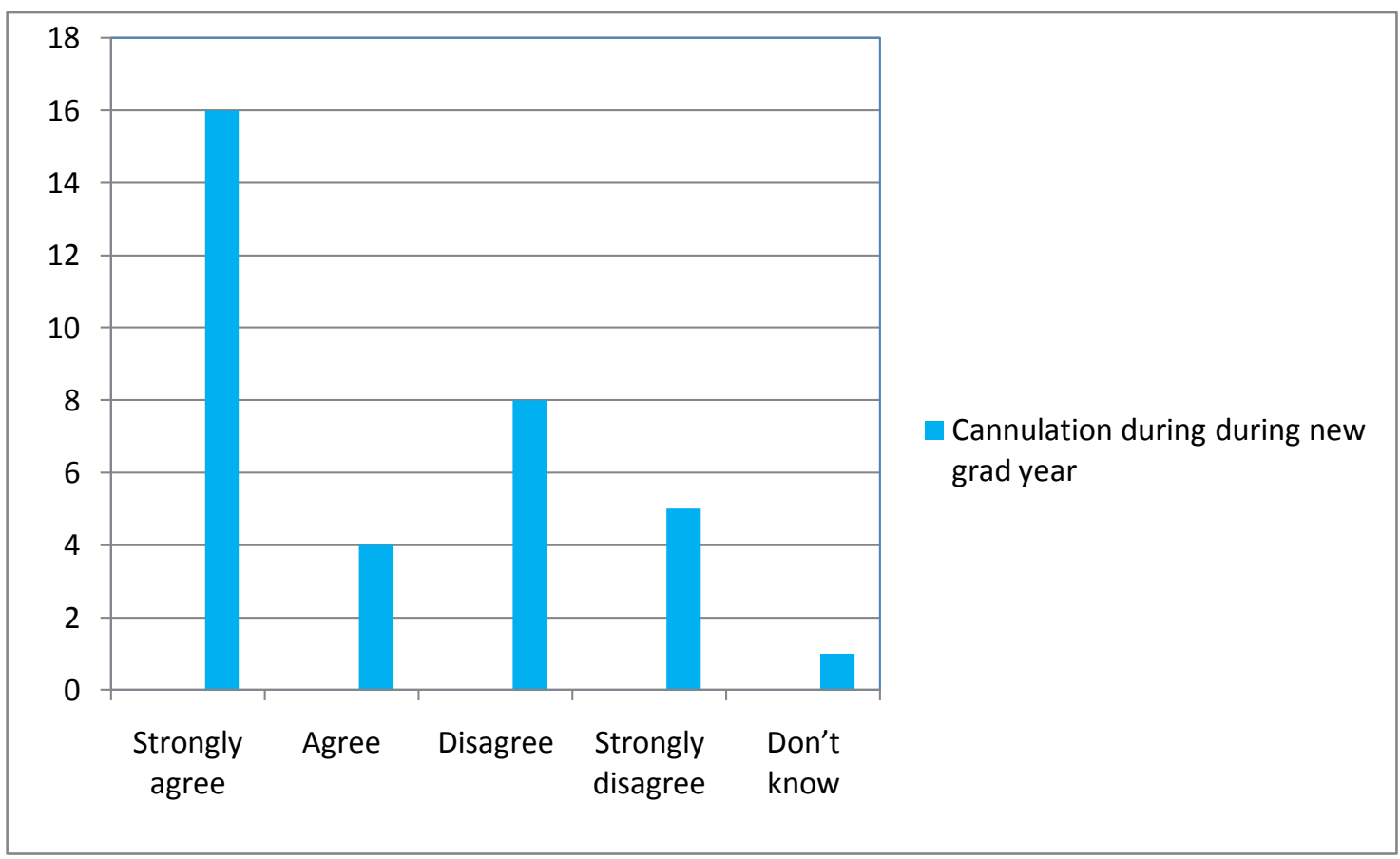


The next question on the survey asked if patient care is more holistic if the nurse can undertake venepuncture or cannulation without having to wait for another nurse or a doctor to perform the task (see Graph 9). The indication is that $77.7 \%(\mathrm{~N}=28)$ of respondents agreed that patient care would be more holistic if the nurse can personally undertake venepuncture or cannulation without having to wait for another nurse or a doctor to perform venepuncture or cannulation. There were $19.4 \%(\mathrm{~N}=7)$ respondents who disagreed with this statement. There were $2.8 \%(\mathrm{~N}=1)$ respondents who responded that they did not know.

\section{Graph 9: Patient care is more holistic}

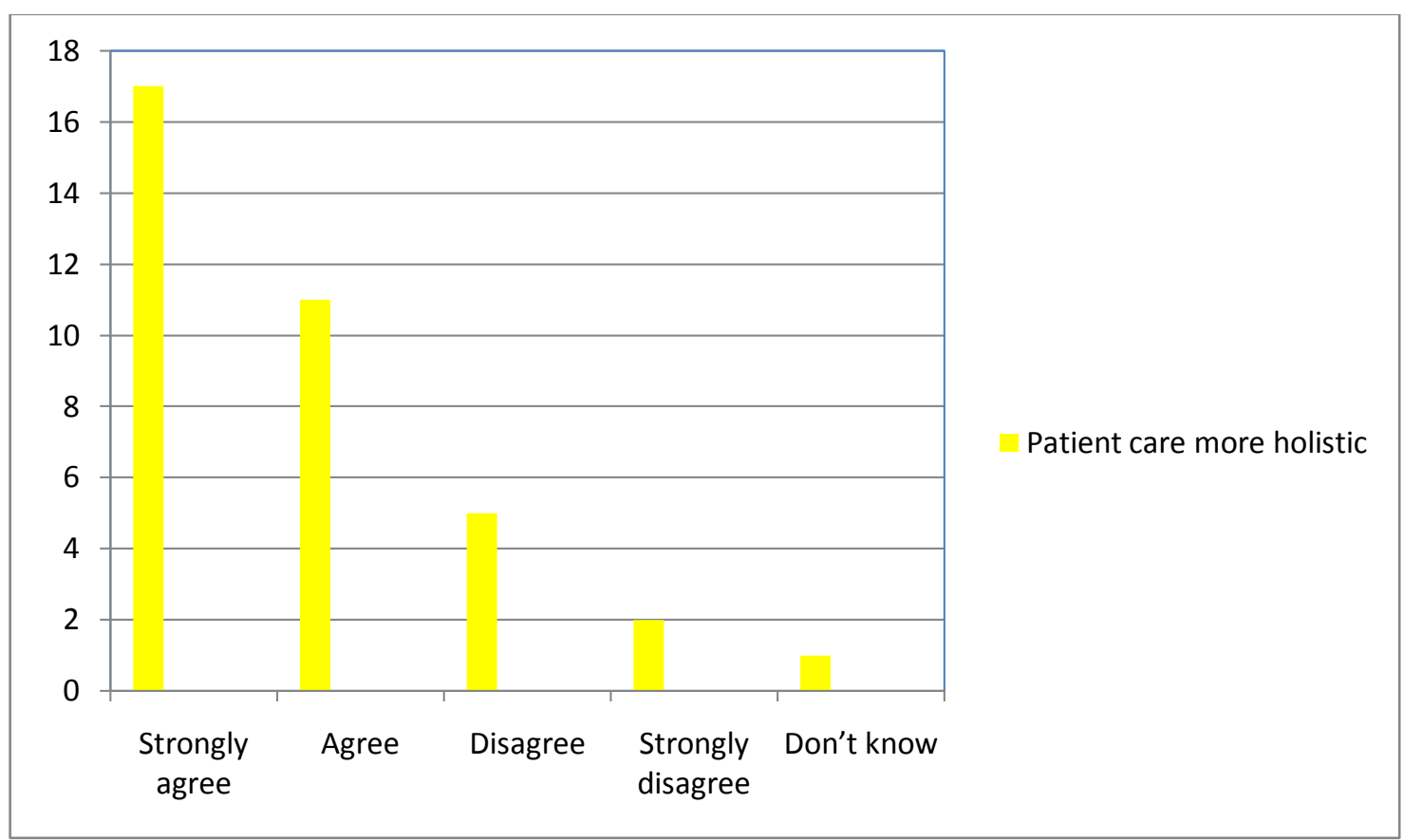


Having examined respondent's thoughts on the provision of holistic care for the patient, it was then asked whether all registered nurses should perform venepuncture (see Graph 10). Supporting the idea, that all registered nurses should perform venepuncture drew a response rate of $58.3 \%(\mathrm{~N}=21)$ who agreed. In opposition to the statement were $41.6 \%(\mathrm{~N}=15)$ of respondents.

Graph 10: All registered nurses should perform venepuncture

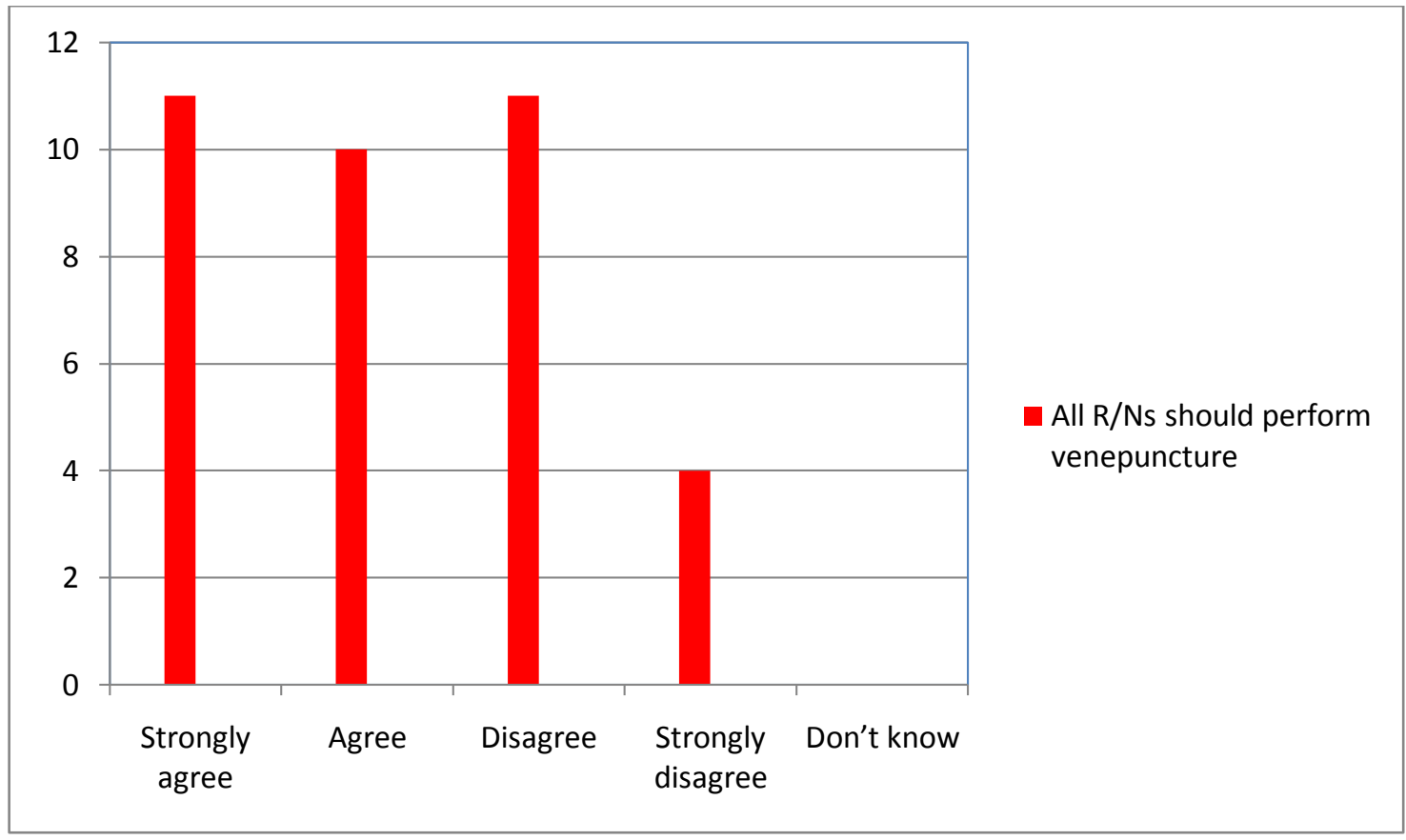


After asking whether all registered nurses should perform venepuncture, it was then important to find out if the respondents believed that all registered nurses should perform cannulation (see Graph 11). It can be seen that there were $63.8 \%(\mathrm{~N}=23)$ of the respondents who agreed that all registered nurses should perform cannulation. In disagreement of this statement were $36.1 \%(\mathrm{~N}=13)$ of respondents who disagreed with this statement.

Graph 11: All registered nurses should perform cannulation

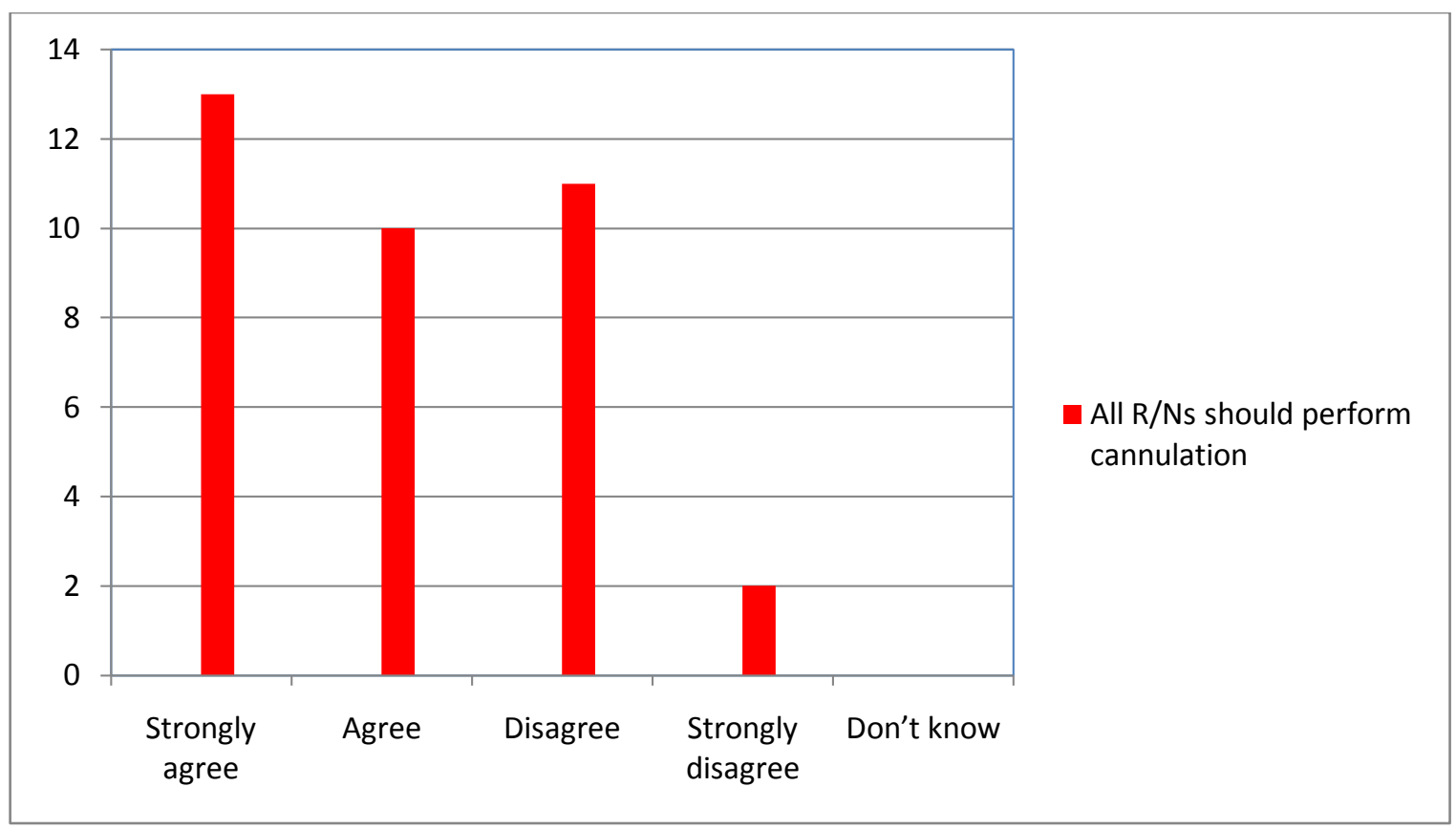


The elicited responses to the question which examined if registered nurses should decide for themselves when to undergo any training, reveal that there were $38.8 \%$ $(\mathrm{N}=14)$ respondents who agreed that all registered nurses should make their own decisions about when to undergo the education required (see Graph 12). There were $50 \%(\mathrm{~N}=18)$ of respondents who disagreed with this statement and $8.3 \%(\mathrm{~N}=3)$ of respondents who did not know. There were $2.8 \%(\mathrm{~N}=1)$ of respondents who failed to respond.

\section{Graph 12: Registered nurses should decide for themselves when to undergo training}

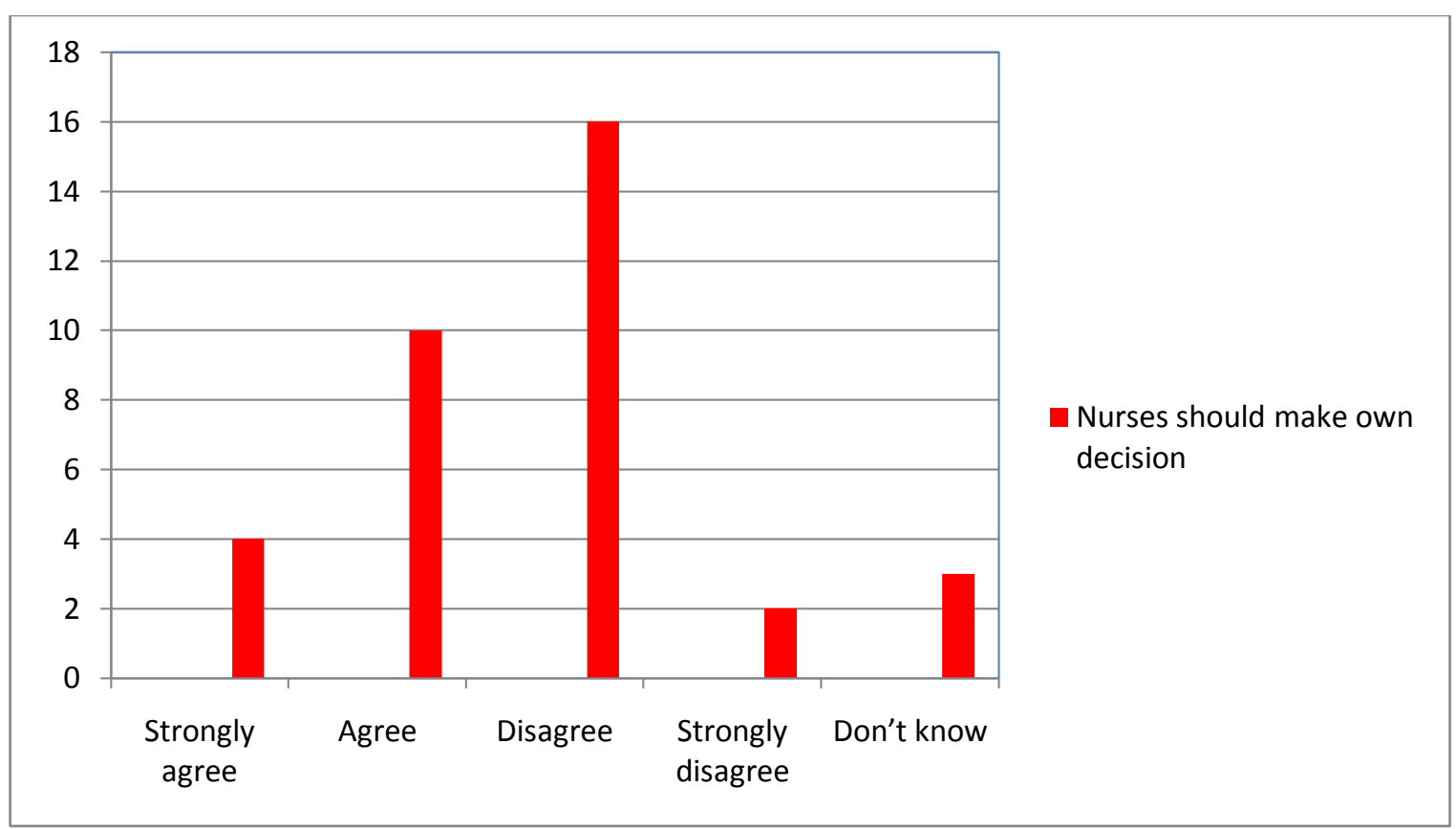


When asked if there should be national consensus about when all the education and training should take place, the respondents indicated that there was a $77.7 \%(\mathrm{~N}=28)$ response who agreed that there should be national consensus when this education should all take place (See Graph 13). There were $16.6 \%(\mathrm{~N}=6)$ of respondents who disagreed with this statement. There was a $2.7 \%(\mathrm{~N}=1)$ of respondents who did not know. There were $2.8 \%(\mathrm{~N}=1)$ of respondents who did not answer this question.

Graph 13: National consensus as to when this education should take place

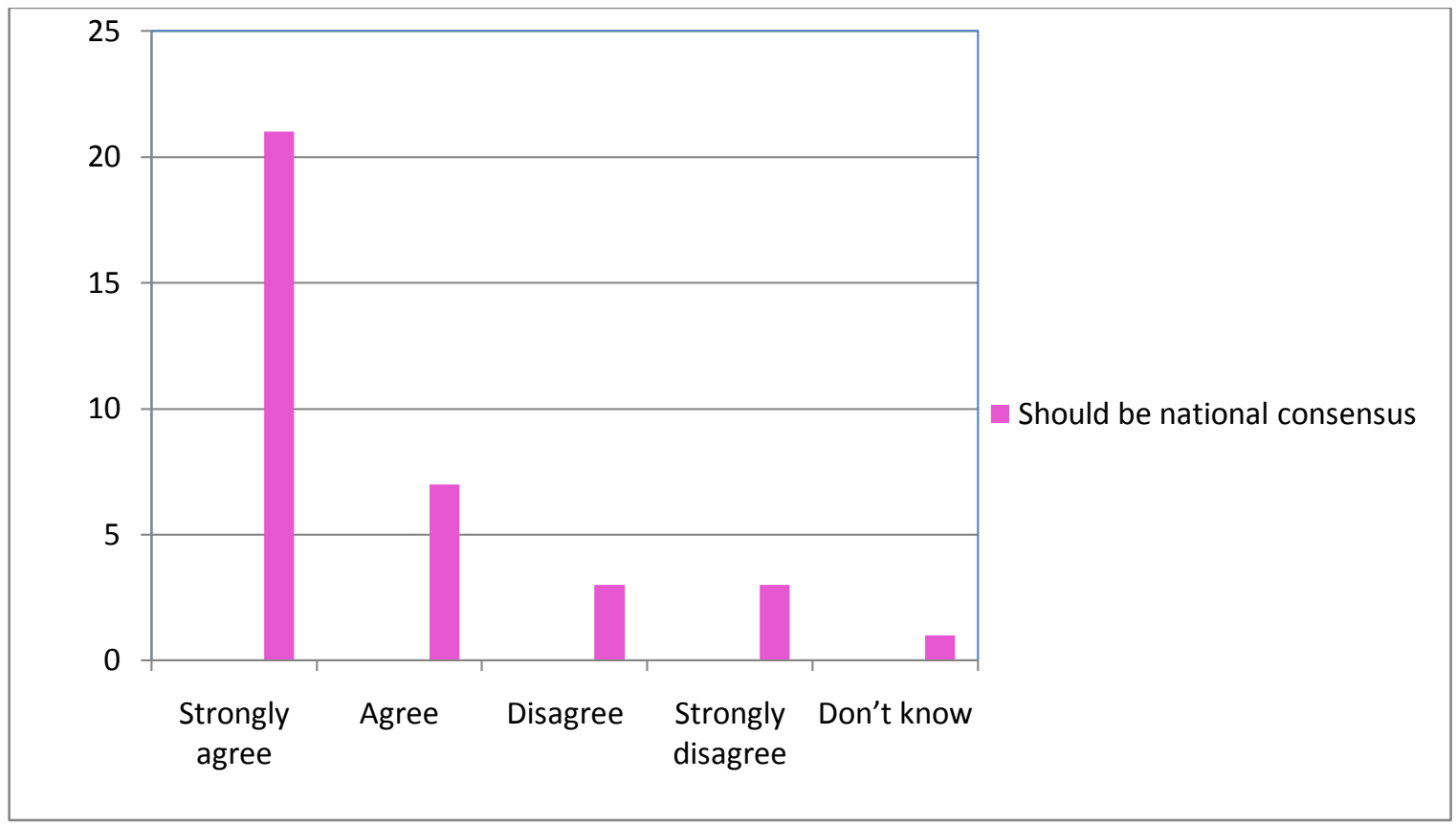


To the question which asked if the respondents believed that there should be a national training programme in New Zealand, there were $83.3 \%(\mathrm{~N}=30)$ who agreed. There were $16.6 \%(\mathrm{~N}=6)$ of respondents who disagreed with the statement (see Graph 14).

Graph 14: There should be a national training programme

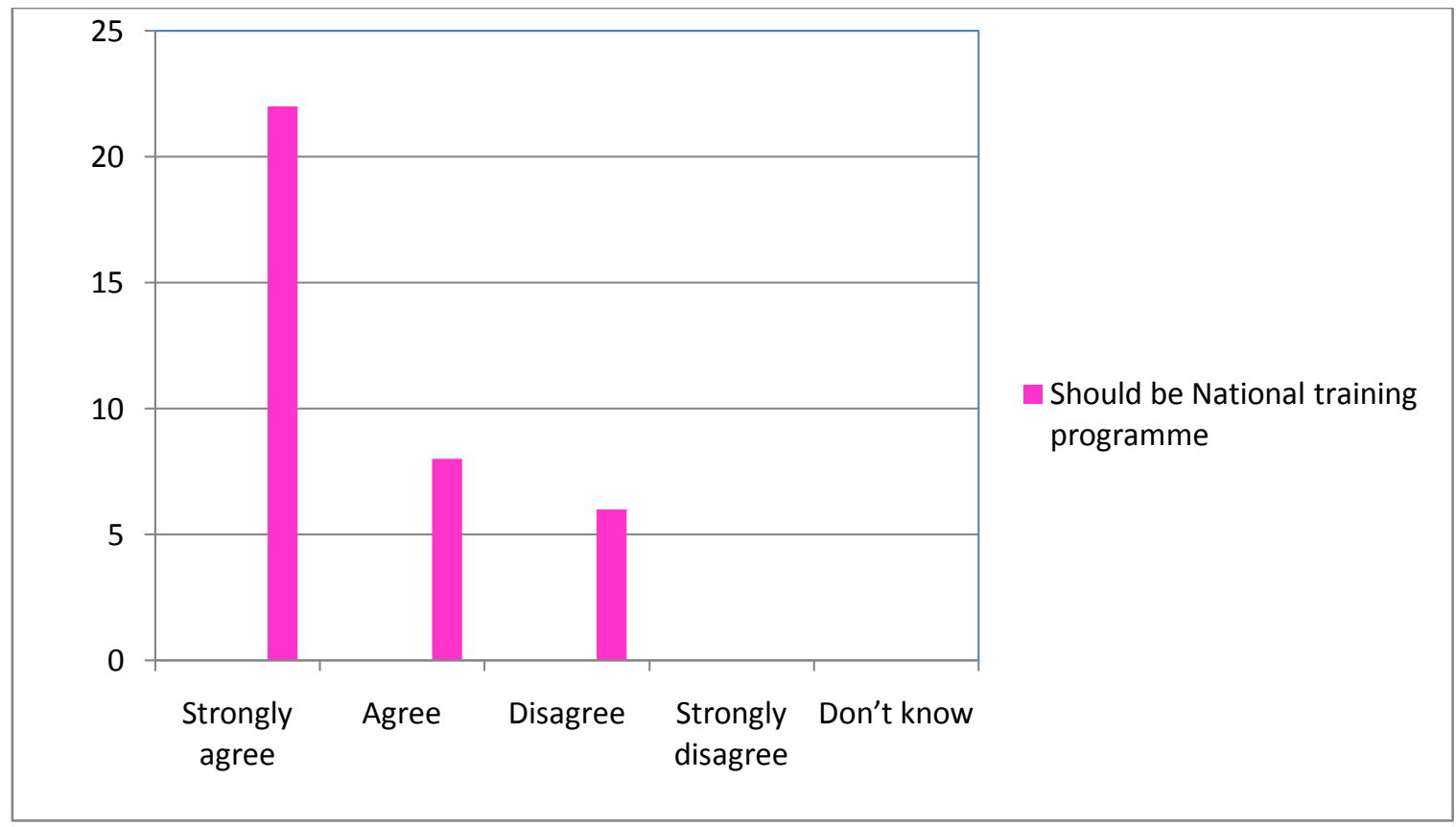

This ends the presentation of responses to the Likert scale questions from the questionnaire distributed to DHBs and Schools of Nursing throughout New Zealand. Question $4 \mathrm{a}$ of the questionnaire appeared to cause some confusion and was not accurately completed which gave limiting information. Please see the limitations section in Chapter Five for a complete discussion of this issue. The final section of the questionnaire invited the participants to add any further comments that they may have regarding the topic of the questionnaire. This open ended option allowed people to add any other comments about the topic and it raised some interesting issues about the topic under study. A total of $88.8 \%(\mathrm{~N}=32)$ wrote additional comments related to the topic and these will be discussed further in the next section. 


\section{Analysis of respondents' comments}

This section looks at responses received from the open ended questions and general feedback will be made by the researcher in response to these comments. The reason behind including open - ended questions in the survey was to see whether a baseline of agreed topics might emerge. The analysis of respondents' comments has been analysed into four distinct themes and the number of respondents who commented on these themes, as indicated in Table 2.

Table 2: Themes

\begin{tabular}{|l|r|}
\hline Themes & Number \\
\hline $\begin{array}{l}\text { Core components for IV } \\
\text { therapy }\end{array}$ & 17 \\
\hline Timing & 20 \\
\hline National consensus & 15 \\
\hline National training & 14 \\
\hline
\end{tabular}

\section{Core components for IV therapy}

The researcher felt it was important to include a section to look at what topics or subjects the respondents felt were important and should be included when any education or training was provided on IV, venepuncture and cannulation. There were $94.5 \%(\mathrm{~N}=34)$ of respondents who indicated what they considered to be necessary to educate nursing students about intravenous therapy, venepuncture and cannulation. The topics that respondents mentioned in their replies and the number of respondents who mentioned them are indicated in Table 3 on the following page. 
Table 3: Topics

\begin{tabular}{|l|r|}
\hline Topics & Number \\
\hline Pharmacology & 3 \\
\hline Infection control & 9 \\
\hline Medication safety & 5 \\
\hline Manual dexterity with the devices & 8 \\
\hline Product information & 6 \\
\hline Reconstitution & 7 \\
\hline Administration & 10 \\
\hline Complications & 12 \\
\hline Intravenous therapy theory and & \\
principles & 9 \\
\hline Documentation & 7 \\
\hline Legal issues & 4 \\
\hline Anatomy and physiology & 10 \\
\hline Blood product management & 7 \\
\hline Trouble shooting & 4 \\
\hline Monitoring & 9 \\
\hline Blood and fluid compatibilities & 5 \\
\hline
\end{tabular}

Some of the narratives gained from the open-ended section of the questionnaire will now be looked at. They indicate that there is an awareness of the necessity for intravenous therapy, venepuncture and cannulation to be included as part of undergraduate education. An overview of the comments will be made and then some direct quotes from the respondents will be identified.

The first narrative from an intravenous educator shows that he or she believes that if IV therapy, venepuncture and cannulation are taught as core skills, it takes away the fear and apprehension that some nurses might feel. The same respondent also believes that if these skills are taught to non medical people, there is no reason for them not to be taught to undergraduate students.

"Making it a core skill takes away the fear and apprehension and allows it to be seen as a basic skill - not an advanced level skill”. (I 1) 
"Cannulation and venepuncture should be considered a core nursing skill. After all it is a skill that is on occasions taught to people other than health professionals e.g. soldiers on peace keeping duties for the UN." (I 1)

It was unanimously discussed by respondents and can be seen from the following two narratives, that the first year of nursing education is a foundation year for gaining knowledge and learning basic skills relating to intravenous therapy. In addition, it is considered to be a valuable skill base by hospitals.

"First year lays foundations for more detailed applications such as infusion therapy. IV therapy education should start in year one and practice should be imbedded throughout the programme”. (E 2)

A number of respondents felt that the second year was a good place to start teaching venepuncture and further intravenous therapy theory as core components, which can continue to be put into practice over the second and third years, while in each clinical placement. However, although a number of respondents felt that in the year two curriculum, that management of intravenous therapy was relevant, there were still some respondents who felt the undergraduates should still not be undertaking venepuncture or cannulation, as can be seen in this narrative from a DoN.

"It should not be in the scope of an undergraduate or new graduate nurse to perform venepuncture and cannulation". There are many more skills the undergraduate and new graduate nurses need to acquire during their training and first year in practice which take priority over venepuncture and cannulation”. (D 2)

There was a high level of consensus among the respondents, that by the time the students have reached their third year of education, they will have had enough background theory to make good decisions regarding IV therapy, venepuncture and cannulation. Nursing students, in most undergraduate nursing programmes, currently can prime lines, draw up IV medications and in some places, carry out tasks such as checking blood and monitor patients receiving blood transfusions, but they are not allowed to administer these or start an infusion. Also, taking into consideration, the 
large percentage of patients within our hospitals having IV therapy, according to a number of respondents, who commented that it should be part of the acute medical or surgical practicum placement. One respondent made the following observation about the current clinical learning environment.

"It is like we let them join a race but not be able to cross the finish line" therefore "the theory should be linked to the practicum - should be part of medication administration and the students should be able to practice this. Cannulation and venepuncture training in the third year, could build on experience already gained across clinical and theoretical experience in first and second years. This would enable the undergraduate to have opportunity for experiential learning in clinical practice for venepuncture and cannulation during their final year and clarify any practice issues. By the time they were new graduate nurses they would be feeling less stressed having to learn even more new skills”. (L 1)

Participants appear to have an understanding of the necessity for IV therapy to be a part of core skills at undergraduate level. However, there was no consensus amongst them about the inclusion of venepuncture and cannulation. The timing of this education will now be discussed.

\section{Timing}

The topic of the 'correct time' for nurses to have the education and training emerged as an important issue for the respondents. There is a wide variation in different clinical specialists and educators aspects as to when they believe is the best time for undergraduate students to learn about intravenous therapy, venepuncture and cannulation. This is an area in which there does not appear to be any available literature to support the best time. The following narratives will show some of the discrepancies in people's thoughts. 
One of the educators who responded gave the following narrative which indicates how this respondent has an understanding of the importance of educating undergraduate students throughout their undergraduate years and continuing through to their graduate years.

"I think IV therapy education should start in year one and practice should be imbedded throughout the programme. I think Venepuncture should be year three and Cannulation graduate year." (E 7)

There are benefits for the DHBs and other workplaces if undergraduates are educated as soon as possible as is discussed by these respondents.

“The sooner undergraduates get IV therapy the better for DHB's and other institutions. There is always going to be differences in products and consumables but the fundamentals are the same." (I 3)

"The third year nursing students are given the opportunity to sit the local DHB IV module and if they pass they can administer IV fluids, IV flushes and some IV medications and additives - under the direct guide of a registered nurse who is IV certified." (L 3)

Another of the respondents in a lecturer role indicated that they felt that the theory and principles should be taught continuously over the whole three years of the undergraduate programme.

"Infusion therapy theory and principles should be taught continuously over the three years in the undergraduate programme." (L 5)

However, this next narrative, also from a lecturer, shows how they feel that only IV fluids and rates should be taught in second year. They mention not teaching venepuncture and cannulation at the same time, but they do not discuss when they believe this should be taught. 
"I think student nurses should be knowledgeable about IV fluids and the rationale for rates / choice of fluids etc in the second year ... but not have venepuncture and cannulation skills taught and practiced at that same point." (L6)

One respondent who indicated their role as 'other', states that they do not agree with educating students in year one in regards to intravenous therapy. However, they believe that by year three they should have all the basics and be able to expand their knowledge.

"Definitely not necessary in first year as these students are just learning the basic nursing skills. By third year, hopefully students have learnt the basics and are ready to expand their knowledge and they also will have the theory behind the practice." (O 2)

These next respondents discuss the point that it is important for undergraduates to learn these skills, which will make them 'work ready' and also they will be able to offer holistic care to their patients.

"Put it all at undergrad to produce a more 'work ready' graduate!!” (I 6)

"If undergraduate nurses had some initial exposure, education and training in venepuncture and cannulation, it would mean that they only need to build on their foundations when they become new graduate nurses and not have to learn from scratch. Year three undergraduates can build on the knowledge they already have and give a clear indication to them that this will be an essential part of their practice as a registered nurse who is expected to deliver holistic care as the primary care giver." (I 7)

Another option offered is that the undergraduate students should have the option of when they do learn about venepuncture and cannulation, but not IV therapy, which is mandatory. 
"Locally our undergraduate students study the district health board IV therapy module and sit the related exam and do the practical with RN's in practice - it is optional and taken up only by those who are interested maybe something like this could be offered for venepuncture and cannulation?" (E5)

Some of the respondents appeared to have conflicting thoughts themselves and in one way saying that IV therapy, venepuncture and cannulation are really important for all nurses to know, but that they should only be taught when they were at a competent level.

"IV therapy venepuncture and cannulation were vital skills all nurses should know" however, "new graduates have so much to learn that venepuncture and cannulation is a skill that should be taught once they were registered and had been assessed as a competent practitioner". (E4)

"One has to remember the 'crowded' nature of the undergraduate curriculum - it is very difficult to manage all the competing 'needs'. As I see it the undergraduate curriculum aims to produce a 'generalist', who with support during the first post graduate year is able to further develop skills that are relevant to the practice setting - this may be calming and restraint, venepuncture, giving of immunizations etc." (E5)

As can be seen by all the previous comments, there is a mixed response from the respondents and this issue will now be discussed under the subject of national consensus.

\section{National consensus}

There was a $77.8 \%(\mathrm{~N}=28)$ response from participants who felt that there should be national consensus as to when this education should take place. However, there were some very interesting comments made by respondents that highlight the lack of 
consensus. The following comment, from an IV specialist, made in the section allocated to extra comments relating to the topic is interesting, as they do not believe that it is necessary to include IV therapy, venepuncture and cannulation as a core skill.

"Some people may never need to learn these skills (venepuncture and cannulation). I believe new grads have plenty of new skills to pick up without worrying about these. I am also concerned about de-skilling house officers."

One of the respondents indicated that they have included IV therapy to their curriculum. The respondent did not discuss however, whether this decision to transition education to undergraduate level also included venepuncture and cannulation for the undergraduate students.

"Our workplace has already made the decision that IV therapy should be part of the undergraduate training and the students are in the process of transitioning to this. The decision was made in recognition that IV therapy is now a standard care process and not a delegated medical task as was the case some $20+$ years ago. We are also removing the requirement for ongoing $I V$ certification as there is no clear evidence that it prevents errors." (E 6)

Some respondents felt that the skills of venepuncture and cannulation, were advanced and the undergraduate nurses needed to have a good understanding of the basic fundamentals of nursing before undertaking these skills. The issue of health and safety was mentioned; however, they did not discuss the NZNC competencies under which the students are measured.

"Quality, safety and what the role of nurse is for them and its importance to public safety”. (E 11)

"New graduates should be grounded in the basic principles of nursing prior to undertaking invasive procedures". (I 7) 
There were a number of comments made by respondents that suggested that students might find having to learn more skills stressful, for example when going into their transition to practice placements.

"Year three is an extremely busy time for the student with study and transition to practice and that introducing more skills at this time could prove quite stressful”. (I 1)

There were some people who responded that because people might work in an area where they will not need to carry out any venepuncture or cannulation, then they felt that this opportunity of exposure to these skills would be wasted.

"Cannulation and venepuncture are skills that are job dependant. NOT every RN would need these skills, so teaching at student level could be a little unnecessary.” (I 4)

As seen by the varying comments, there is certainly no national consensus about education and training in relation to IV therapy, venepuncture and cannulation. There were many of the respondents who felt that a national training programme would be beneficial and this issue will now be discussed.

\section{National training programme}

The statement that there should be a national education and training programme was agreed by $83.3 \%(\mathrm{~N}=30)$ of the respondents. There were no specific comments offered by respondents that really fit into this section, although so many people agreed with this statement. We are never all going to be midwives, but at some stage in our career, every nurse will have to participate in some form of intravenous therapy. One of the respondents commented that midwifery students are taught to perform venepuncture and cannulation. They continued to say that this opportunity was not offered to the undergraduate nurses at the same educational institution and 
have offered no rationale as to why they have chosen not to educate the undergraduate nurses with the same skills.

"Midwifery students are currently taught to undertake venepuncture and cannulation at one educational institute, however, at the same educational institute, student nurses are not given the same opportunities to be educated in these skills." (O3)

After reading through all the responses received, the researcher was struck by the thought that each educational institute should work alongside their local DHB. The IV educator of each DHB could attend some of the clinical practical training days to provide IV therapy, venepuncture and cannulation education and training. This would also ensure that the undergraduates would be aware of local policies and procedures prior to going out into their clinical placements.

\section{Chapter summary}

This chapter presented the results of the questionnaire. Response rates and demographic data were described. This was followed by a presentation of the responses to a range of statements by respondents to the questionnaire. Some respondents wrote additional comments, which reported what their beliefs about the topic of IV therapy, venepuncture and cannulation were, as well as recommendations for what they believe could or should happen around education in the New Zealand context. These results, which are from a convenience sample population of New Zealand nurse educators teaching undergraduate programmes and registered nurse clinicians at places such as DHBs, raised some interesting points. What emerged was a general agreement that there should be national consensus about when the education and training should take place and that there should also be a national training programme. It also emerged that respondents strongly believed that students should be taught the basics of intravenous therapy during their undergraduate degree study. The results will be further discussed in Chapter Five, within the context of the conceptual framework and current literature. 


\section{CHAPTER 5}

\section{Discussion}

This study has offered some findings that will inform educators of nursing students and ultimately will contribute to better outcomes for patients in New Zealand. This chapter offers a discussion of the major findings that emerged from the questionnaire and will highlight how it confirms what is known from the literature. In addition the chapter will explore how it will enhance or contrast with available literature and then examine how this research has filled the knowledge gaps. There will also be a discussion about the limitations of this study. Some suggestions will be made for further research. Finally, there will be discussion of the implications of this study for New Zealand and internationally.

\section{Revisiting the aim of the study}

The aim of this research was to explore clinical educators and registered nurse clinicians' perspectives about the optimal timing of education of undergraduate or new graduate nurses in the role of intravenous therapy, venepuncture and cannulation. The question which guided this study was: "Should nurses in New Zealand be prepared to administer intravenous therapy, undertake venepuncture and cannulation prior to or following registration?" It became evident in the course of this study that there are large gaps in the literature, both nationally and internationally, about the timing of education for intravenous therapy, venepuncture and cannulation.

The research objectives in this study were:

* To identify when intravenous therapy, venepuncture and cannulation education and training of undergraduate and new graduate nurses should take place.

* To identify what aspects of IV therapy, venepuncture and cannulation should be included in undergraduate nursing curricula according to the different District Health Boards (DHBs) and nursing schools in New Zealand. 


\section{Design}

The researcher chose to use an exploratory descriptive approach to answer the research question, and gathered information via a convenience sample of a variety of people from all over New Zealand from different Schools of Nursing and DHBs over a four week timeframe in the early part of 2009. This approach is employed when little is known about the topic under investigation. The framework that informed this study was Benner's theory of Novice to Expert, Benner (1984). A questionnaire was utilised to gain the information needed to answer the research question.

\section{Responses from different work settings and roles.}

Of all the responses that were returned, $86 \%$ were from Nursing Schools and DHBs. Seventy two percent of the respondents indicated that they were in an educational role of some description. As the topic under investigation was specifically related to education, it was important to have as much input from educators as possible, as they would be the people that would be educating undergraduate and registered nurses.

\section{Major findings}

There were a number of different themes that emerged from this study. They have been grouped together with the major findings that emerged from this study being:

1. All the questionnaires that were returned agreed that intravenous therapy should be a core component of undergraduate study.

2. There was no agreement about the timing of venepuncture and cannulation education and training.

3. There should be national consensus about when nurses should undergo any intravenous therapy, venepuncture and cannulation education.

4. There should be a national training programme. 


\section{Core component}

Throughout the study and also from all the comments made by respondents, it could be noted that there was agreement about intravenous therapy being a core component at undergraduate level. There was absolutely no question about the fact that all undergraduate students should have a thorough knowledge about intravenous therapy. The replies from the respondents indicate that all respondents are fully aware of the emerging trend that the majority of patients admitted to hospital will undergo some form of intravenous therapy. Due to this, it is imperative that all nurses have solid background knowledge, keep up to date with all the changes by maintaining their skills, attend refresher courses, as and when necessary, and also reading up to date literature on the topic.

The issue that arises from this is that it would be beneficial for the NZNC to give guidance about what needs to be included into the curricula. If there are only guidelines given, then it allows for large discrepancies in the education and skills bases that will be delivered. America has a licensing body which provides these guidelines. As this is not the role of the NCNZ and as New Zealand is only a small country, it could be beneficial to create a national body, which could then decide on the national standards and guidelines relating to all aspects of nursing skills. Although the public are protected by the HPCAA, it still remains the responsibility of each registered nurse to ensure that they are competent to provide the appropriate care for their patients. If no national guidelines exist, then it is difficult for registered nurses to gauge what 'competence' is.

All of the respondents agreed that intravenous therapy is a very important part of nurse education and needs to be undertaken early in undergraduate study. There was certainly no other area in the study where all the respondents indicated the same reply to a question.

There is also common agreement, from all respondents to the questionnaire, that intravenous therapy education is an integral part of all nurses' basic nursing care and that having to keep updated in evidenced based research will be an ongoing need throughout their nursing careers. This finding is not too surprising given how 
contentious this issue is internationally (see Chapter 2). Indeed, what appears to have emerged out of this current study is that people and institutions are making individual decisions about what education is needed and when they believe this education should take place. However, there does not seem to be much evidencebased research to support the decision making process in relation to these specific issues (Collins and Henderson, 1991; Coulon et al., 1996; Shields and Watson, 2007). Spader (2006) comments that although the debate brews among the nursing community about who is directly responsible for IV skills training, experts agree the entire health care system must participate to properly prepare nurses with the diversity of skills needed in today's rapidly changing environment.

The majority of respondents $(n=36)$ agreed that intravenous therapy is a very important part of nurse education and needs to be undertaken early in undergraduate study. There is also common agreement from all respondents to the questionnaire, that intravenous therapy education is an integral part of all nurses' basic nursing care and that having to keep updated in evidenced based research will be ongoing throughout their nursing careers. However, a number of researchers and clinical experts do not appear to be able to reach consensus about when this should occur, which is an idea discussed by many authors (Bakewell, 1994; Collins and Henderson, 1991; Coulon et al., 1996; Edwards.1995; Feddock, 2007; Gray, 1997; Gruber et al., 2007; Shields and Watson, 2007; Walker et al., 2006). Indeed one of the significant findings of this study is that people and institutions are making individual decisions about what education is needed and when they believe this education should take place.

The number of respondents that replied and made extra comments, demonstrated a high level of consensus among the respondents, that all student nurses should undergo basic IV therapy education prior to going into the hospital setting. There was recognition that the majority of patients will at some stage have some IV therapy and it was important that all undergraduate nurses should be able to provide basic maintenance of these. This education at the tertiary institutions would give them the basic theoretical knowledge needed to look after patients undergoing IV therapy. Then once they were in a clinical setting they could put this theory into practice 
whilst working within their scope of practice and under the supervision of a registered nurse.

As discussed in Chapter 4 there were a large number of main topics that respondents believed that undergraduates should be educated about prior to going into clinical placement. Interestingly, even when some of the respondents were against undergraduates learning about venepuncture and cannulation, they were still in agreement that it was important that these undergraduates have background knowledge about the IV equipment and how it was used. These are all topics that were found to be important in research conducted by Evans et al., (2007), Inwood (1996), Koh (1996), McBrien (2006), Logan et al., (2005) and Wilkinson (1996). These authors also discussed the necessity of a good background education in all aspects of IV therapy and the importance of registered nurses being able to carry these skills out competently.

The research outcomes definitely indicate that there is a need for intravenous therapy, venepuncture and cannulation to be a core part of the undergraduate curriculum. The issues that the respondents highlighted as being important for undergraduates to learn, indicates the complexity of educating undergraduate nursing students and highlights the issues involved for educators when developing any new curriculum.

It is imperative that there is consensus amongst tertiary institutions and educators and collaboration with the NCNZ is needed, about what their expectations and also those of the DHBs are about intravenous and infusion therapy, venepuncture and cannulation and how it would best be able to be delivered. In coming to some national agreement, the undergraduate nurses could be assured that they would begin their careers with the necessary education to underpin their practice, no matter where they went to begin their careers. This will ensure a more work ready newly graduated nurse. 


\section{National consensus}

The majority of respondents thought that the research focus is very topical currently. Some respondents went on to say how they were in the process of having discussions about requiring IV certification during the last placement for third year undergraduate students. It appears from respondents that there are often debates and discussions held between clinical and education based staff and there is never any agreement by all the staff as to when students should be allowed to undertake these skills and tasks. Cassie (2009) discusses the implications for New Zealand nurses and discussed that nurse leaders have been meeting in order to try and set up a framework with nationally agreed standards. This could be used as a start to gaining national consensus about what should be taught and added to education programmes.

As well as deciding about what need to be taught, it is also important that the timing of this education is agreed upon and this will be discussed in the next section.

\section{Timing}

The topic of the 'correct time' for nurses to have the education and training is an important issue. Respondents highlight a range of ideas about when the 'ideal' time would be. It appeared that there were many different variables in respondent's thoughts about this issue. This is an area in which there does not appear to be any available literature to support the best time. The information resulting from this research will give an indication to DHBs and Schools of Nursing of when respondents believe this education should take place.

To the questions about venepuncture, in question three (questions $\mathrm{b}$, e and $\mathrm{g}$ ), there are a wide range of responses. It appears that the majority of respondents see venepuncture education taking place during the first year as a registered nurse and not during undergraduate study. There were also a majority of respondents that believed that registered nurses should be able to perform venepuncture. 
Question three goes on to ask (questions c, f and h) about cannulation, and the respondent's comments demonstrate the majority believe that all nurses should be able to cannulate. However, the greater percentage felt that it was not appropriate for undergraduates to learn how to cannulate and that they should not undertake this procedure. This is an interesting finding, as there are some hospitals and schools of nursing who are allowing students to perform this procedure as long as they have undergone the relative education and training at their local DHB.

Spader (2006) from the USA suggests that currently undergraduate nurses are receiving very little IV therapy and insertion training as part of their education. She continues to suggest that some nursing schools are using IV therapy as a prototype to teach the fundamentals of aseptic technique, infection control and also good bedside manner. Boxer and Kluge (2000), Collins et al., (2006), Gray (1997) and Morris (2006), all discuss the importance of this education occurring at undergraduate level, rather than as a new graduate, as it provides for more holistic care.

As can be seen from responses received and also in the discussed lack of literature relating to the timing of education and training, it will take a larger national and international study to reach any form of consensus. There will now be discussion as to whether there should be a national training programme.

\section{National training programme}

The questionnaire also explored if nurses should have a choice about whether they should learn to perform these procedures. There were no additional written comments made by the respondents about this statement. This was interesting, as $(n=18)$ of the respondents disagreed with this statement, but even when provided an opportunity, they did not add extra comments. There needs to be national consensus, so that both nursing students and registered nurses have a clear understanding of what is expected of them and that they should know at what stage of their careers they should be able to perform venepuncture and cannulation. Currently there is 
variation about when this is allowed to be undertaken by students and new graduates. This causes confusion for the preceptors in knowing what the boundaries are.

The researcher is aware that there are some educational institutions that do include intravenous therapy, venepuncture and cannulation in their curricula. There are also some DHBs that have a specific policy relating to students assisting or carrying out these skills under supervision. Spader (2006) states that the National League for Nursing is concerned about the lack of IV therapy and insertion education and they have now issued a public statement which explains that this education is now mandatory. Again, this highlights the point that New Zealand might require a national nursing education body to oversee these issues.

A number of respondents commented that they felt it is important for all Hospitals and Nursing Schools to be involved in this research and they looked forward to receiving the results once they had been published.

There was strong agreement $(\mathrm{N}=28)$ with the idea that there should be National consensus about when this education and training takes place. Only six respondents replied that they did not feel there should be national consensus about the timing of this education and training. There were thirty positive responses to the question that explored if there should be a National training programme. The researcher is of the opinion that there would be a positive outcome if a national programme existed, with guidelines for the timing of the proposed programme.

General additional comments made on some of the issues that arose through the study will now be discussed.

\section{Additional comments}

There were a few other findings that emerged from this study that need to be discussed. They include: holistic care, education providers, extension of roles, and 
misinterpretation of definitions. The discussion on these issues is laid out in the following paragraphs.

The responses in this study mirror the literature, as there appears to be conflict about who should be providing the "technical skills" that are required for patient care. In some countries for example: United States, United Kingdom, Australia, Greece and Jordania, the nurse's role has been expanded in response to medical staffing crisis (Carlisle et al., 1998; Collins and Henderson, 2001; Harris and Redshaw, 1994; Jackson, 1997; Shields and Watson, 2007; Ung et al., 2002; Walker et al., 2006; Woodrow, 1997). If nurses are prepared to undertake the necessary post-basic courses, then surely as long as patient care is not compromised, this is what should guide decisions that are made regarding the expansion of their roles? Many doctors will acknowledge that they cannot practice without highly educated, knowledgeable and competent nurses as part of the health care team (Shields and Watson, 2007).

Extensions of roles or advancing roles are common themes that emerge from the literature (Albarran and Whittle, 1997; Bowler and Malik, 1996; Edwards, 1995; Gray, 1997; Hand, 1992; Pearcey, 2007; Rieu, 1994; Wright, 1995). This was also part of the theme that emerged in conjunction with a national consensus in New Zealand being necessary. It is important to ensure that when undergraduate or new graduate nurses are undertaking new or extended roles that this is done with sufficient consultation. Rieu (1994) and Last et al., (1995) discuss this issue and comment that there always have been, and always will be, divisions between different health care professionals and what they believe should be included in a nurse's role.

The questionnaire also explored if respondents believed that patient care would be more holistic if nurses were able to perform these procedures. The responses to this statement indicated that the respondents supported this idea $(\mathrm{N}=28)$. Patient care needs to be holistic, which is a concept echoed in the studies carried out by Studdy et al., (1993), Simpson (1989), Ryan (1992) and Wainwright (1987). These authors state that holistic patient care happens, when nurses can provide for all the needs of their patients, without having to rely on other medical staff to carry out some specific skills in order for treatment to be undertaken. 
It was intriguing to read the respondent's comments as it appears there is confusion about IV therapy versus infusion therapy, with respondents combining all the aspects of the two. In some places they are used intermingled and yet their meanings are all totally different. It is important that they all remain separate entities, so that there is no confusion about what the expectations of nurses are. There also appear to be authors of literature that intertwine the terms, such as Campbell and Lunn (1997), Hanchett (2001), Scales (2009) and Wilkinson (1996). The differences can be read in the glossary provided (see p. 1).

A discussion will now follow on the implications for practice in New Zealand as a result of this study.

\section{Implications for practice in New Zealand}

Following this examination of opinion on IV therapy, venepuncture and cannulation education in New Zealand, it is obvious that there is no clear opinion from the respondents on the issue. There needs to be agreement by all educational institutions and DHBs in this country about what the core requirements are. These core requirements need to be agreed on, to ensure that nurses are equipped with the correct knowledge and skills in order to provide the best care for their patients. NZNC needs to take the lead and provide their contribution about the basic core education required and then they could also give other options to allow individuality in delivery of programmes.

It is imperative that there is some national discussion about the issues relating to infusion therapy, venepuncture and cannulation. It cannot be determined only by IVNNZ what the core needs are. All DHBs, Schools of Nursing and any other interested people need to be able to make submissions in order to get a wider perspective of what needs to be included. In this way national standards can be developed. It is important to remember that New Zealand is a small country and that it is important to find consensus amongst education providers. 
Another implication for New Zealand is that of competence. Competency is an issue that must be addressed by the different health providers and there needs to be national standards set. Morris (2006) discusses the concerns that some students are learning from observing bad practice. Breton and Ferguson, (2009) discussed that ongoing IV education and training resulted in improved patient outcomes and clinical practice. They did however, suggest that they were unsure whether IV certification gave the same results and that it was imperative that further research was urgently needed. Collins and colleagues (2006) state that cannulation is a skill learnt by many but not always used in practice and this is often because there is a lack of supervision available by an experienced practitioner. So if venepuncture and cannulation are taught, how is competency managed and who determines if registered nurses are allowed to continue practicing if they have had a long break between times since they last practiced? Or what happens if they were educated and practiced in a different country; do we just grant them automatic competency? Cassie (2009) discusses the implications for New Zealand nurses in her research that looks at nurses' credentials. She discussed that nurse leaders have been meeting in order to try and set up a framework with nationally agreed standards.

The limitations that the researcher encountered during the research project will now be identified and discussed.

\section{Limitations to this study}

As with all survey-based research, there are limitations to the interpretation of the results. Generalisability implies that the findings of one study can be applicable to other settings (LoBiondo-Wood and Haber, 2006). Due to the method employed to disseminate the survey the exact figures as to how many people actually received the questionnaire are not known. To this end if the researcher were to repeat the study, they would distribute the emails to people personally to be able to keep control of the figures. It might have been a better choice to print the survey into hard copy and mail the questionnaires out with reply paid envelopes. The researcher certainly believes that this would have provided a better way of controlling how many 
questionnaires were distributed. This would also have allowed the researcher to have exact data for the number of distributed questionnaires.

The format of some questions allowed for only one response, which may have limited free expression of opinion by respondents. In retrospect, respondents should have had a space allocated after each question to allow them to provide extra comments as they worked through the questionnaire. This may have provided more information for this research study.

As in all research, other researchers may have interpreted some of the data differently from how the researcher has interpreted it. In Chapter Three the researcher addressed the issue of credibility by explaining that this research project is a part of a formal qualification and it has required supervision. Critique of the work was done by the researcher's supervisor and also that of a 'second reader'. The researcher has also provided an audit trail of how they carried out the whole study and this can be found in Chapter Four.

Use of a structured survey conducted face-to-face with a researcher would have facilitated what is referred to in Parahoo (2006) as 'non-directive probes'; such as "in what way?" or "what do you mean?". With this research project there were self completed questionnaires and no opportunity for any clarification and so it was a case of having to "rely on the respondents understanding and answering the questionnaire" (De Vaus, 2002, p.123). If group interviews or face to face interview methods had been employed, it may have been a better way to question the respondents, as it could have given more insight to their reasons for choosing certain answers. In addition, Cormack (2000) states that some respondents do not answer questions and this could be due to the fact that the questions were poorly structured; however, to avoid this occurring, the questionnaire went through a number of iterations and was extensively piloted with registered nurses, educators and academics.

Participants appeared to be representative of the number of DHBs and Schools of Nursing in New Zealand, however, true comparisons cannot be made. In retrospect, as the researcher, it would have been interesting to have the information about 
exactly who did respond from which regions of New Zealand, but this information was removed by the collator as she had been instructed to do. This information would have allowed the researcher to analyse any trends across geographic areas.

When the researcher tested the survey on trial participants, they did not identify any issues with it. However, a number of comments from respondents about the survey tool led to the realisation that a number of changes should be made, before using it again. The electronic questionnaire was saved in MS Word 2007 and the researcher had not taken into consideration that not all respondents would have access to the same programmes. Seven people requested the questionnaire be redelivered in a new format to allow them to access it. Four of the respondents could not fill in the form electronically and so they requested a postal address to mail the hard copies to the collator. Taking all of these issues into account, the format used needs to be Microsoft Word 1997. Therefore, the researcher would change the programme used for any further research.

The table that was provided in the questionnaire (see Appendix 1) for respondents to answer question 4a: When should undergraduate nurses receive theory and practice related to intravenous therapy, venepuncture, and cannulation? Please select and rank your option(s) in order of preference, really proved to be a stumbling block for respondents. The pilot group however, had not had an issue with completing it. The researcher did not gain any information from this table that adequately answered the question and therefore, the decision was made not to include it in the findings presented in Chapter Four. It was also decided that there were an adequate number of written responses which gave enough information to write meaningfully about the respondent's perspectives related to this question.

The way that the researcher plans to communicate the findings of this research will now be discussed. 


\section{Communication of findings}

Once the research is completed, all participating DHBs and Schools of Nursing (known only to the collator), will be offered the results that came from the study. This will allow them to use the results to inform future plans for education of their undergraduate students or registered nursing staff. Eight of the Schools of nursing and DHBs asked for results to be shared with them after completion of the study. The collator will contact all the places that responded and offer them the results.

A presentation was given at the researcher's place of work, which was the School of Nursing on $8^{\text {th }}$ December 2009 , to share the research study and findings with their fellow colleagues. This presentation provoked some very interesting debate amongst the staff. The researcher has been invited to return next year to share how she believes this could be incorporated as an educational package into the curriculum for the local school of nursing.

Future research possibilities will now be discussed.

\section{Future research}

Additional research is needed to further enhance understanding of the issue of timing of education and training in regards to IV therapy, venepuncture and cannulation. This research is needed before the research question can be fully answered. To date there has been an uncoordinated approach to undergraduate nurse education in New Zealand. There is requirement that the NCNZ provide directions to the schools of nursing about absolute core components of IV therapy, venepuncture and cannulation that should be included in undergraduate study. Once that decision is made, then the DHBs can plan their education programmes in relation to IV therapy, venepuncture and cannulation.

The themes that emerged from this New Zealand based study did not appear to be the same as all the themes that emerged from the literature search that the researcher had undertaken from international research. A larger study carried out in New Zealand, 
targeting specific groups, for example nursing students, newly graduated nurses, all members of Intravenous Nurses of New Zealand (IVNNZ) and all IV educators would be a positive step in order to find out any other issues which could then be addressed by NCNZ.

The researcher believes that it would be naive to base the future direction of undergraduate nurse education on a single study. Therefore, the first recommendation from this research is for a larger scale research study to be undertaken. The researcher would also recommend that inclusion criteria be opened to include all nurse educators teaching in postgraduate nursing programmes and a proportion of registered nurses working in DHBs who have performed IV therapy, venepuncture and cannulation. Face-to-face interviews and or focus groups in which the voices and experiences of all these respondents could be heard would also add to the richness of the data yielded by larger research.

This study contributes to the body of literature that is available related to IV therapy, venepuncture and cannulation. Further research studies could be carried out on the different aspects of findings from this study. There needs to be further research done specifically about core skills for undergraduates. These studies need to be carried out both nationally and internationally to get a better idea of what is expected of nurses if they intend to travel and practice nursing internationally. This study could be carried out and divided into three different studies, looking specifically at timing of education and training in relation to each of the modalities of IV therapy, venepuncture and cannulation.

Age and gender were not explored in the survey. In hindsight, the researcher believes it would have been interesting to know what the participant's qualifications were and also how long the respondents had been in practice and employed in that particular role. Also of interest may have been to ascertain the point at which in their training or career they had undertaken IV therapy, venepuncture or cannulation training.

Teacher's behaviour probably influences the character of the learning environment more than any other single factor (Knowles, 1980). This makes the researcher 
wonder how this influences our students when they are in clinical placement, if they have registered nurses overseeing their clinical placement that do not allow them to advance their practice and try new skills. The students might look at the specific skill and come to an understanding that they are not capable or able to perform it. The researcher can see this being a good topic for future research, as there were some comments from respondents about preceptors and their attitudes towards the students.

\section{Conclusion}

This exploratory descriptive study examined clinical educators and registered nurses perspectives about the optimal timing of education of undergraduate or new graduates in the role of intravenous therapy, venepuncture and cannulation. The research findings reveal that there was no consensus about the issue of venepuncture and cannulation education and training, or the timing of it between the correspondents. However, the second objective has certainly been met in relation to what registered nurse clinicians believe should be in the New Zealand curricula in relation to IV therapy. The baseline information gained from this examination may be beneficial to plan education programmes for nursing curricula so that students will receive the maximum benefit of these skills in the lab and clinical setting. It could also be useful for hospital clinicians working towards consensus about what education and training they will need to provide to newly employed staff nurses, based on knowing what education they have already undergone during their undergraduate study. 


\section{Personal reflection}

On reflection through my journey doing this research study, I have gained many new skills and it has been a great learning curve for me. I have developed an insight into the practicalities and realities of research. It has not been an easy road, but I thank all those who have contributed to allow me the opportunity to make a scholarly contribution to intravenous therapy in nursing.

After completing any research there will always be discussion about how the project ended up. It has raised many more questions for me and how this might affect clinical practice. Not all the initial questions of the study were answered and so I will strive to get answers. And still I ponder as to how to bring about the changes.

In my own clinical practice I will strive to make a change in the timing of students being introduced to IV therapy, venepuncture and cannulation, by becoming more involved in IVNNZ and possibly making a submission to the NZNC about the findings of this study.

My hope from doing this study is that there will be a resurgence of interest in IV therapy research. From this, I would hope there will be a multitude of new research projects being undertaken in the near future which will allow further changes in evidence-based practice.

I have completed this research study with the same convictions that I began with. Over thirty years ago when I began my training as a student nurse in South Africa, I learnt about IV therapy, venepuncture and cannulation. I have always believed it to be a necessary skill, in order for nurses to be able to provide holistic care for patients receiving IV therapy. Therefore, I remain convinced that it is imperative for undergraduate students to be educated in regards to all aspects of IV therapy, venepuncture and cannulation during their course of study. 


\section{REFERENCES}

Alavi, C., Loh, S.W., \& Reilly, D. (1991). Reality basis for teaching psychomotor skills in a tertiary curriculum. Journal of Advanced Nursing, 16, 957-965.

Albarran, J. W., \& Whittle, C. (1997). An analysis of professional, specialist and advanced nursing practice in critical care. Nurse Education Today, 17, 72-79.

Anderson, D. M., Elliot, M. A., Keith, J., \& Novak, P. D. (2002). Mosby's medical, nursing, \& allied health dictionary. St. Louis, Missouri: Mosby.

Ashworth, P., \& Morrison, P. (1989). Some ambiguities of the student's role in undergraduate nursing. Journal of Advanced Nursing, 14(12), 1009-1015.

Babbie, E. (2007). The practice of social science research. California: Thomson Wadsworth.

Bakewell, J. (1994). Extended role of the nurse. British Journal of Nursing, 48, 479.

Barribal, K.L., Christian, S.L., While, A.E., \& Bergen, A. (1996). The telephone survey method: A discussion paper. Journal of Advanced Nursing, 24, 115121.

Bell, J. (1993). Doing your research project: A guide for first time researchers in education and social science. Buckingham: Open University Press.

Benner, P. (1994). From novice to expert: Excellence and power in clinical nursing practice. California: Addison-Wesley Publishing Company.

Benner, P. (2001). From novice to expert: Excellence and power in clinical nursing practice. California: Prentice-Hall.

Bergman, R. (1981). Accountability - definition and dimensions. International Nursing Review, 28(2), 53-59.

Bowler, S., \& Mallik, M. (1998). Role extension or expansion: a qualitative investigation of the perceptions of senior medical and nursing staff in an adult intensive care unit. Intensive and Critical Care Nursing, 14, 11-20.

Bowling, A. (2002). Research methods in health: Investigating health and health services. Philadelphia: Open University Press.

Bowling, A. (2005). Quantitative social science: The survey. In A. Bowling and S. Ebrahim (Eds.). Handbook of health research methods. New York: Open University Press.

Boxer, E., \& Kluge, B. (2000). Essential clinical skills for beginning registered nurses. Nurse Education Today, 20, 327-335. 
Breton, C., \& Ferguson, R. (2009). What do nurses think about IV certification? Nursing Review, 9(10), 12-13.

Brink, P. J., \& Wood, M. J. (1983). Basic steps in planning nursing research. California: Wadsworth.

Brouwer, D. (1995). Cannulation camp: Basic needle cannulation training for dialysis staff. Dialysis and Transplantation. 24(11), 1-4.

Burns, N., \& Grove, S. K. (1999). Understanding nursing research. Philadelphia: W.B.Saunders.

Campbell, T., \& Lunn, D. (1997). Intravenous therapy: current practice and nursing concerns. British Journal of Nursing, 6(21), 1218-1228.

Carlisle, C., Luker, K.A., Davies, C., Stilwell, J., \& Wilson, R. (1999). Skills competency in nurse education: Nurse managers' perceptions of diploma level preparation. Journal of Advanced Nursing, 29(5), 1256-1264.

Cassie, F. (2009). Show us your credentials. Nursing Review, 9(12), 10-11.

Castledine, G. (1992). Nursing degrees: Hindrance or help? British Journal of Nursing, 1(13), 671.

Collins, S. S., \& Henderson, M. C. (2001). Autonomy: Part of the nursing role? Nursing Forum, 26(2), 23-29.

Collins, M., Phillips, S., Dougherty, L., de Verteuil, A., \& Morris, W. (2006). A structured learning programme for venepuncture and cannulation. Nursing Standard, 20(26), 34-40.

Cormack, D. (Ed.). (2000). The research process in nursing. Descriptive research. Oxford: Blackwell Science.

Corrigan, A. M., Pelletier, G., \& Alexander, M. (Eds.). (2000). Intravenous Nurses Society: Core Curriculum for Intravenous Nursing. Philadelphia: Lippincott Williams and Wilkins.

Coulon, L., Mok, M., Krause, K-L., \& Anderson, M. (1996). The pursuit of excellence in nursing care: what does it mean? Journal of Advanced Nursing, $24,817-826$.

Coutts-Jarman, J. (1993). Using reflection and experience in nurse education. British Journal of Nursing, 2(1), 77-80.

Crowley, M. (2008). Practice makes perfect. Nursing Standard, 22(37), 62-63.

David, J. \& Pritchard, A. (1988). Royal Marsden Manual of Clinical Procedures. London: Royal Marsden Hospital. 
Davies, S. R. (1997). The role of nurses in intravenous cannulation. Nursing Standard, 12(17), 43-46.

de Vaus, D. A. (2002). Surveys in social research. Sydney: Allen \& Unwin.

DiCenso, A., Guyatt, G., \& Ciliska, D. (2005). Evidence-based nursing: A guide to clinical practice. Philadelphia: Elsevier Mosby.

Dodds, F. (1991). First class nurses - or second class doctors? British Journal of Theatre Nursing, 1(9), 6-8.

Dougherty, L. (2008). Peripheral Cannulation. Nursing Standard, 22(52), 49-56.

Dougherty, L., \& Lamb, J. (Eds.). (2008). Intravenous therapy in nursing practice. Oxford: Blackwell Publishing Ltd.

Dreyfus, H. L., \& Dreyfus, S. E. (1980). A five stage model of the mental activities involved in directed skill acquisition. Retrieved November 30, 2009, from http://stinet.dtic.mil/cgiin/GetTRDoc?AD=ADA084551\&Location=U2\&doc=GetTRDoc.pdf

Edwards, K. (1995). What are nurses' views on expanding practice? Nursing Standard, 9(41), 38-40.

Evans, J., Boxer, E., \& Sanber, S. (2007). The strengths and weaknesses of transitional support programs for newly registered nurses. Australian journal of advanced nursing, 25(4), 16-22.

Farrand, P., McMullan, M., Jowett, R., \& Humphreys, A. (2006). Implementing competency recommendations into pre-registration nursing curricula: Effects upon levels of confidence in clinical skills. Nurse Education Today, 26, 97103.

Farwell, P., \&. Bramadat, I. (1990). Paradigm case analysis and stimulated recall: Strategies for developing clinical reasoning. Clinical Nurse Specialist, 3(4), 153-157.

Feddock, C. A. (2007). The lost art of clinical skills. The American Journal of Medicine, 120(4), 374-378.

Fitzsimons, R. (2001). Intravenous cannulation. Paediatric Nursing, 13(3), 21-23.

Freeth, D., \& Nicol, M. (1998). Learning clinical skills: An interprofessional approach. Nurse Education Today, 18, 455-461.

Funk, S. G., Champagne, M. T., Wiese, R. A., \& Tornquist, E. M. (1991). Barriers to using research findings in practice: the clinician's perspective. Applied Nursing Research, 4(2), 90-95. 
Gomez, G. E., \& Gomez, E. A. (1984). The teaching of psychomotor skills in nursing. Nurse Educator, Winter, 35-39.

Gray, E. S. (1997). Expanding practice to include IV cannulation. Professional Nurse, 13(3), 181-182.

Greenfield, T. (1996). Research methods: Guidance for postgraduates. London: Edward Arnold.

Green-Thompson, L. (2006). Teaching safe intravenous cannulation - an undergraduate imperative. South African Journal of Anaesthesia and Analgesia, March 2006, 40.

Gruber, P. C., Gomersall, D. C., Joynt, G. M., Shields, F. M., Chu, M. C., \& Derrick, J.L. (2007). Teaching acute care: A course for undergraduates. Rescuscitation, 74(1), 142-149.

Hammer, J., \& Souers, C. (2004). Infusion therapy: A multifaceted approach to teaching in nursing. Journal of Infusion Nursing, 27(3), 151-156.

Hanchett, M. (2001). Where is the theory to support infusion nursing? Journal of Infusion Nursing, 24(1), 56-60.

Hanchett, M. (2005). Infusion nursing's greatest barrier: The lack of evidence to support evidence-based practice. Topics in Advanced Practice Nursing eJournal, 5, 1-6.

Hand, D. (1992). Taking a giant leap towards freedom. Nursing Standard, 6(42), 23.

Hankins, J., Waldman Lonsway, R. A., Hedrick, C., \& Perdue, M. B. (Eds.). (2001). Infusion therapy in clinical practice. Philadelphia: W.B. Saunders Company.

Harris, A., \& Redshaw, M. (1994). The changing role of the nurse in neonatal care: A study of current practice in England. Journal of Advanced Nursing, 20, 874-880.

Health and Disability Commissioner. (1994). Having a problem with a health or disability service? [Brochure]. Auckland: Author.

Health and Disability Commissioner. (n.d.). Code of health and disability services consumers' rights [Brochure]. Auckland: Author.

Hicks, C. (1996). Undertaking midwifery research: A basic guide to design and analysis. Edinburgh: Churchill Livingstone.

Hobson, P. (2008). Venepuncture and cannulation: Theoretical aspects. British Journal of Healthcare Assistants, 2(2), 75-78. 
Hunt, J. (1981). Indicators for nursing practice: The use of research finding. Journal of Advanced Nursing, 6, 189.

Ingersoll, G. (2000). Evidence-based nursing: What it is and what it isn't. Nursing Standard, 48(4), 151-152.

Inwood, S. (1996). Designing a nurse training programme for venepuncture.

Nursing Standard, 10(21), 40-42.

Jackson, A. (1997). Performing peripheral intravenous cannulation. Professional Nurse, 13(1), 21-25.

Joseph, A. C. (2008). What's the significance of evidenced-based practice: Do we really need levels of evidence? Urologic Nursing, 28 (1), 11-12.

Josephson, D. L. (1999). Intravenous infusion therapy for nurses: Principles and practice. New York: Delmar Publishers.

Knowles, M. (1980). The modern practice of adult education. Chicago: Follet Publishing Company.

Koh, L. C. (1996). Teaching technical skills to Project 2000 students. Nursing Standard, 10(28), 47-49.

Kumar, R. (2005). Research methodology: A step by step guide for beginners (2nd ed). London: Sage.

Lamb, J. (1993). Peripheral IV therapy. Nursing Standard, 7(36), 31-36.

Last, T., Self, N., Kassab, J., \& Rajan, A. (1992). Extended role of the nurse in ICU. British Journal of Nursing, 1(13), 672-675.

Lavery, I., \& Ingram, P. (2005). Venepuncture: Best practice. Nursing Standard, 19(49), 55-65.

LoBiondo-Wood, G., \& Haber, J (2006). Nursing research: Methods, critical appraisal for evidence-based practice. St. Louis, Elsevier Mosby.

Logan, K., Forbes, E., \& Carachi, R. (2005). Clinical skills teaching revisited. Scottish Medical Journal. 50(4), 177-178.

Macnee, C. L. (2004). Understanding nursing research: Reading and using research in practice. Philadelphia: Lippincott Williams \& Wilkins.

Marshall, Z., \& Luffingham, N. (1998). Does the specialist nurse enhance or deskill the general nurse? British Journal of Nursing, 7(11), 658-662.

Masoorli, S. (2002). Legally speaking. Journal of Vascular Access Devices, 7(4), 49.

McAdams, C., Rankin, E. J., Love, B., \& Patton, D. (1989). Psychomotor skills 
laboratories as self-directed learning: A study of nursing student's perceptions. Journal of Nursing Education, 14(9), 788-796.

McBrien, B. (2006). Clinical teaching and support for learners in the practice environment. British Journal of Nursing, 15(12), 672-677.

Ministry of Health. (1998). Report on the ministerial taskforce on nursing: Releasing the potential of nursing. Wellington. Author.

Ministry of Health. (2003). Health Practioners Competence Assurance Act. Wellington: Author.

Morris, R. (2006). Intravenous drug administration: A skill for student nurses? Paediatric Nursing, 18(3).

Neary, M. (1994). Teaching practical skills in colleges. Nursing Standard, 8(27), 35-38.

Neighbours, M., Eldred, E., \& Sullivan, M. (1991). Nursing skills for competency in the high-tech health care system. Nursing and Health Care, 12(2), 92-97.

Nieswiadomy, R. M. (2008). Foundations of nursing research. New Jersey: Pearson Prentice Hall.

Norton, E. A. (1993). Social perception and the nurse educator. British Journal of Nursing, 2(5), 282-284.

Nursing Council of New Zealand. (2005). Education programme standards for the registered nurse scope of practice. Wellington: Author.

Nursing Council of New Zealand. (2007). Competencies for registered nurses. Wellington: Author.

Nursing Council of New Zealand. (2008). Code of conduct for nurses. Retrieved 28 May 2009, from http://www.nursingcouncil.org.nz/code\%20of\%20conduct\%20March\%20200 8.pdf

Pallant, J. (2007). SPSS survival manual: A step by step guide to data analysis using SPSS for windows (3rd ed.). New York: Open University Press.

Parahoo, K. (2006). Nursing research: Principles, process and issues. New York: Palgrave Macmillan.

Pearcey, P. (2007). Tasks and routines in 21st century nursing: Student nurses' perceptions. British Journal of Nursing, 16(5), 296-300.

Pearson, A. (1987). The unique role of the nurse. Senior Nurse, 6(4), 45-49.

Pine, R. (2007). Return on investment: Benefits and challenges of a baccalaureate 
residency programme. Retrieved 11 August, 2008, from

http://www.medscape.com/viewarticle/555120_print

Polgar, S., \& Thomas, S. A. (2008). Research in the health sciences (5th ed.). Philadelphia: Elsevier.

Polit, D. F., \& Beck, C. T. (2004). Nursing research: Principles and methods. Philadelphia: Lippincott Williams \& Wilkins.

Polit, D.F., Beck, C. T., \& Hungler, B.P. (2001). Essentials for nursing research: Methods, appraisal and utilization. Philadelphia: Lippincott, Williams \& Wilkins.

Polit, D. F., \& Hungler, B. P. (1997). Essentials of nursing research: Methods, appraisal, and utilization. Philadelphia: Lippincott-Raven.

Pyne, R. (1992). Accountability in principle and practice. British Journal of Nursing, 1(6), 301-305.

Reilly, D. E., \& Oermann, M. H. (1985). The clinical field: Its use in nursing education. Connecticut: Appleton-Century-Crofts.

Rieu, S. (1994). Error and trial: The extended role dilemma. British Journal of Nursing, 3(4), 168-174.

Roberts, K., \& Taylor, B. (1999). Nursing research processes: An Australian perspective. Melbourne, Victoria: Nelson Thomson Learning.

Robson, C. (1997). Real world research: A resource for social scientists and practitioner-researchers. Oxford, England: Blackwell Publishers.

Rolfe, G. (1996). Choosing the theory-practice gap: A new paradigm for nurses. Oxford: Butterworth-Heinemann.

Rowden, R. (1987). The extended role of the nurse. Nursing, 3(14), 516 - 517.

Ryan, T. (1992). Nurse performed cannulation $v s$ medical officer cannulation: Is there a difference? Retrieved 11 November, 2008, from http://www.ciap.health.nsw.gov.au/hospolic/stvincents/1993/a01.html.

Scales, K. (2009). Intravenous therapy: The legal and professional aspects of practice. Nursing Standard, 23(33), 51-57.

Schmidt, N. A., \& Brown, J. M. (2009). Evidence-based practice for nurses: Appraisal and application of research. Ontario: Jones and Bartlett Publishers.

Schneider, Z., Whitehead, D., \& Elliott, D. (2007). Nursing \& midwifery research: Methods and appraisal for evidence-based practice (3rd ed.). Sydney: Elsevier.

Schön, D. A. (1987). Educating the reflective practitioner: Toward a new design for 
teaching and learning in the professions. San Francisco: Jossey-Bass Inc.

Scott, H. (2003). Intravenous therapy is not being carried out effectively. British Journal of Nursing, 12(20), 1172.

Shields, L., \& Watson, R. (2007). The demise of nursing in the United Kingdom: A warning for medicine. Journal of the royal society of medicine, 100, 70-74.

Simpson, T. F. (1989). American Association of Critical Care Nurses demonstration. Heart and lung. Journal of Critical Care, 18(4), 325.

Skally, M. H. (2007). An exploration of the preparation of New Zealand nurse educators for their role in teaching postgraduate clinical nursing courses. Wellington: Victoria University.

Spader, C. (2006). IV insertion - still a special skill. Nurse Week. Retrieved 3 October, 2008 from http://www2.nursingspectrum.com/articles/article.cfm?aid $=19901$

Steinberg, D. M. (2004). The social work student's handbook. New York: The Haworth Social Work Practice Press.

Stommel, M., \& Wills, C. E. (2004). Clinical research: Concepts and principles for advanced practice nurses. Philadelphia: Lippincott Williams \& Wilkins.

Studdy, S. J., Nicol, M. J., \& Fox-Hiley, A. (1994). Teaching and learning clinical skills: Part 1- Development of a multidisciplinary skills centre. Nurse Education Today, 14, 177-185.

Turnbull, G. I. (1994). Dialogue, educating tomorrow's colleagues: The physiotherapist in the university system. Physiotherapy Canada, 46(1), 9-14.

Turner, R. S. (2007). Preceptorship in nursing: preceptors' and preceptees' experiences of working in partnership. Wellington: Victoria University.

Ung, L., Cook, S., Edwards, B., Hocking, L., Osmond, F., \& Buttergieg, H. (2002). Peripheral intravenous cannulation in nursing. Journal of Infusion Nursing, 25(3), 189-195.

Vesely, T. M., Stranz, M., Masoorli, S., \& Hadaway, L. (2002). The diverse and conflicting standards and practices in infusion therapy. Journal of Vascular Access Devices, 7(9), 23-25.

Wainwright, P. (1987). Dictionary for nurses. London: Sphere.

Walker, S.R., Farraj, R., Papavassiliou, V., \& Arvanitis, D. (2006). A descriptive survey of the different management practices for peripheral IV catheters among Greek, Jordanian and Australian hospitals. Journal of Infusion Nursing, 29(2), 101-108.

Walliman, N. (2001). Your research project: a step-by-step guide for the first time 
researcher. Trowbridge: The Cromwell Press Ltd.

Weinstein, S. M. (2001). Plumer's principles \& practice of intravenous therapy. Philadelphia: Lippincott Williams \& Wilkins.

Wells, S. (2008). "Venous access in oncology and haematology patients: part one." Nursing Standard 22(52): 39 - 46.

Wilkinson, R. (1996). Nurses' concerns about IV therapy and devices. Nursing Standard, 10(35), 35-37.

Winch, S., Creedy, D., \& Chaboyer, W. (2002). Governing nursing conduct: The rise of evidence-based practice. Nursing Enquiry, 9(3), 156-161.

Woodrow, P. (1997). Nursing perspectives for intensive care. Intensive and critical care nursing, 13, 151-155.

Workman, B. (2000). Enhancing the nursing role: Why nurses want to cannulate. British Journal of Nursing, 9(9), 251-256.

Wright, S. G. (1995). The role of the nurse: Extended or expanded? Nursing Standard, 9(33), 25-29. 


\title{
Appendix 1
}

\section{Survey Questionnaire}

\section{VICTORIA UNIVERSITY OF WELLINGTON}

Te Whare Wānanga o te Ûpoko o te Ika a Māui

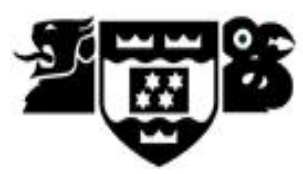

GRADUATE SCHOOL OF NURSING, MIDWIFERY \& HEALTH

\begin{abstract}
I need your help! The purpose of this questionnaire is to explore the feasibility of whether nurses in New Zealand should be prepared to administer intravenous therapy, undertake venepuncture and cannulation training prior to or following registration. The information will be used to inform the theory and practice development for student nurses and first year registered nurses to undertake these skills.
\end{abstract}

All information is strictly confidential and will only be used for this purpose. Please

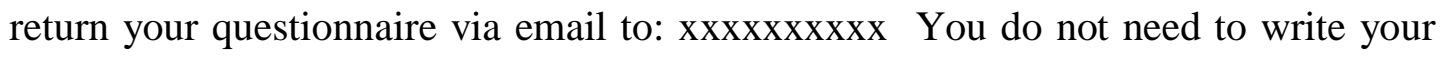
name on this form.

1. What best describes your work setting? (please tick)

Tertiary education institution (Institute of Technology, Polytechnic, University)

Tertiary teaching hospital

Smaller regional or provincial hospital

Non-governmental agency

Other (please specify)

2. What is your role? 
3. Please rate the statements below by circling 1, 2, 3, 4 or 5:

( $1=$ strongly agree; $2=$ agree; $3=$ disagree; $4=$ strongly disagree; $5=$ don't know)

\begin{tabular}{|l|l|l|l|l|l|}
\hline a) Undergraduate nurses need to have knowledge and 1 & 2 & 3 & 4 & 5 \\
experience of intravenous therapy prior to completing their & & & & \\
degree programme. & & & \\
\hline b) Undergraduate nurses need to have knowledge and 1 & 2 & 3 & 4 & 5 \\
\end{tabular}
experience of performing venepuncture prior to completing their degree programme.

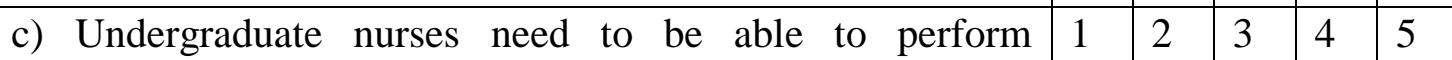
cannulation prior to completing their degree programme.

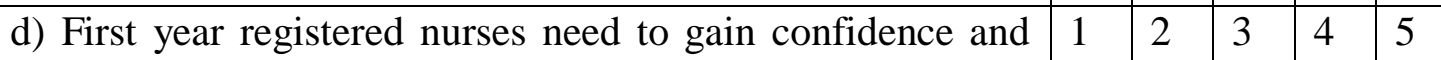
competence in intravenous therapy.

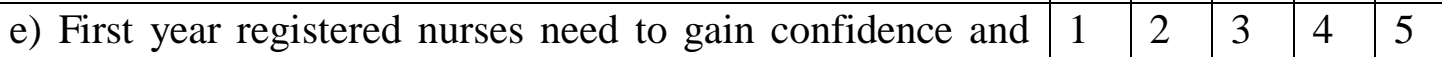
competence in venepuncture.

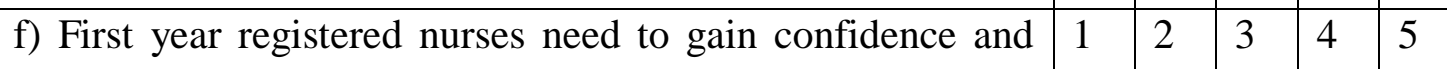
competence in cannulation.

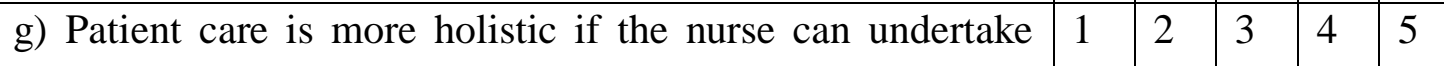
these skills without having to wait for another nurse or a doctor to perform them.

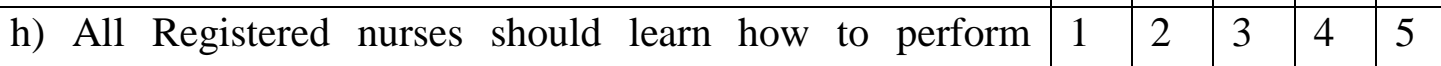
venepuncture.

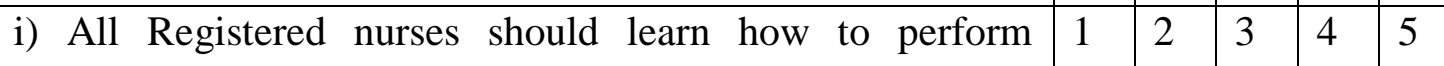
cannulation.

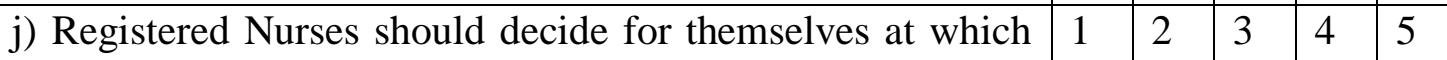
point of their career that they will learn to perform venepuncture and cannulation.

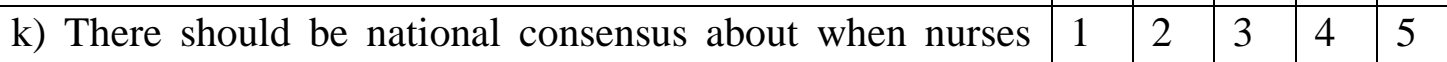
should undergo this training.

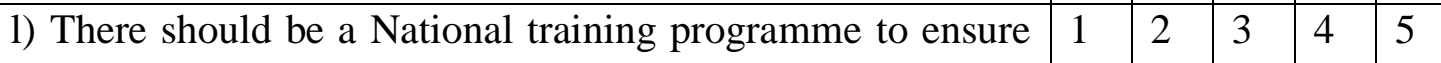
consistent education. 
4a) When should undergraduate nurses receive theory and practice related to intravenous therapy, venepuncture, and cannulation? Please select and rank your option(s) in order of preference from the list below.

\begin{tabular}{|l|l|l|l|l|l|l|}
\hline $\begin{array}{l}\text { Theory and practice } \\
\text { Times }\end{array}$ & $1^{\text {st }}$ & $2^{\text {nd }}$ & $3^{\text {rd }}$ & $4^{\text {th }}$ & $5^{\text {th }}$ & $6^{\text {th }}$ \\
option & option & option & option & option \\
\hline i) Year 1 Semester 1 & & & & & & \\
\hline ii) Year 1 Semester 2 & & & & & & \\
\hline iii)Year 2 Semester 1 & & & & & & \\
\hline iv)Year 2 Semester 2 & & & & & & \\
\hline v)Year 3 Semester 1 & & & & & & \\
\hline vi)Year 3 Semester 2 & & & & & & \\
\hline
\end{tabular}

4b) Please explain why you have ranked them this way.

4c) In relation to $4 \mathrm{a})$ above, please outline what theory and practice would be included in your option(s) .

5. Are there any other comments about the topic that you wish to make?

Thank-you for taking the time to answer the questionnaire. Please return via email to: $\operatorname{xxxxxxxxxx}$ 


\section{Appendix 2}

\section{Ethics approval}

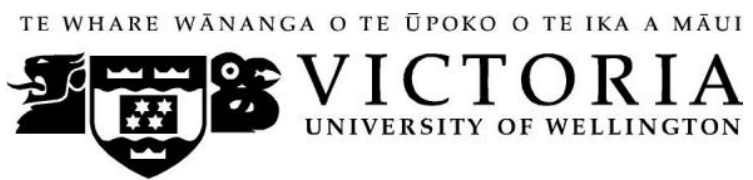

MEMORANDUM
Phone $\operatorname{xxxxxxxx}$

Fax $\quad \operatorname{xxxxxxxx}$

Email xxxxxxxx@vuw.ac.nz

\begin{tabular}{l|l}
\hline TO & Bronwynne Anderson \\
\hline COPY TO & Associate Professor Rose McEldowney \\
\hline FROM & XXXXXXXXX, Convener, Human Ethics Committee \\
\hline
\end{tabular}

\begin{tabular}{l|l}
\hline DATE & January 28,2009 \\
\hline PAGES & 1 \\
\hline
\end{tabular}

\begin{tabular}{l|l}
\hline SUBJECT & $\begin{array}{l}\text { Ethics Approval: No 16280, Undergraduate/New Graduate Nurses - } \\
\text { when should they learn intravenous therapy, venepuncture and } \\
\text { cannulation? }\end{array}$ \\
\hline
\end{tabular}

Thank you for your application for ethical approval, which has now been considered by the Standing Committee of the Human Ethics Committee.

Your application has been approved from the above date and this approval continues until 31 July 2009. If your data collection is not completed by this date you should apply to the Human Ethics Committee for an extension to this approval.

Best wishes with the research.

XXXXXXXXXXXXXXXX

Convener 


\section{Appendix 3}

\section{Participant letter}

\section{VICTORIA UNIVERSITY OF WELLINGTON}

Te Whare Wānanga o te Ûpoko o te Ika a Māui

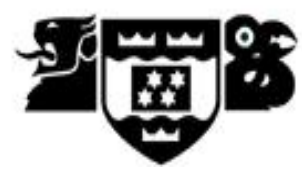

Dear participant

I am a graduate student in the Master of Nursing (Applied) Program at Victoria University, Wellington under supervision of Dr. Rose McEldowney. I am conducting a research study to explore the feasibility of whether nurses in New Zealand should be prepared to administer intravenous therapy, undertake venepuncture and cannulation prior to or following registration. The information will be used to inform the theory and practice development for student nurses and first year registered nurses to undertake these skills. This gained ethical approval on 28/01/2009. Number 16280.

I would appreciate it if you could complete the questionnaire. The entire process should take no longer than 15 minutes. Your participation is voluntary. The results of the study will be published, but neither your name nor that of your institution will be used. All responses will be kept confidential and anonymous. Please ensure that

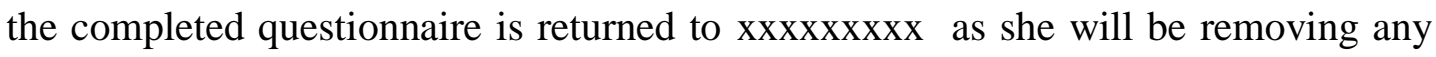
identifying information prior to sending it on to me. The only people that will have access to the information will be the researcher, supervisor and the collator.

If you, on behalf of your institution agree to take part in this study, there may or may not be direct benefit to you. It is hoped that the information gleaned from this study will promote an understanding of whether it would be beneficial and efficacious for undergraduate nurses to be educated/trained regarding intravenous therapy/venepuncture and cannulation during their final year of nursing training or whether registered nurses should only undertake this education/training at a later stage. This research may be significant in providing research data that is relevant for New Zealand Schools of Nursing to utilise when planning their future curricula and 
it may also benefit New Zealand DHB's in their planning of extended roles for registered nurses.

If you have any questions concerning the research study, please call me on

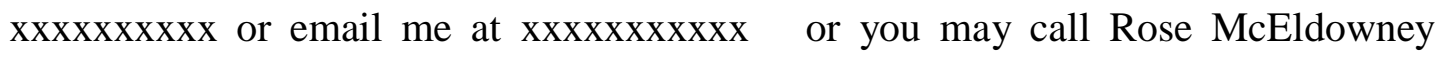
(Associate Professor in Nursing) on: $x x x x x x x x x x x x x$ Or email her at $x x x x x x x x x x$ Sincerely,

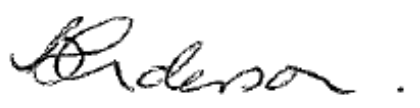

Bronwynne Anderson. RN, RM, PG Cert 


\section{Appendix 4}

\section{Research assistant confidentiality form}

VISTCRIA UNTVERST TY ON WELINGTON

Te Whare Wanargate llpokn ate ika a Mau

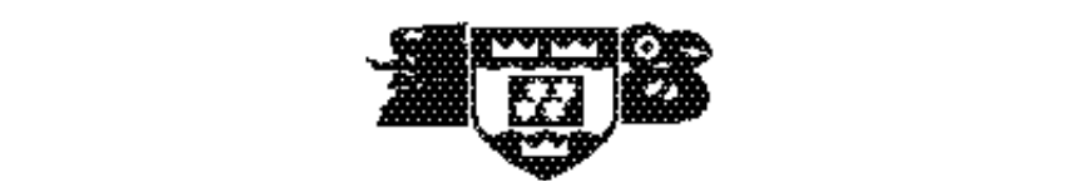

I agree to maintain confidentiality when working with data from the survey data.

I will not disclose any information related to the participants in the research project.

I also understand that the only communication I have related to working with the project data will be with the researcher Bronwynne Anderson.

Signed: $\quad$ XXXXX Name of Research Assistant: $X X X X X X X X$

Date: $\quad 27$ November 2008 


\section{Appendix 5}

Director of nursing letter

VICTORIA UNIVERSITY OF WELLINGTON

Te Whare Wānanga o te Ûpoko o te Ika a Māui

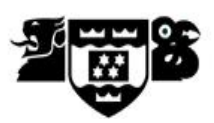

To the Director of Nursing,

I am a graduate student in the Master of Nursing (Applied) Program at Victoria University, Wellington under supervision of Dr. Rose McEldowney. I am conducting a research study to explore the feasibility of whether nurses in New Zealand should be prepared to administer intravenous therapy, undertake venepuncture and cannulation training prior to or following registration. The information will be used to inform the theory and practice development for student nurses and first year registered nurses to undertake these skills. The project gained ethical approval on 28/01/2009. Number 16280.

I would appreciate it if you could nominate a member/s of your staff who coordinates the education/training of post registration nurses for intravenous therapy, venepuncture and cannulation, to participate in this study. I am attaching a participant information sheet and the questionnaire that I would ask you to forward to them to complete. The entire process should take no longer than 15 minutes of their time. Their participation is voluntary. It would be appreciated if you could notify us of how many questionnaires you forward for statistical purposes. The results of the study will be published, but neither the nominated staff member's name nor that of your institution will be used. A report on the findings of the study will be emailed to you after completion of the study. All responses will be anonymous.

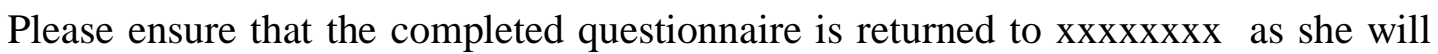
be removing any identifying information prior to sending it on to me. The only people that will have access to the information will be the researcher, supervisor and the collator. All the electronic data will be kept in a data password access file and all printed information will be kept in a locked file. All the data will be destroyed after 2 years. 
It is hoped that the information arising from this study will promote an understanding of whether it would be beneficial and efficacious for undergraduate nurses to learn about intravenous therapy/venepuncture and cannulation during their nursing training or whether only registered nurses should undertake this education/training. This research may be significant in providing data that is relevant for New Zealand DHBs in their planning of extended roles for registered nurses. If you have any questions

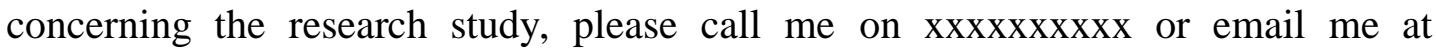

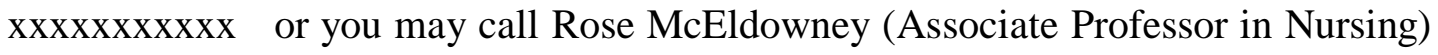

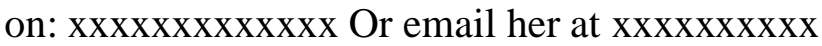

Thank you for participating and your support of my project.

Yours Sincerely,

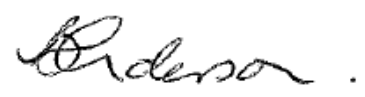

Bronwynne Anderson. RN, RM, PG Cert in Nursing 


\section{Appendix 6}

\section{Head of Schools of Nursing letter}

\section{VICTORIA UNIVERSITY OF WELLINGTON \\ Te Whare Wānanga o te Ûpoko o te Ika a Māui

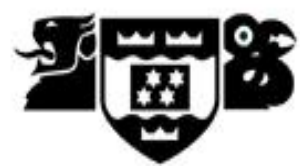

To the Head of School,

I am a graduate student in the Master of Nursing (Applied) Program at Victoria University, Wellington under supervision of Dr. Rose McEldowney. I am conducting a research study to explore the feasibility of whether nurses in New Zealand should be prepared to administer intravenous therapy, undertake venepuncture and cannulation training prior to or following registration. The information will be used to inform the theory and practice development for student nurses and first year registered nurses to undertake these skills. The project gained ethical approval on 28/01/2009. Number 16280.

I would appreciate it if you could nominate a member/s of your staff that teaches or is interested in educating/training undergraduate nurses for intravenous therapy, venepuncture and cannulation, to participate in this study. I am attaching a participant information sheet and the questionnaire that I would ask you to forward to them to complete. The entire process should take no longer than 15 minutes of their time. Their participation is voluntary. It would be appreciated if you could notify us of how many questionnaires you forward for statistical purposes. The results of the study will be published, but neither the nominated staff member's name nor that of your institution will be used. A report on the findings of the study will be emailed to you after completion of the study. All responses will be anonymous. Please ensure that the completed questionnaire is returned to $\operatorname{xx} \operatorname{xxxxxxx}$ as she will be removing any identifying information prior to sending it on to me. The only people that will have access to the information will be the researcher, supervisor and the collator. All the electronic data will be kept in a data password access file and all 
printed information will be kept in a locked file. All the data will be destroyed after 2 years.

It is hoped that the information arising from this study will promote an understanding of whether it would be beneficial and efficacious for undergraduate nurses to learn about intravenous therapy/venepuncture and cannulation during their nursing training or whether only registered nurses should undertake this education/training. This research may be significant in providing data that is relevant for New Zealand Schools of Nursing to utilise when planning their future curricula.

If you have any questions concerning the research study, please call me on

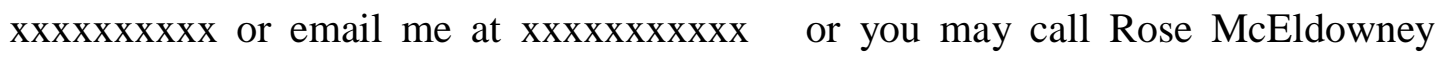

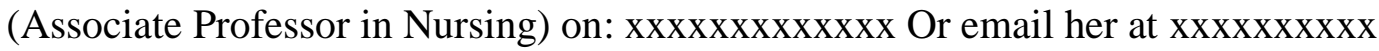
Thank you for participating and your support of my project.

Yours Sincerely,<smiles>CCOCC1C2CC23CC13</smiles>

Bronwynne Anderson. RN, RM, PG Cert in Nursing 